Thresholds of intrabed flow and other interactions of turbidity currents with soft muddy substrates

Baas, Jacobus; Manica, Rafael; Puhl, Eduardo; Borges, Ana Luiza de O

\title{
Sedimentology
}

DOI:

$10.1111 /$ sed.12292

Published: 01/12/2016

Peer reviewed version

Cyswllt i'r cyhoeddiad / Link to publication

Dyfyniad o'r fersiwn a gyhoeddwyd / Citation for published version (APA):

Baas, J., Manica, R., Puhl, E., \& Borges, A. L. D. O. (2016). Thresholds of intrabed flow and other interactions of turbidity currents with soft muddy substrates. Sedimentology, 63(7), 20022036. https://doi.org/10.1111/sed.12292

\footnotetext{
Hawliau Cyffredinol / General rights

Copyright and moral rights for the publications made accessible in the public portal are retained by the authors and/or other copyright owners and it is a condition of accessing publications that users recognise and abide by the legal requirements associated with these rights.

- Users may download and print one copy of any publication from the public portal for the purpose of private study or research.

- You may not further distribute the material or use it for any profit-making activity or commercial gain

- You may freely distribute the URL identifying the publication in the public portal?
}

Take down policy

If you believe that this document breaches copyright please contact us providing details, and we will remove access to the work immediately and investigate your claim. 
Received Date : 24-Aug-2015

Revised Date : 23-Mar-2016

Accepted Date : 18-Apr-2016

Article type : Original Manuscript

\section{Thresholds of intrabed flow and other interactions of turbidity currents with soft muddy substrates}

Jaco H. Baas ${ }^{1}$, Rafael Manica ${ }^{2}$, Eduardo Puhl ${ }^{2}$, Ana Luiza de O. Borges ${ }^{2}$

${ }^{1}$ School of Ocean Sciences, Bangor University, Menai Bridge, Isle of Anglesey, LL59 5AB, Wales, United Kingdom,e-mail:j.baas@bangor.ac.uk

2 Instituto de Pesquisas Hidráulicas, Departamento de Hidromecânica e Hidrologia, Universidade Federal do Rio Grande do Sul, Av. Bento Gonçalves, 9500, CEP 91501-970,

Caixa Postal 15029, Porto Alegre, Rio Grande do Sul, Brazil

Associate Editor - Peter Talling

Running title - Intrabed flow thresholds in turbidity currents

This is an Accepted Article that has been peer-reviewed and approved for publication in the Sedimentology, but has yet to undergo copy-editing and proof correction. Please cite this article as an "Accepted Article"; doi: 10.1111/sed.12292

This article is protected by copyright. All rights reserved. 
Keywords: Cohesion, fluid mud, flume experiments, intrabed flow, turbidite, turbidity current

\section{ABSTRACT}

Controlled laboratory experiments reveal that the lower part of turbidity currents has the ability to enter fluid mud substrates, if the bed shear stress is higher than the yield stress of the fluid mud and the density of the turbidity current is higher than the density of the substrate. Upon entering the substrate, the turbidity current either induces mixing between flow-derived sediment and substrate sediment, or it forms a stable horizontal flow front inside the fluid mud. Such 'intrabed' flow is surrounded by plastically deformed mud; otherwise it resembles the front of a 'bottom-hugging' turbidity current. The 'suprabed' portion of the turbidity current, i.e. the upper part of the flow that does not enter the substrate, is typically separated from the intrabed flow by a long horizontal layer of mud which originates from the mud that is swept over the top of the intrabed flow and then incorporated into the flow. The intrabed flow and the mixing mechanism are specific types of interaction between turbidity currents and muddy substrates that are part of a larger group of interactions, which also include bypass, deposition, erosion and soft sediment deformation. A classification scheme for these types of interactions is proposed, based on an excess bed shear stress parameter, which includes the difference in the bed shear stress imposed by the flow and the yield stress of the substrate and an excess density parameter, which relies on the density difference between the flow and the substrate. Based on this classification scheme, as well as on the sedimentological properties of the laboratory deposits, an existing facies model for intrabed turbidites is extended to the other types of interaction involving soft muddy substrates. The physical threshold of flow-substrate mixing versus stable intrabed flow is defined using the gradient Richardson number, and this method is successfully validated

This article is protected by copyright. All rights reserved. 
with the laboratory data. The gradient Richardson number is also used to verify that stable intrabed flow is possible in natural turbidity currents, and to determine under which conditions intrabed flow is likely to be unstable. It appears that intrabed flow is likely only in natural turbidity currents with flow velocities well below c. $3.5 \mathrm{~m} \mathrm{~s}^{-1}$, despite the fact that a wider range of flows is capable of entering fluid muds. Below this threshold velocity, intrabed flow is stable only at high density gradients and low velocity gradients across the upper boundary of the turbidity current. Finally, the gradient Richardson number is used as a scaling parameter to set the flow velocity limits of a natural turbidity current that formed an inferred intrabed turbidite in the deep-marine Aberystwyth Grits Group, West Wales, United Kingdom.

\section{(A) INTRODUCTION}

Sediment gravity flows, for example turbidity currents, debris flows and hybrid flows (Talling et al., 2004; Haughton et al., 2009; Baas et al., 2011), carry vast amounts of particulate and dissolved matter into the deep ocean (Talling et al., 2012). Indeed, turbidity currents are able to move larger volumes of sediment in one event than all of the world's rivers achieve in one year (Talling et al., 2007). Most of this sediment is stored as turbidite deposits within submarine fans. Turbidites are not only an important sink for shallow marine and terrestrial sediment, but they also store environmentally significant amounts of carbon, nutrients and pollutants. From an economic point of view, sediment gravity flows are a risk to submarine communication cables and other engineering structures, and their deposits within submarine fans host the largest volumes of hydrocarbons on Earth (Weimer \& Pettingill, 2007). This high environmental and economic significance of sediment gravity flows was recently reiterated in the proceedings of an international workshop (Talling et al., 2015), where scientists and practitioners made strong recommendations for future research on the back of

This article is protected by copyright. All rights reserved. 
the latest technical developments for studying modern turbidity currents, and the integration with laboratory experiments, numerical modelling and outcrop studies. Talling et al. (2015) highlighted the importance of process-based studies of sediment gravity flows, with particular relevance to their distance of travel (e.g. Talling et al., 2010; Stevenson et al., $2014 b)$, and the role of cohesive clay in modulating the dynamic properties of sediment gravity flows and the textural and structural properties of the deposits of these flows (Baas \& Best, 2002; Baas et al., 2009; Sumner et al., 2009; Baas et al., 2011).

One of the key controls on the dynamic behaviour of sediment gravity flows and the properties of their deposits is the interaction of the flow with the substrate. At first order, this interaction comprises five main processes: bypass, deposition, erosion, mixing and injection. In strict terms, bypass denotes flow over a substrate without exchange of sediment between flow and bed but, in reality, some entrainment of bed material by the passing sediment gravity flow is common, tractional forces may reshape the bed into non-climbing bedforms and thin deposits may develop, for example in the tail of the flow (e.g. Mutti, 1985; Mutti \& Normark, 1987; Cornamusini, 2004; Stevenson et al., 2015). Deposition of suspended sediment particles from a sediment gravity flow takes place if the shear velocity of the flow is smaller than the particle settling velocity. In sediment gravity flows that carry cohesive clay particles, the rate of deposition is controlled by the size of clay aggregates, or 'floccules'. Deposition may take place en masse in clay-rich flows, if the clay forms a gel, i.e. a pervasive network of clay particle bonds (Winterwerp \& van Kesteren, 2004; Baas et al., 2011; Baas et al., 2016). The textural and structural properties of sediment gravity flow deposits are controlled by spatio-temporal changes in flow dynamics and sediment properties. Deposition often leads to a reduction in the density difference between the flow and the ambient water, and tends to cause a reduction in the travel distance of the flow. However, Baas et al. $(2011,2016)$ showed that deposition of cohesive clay from quasilaminar and upper transitional plug flow may lead to restoration of particle support by turbulence, and thus potentially a prolonged distance of travel.

This article is protected by copyright. All rights reserved. 
Erosion of the substrate below a sediment gravity flow occurs if the bed shear stress of the current is greater than the critical bed shear stress for the movement of particles on the substrate, and the rate of entrainment of particles into the flow is greater than the rate of settling of particles onto the substrate. The bed shear stress depends on the density, the velocity and the turbulence structure of the sediment gravity flow, and the roughness of the substrate, while the critical bed shear stress is a function of the diameter, density and shape of the sediment particles, and the strength of the bed imposed by the presence of cohesive clay. Bed erosion fuels the sediment gravity flow with sediment, possibly also involving autosuspension (Bagnold, 1962); the resulting increase in excess density may lead to an increase in the travel distance of the flow. However, this assumes that the concentration of suspended sediment, in particular cohesive clay, does not pass the rheological threshold at which turbulent support becomes suppressed and matrix strength is also insufficient to support the sediment, thus promoting sediment settling (Baas et al., 2009, 2011; Baas et al., 2016).

Recently, Verhagen et al. (2013) and Baas et al. (2014) investigated the interaction of experimental turbidity currents with a soft muddy substrate. Besides bypass, erosion and deposition, Verhagen et al. (2013) and Baas et al. (2014) found three additional types of flow-bed interaction: deformation, mixing and intrabed flow. Substrate deformation occurred when the bed shear stress was high enough to plastically deform the substrate, mainly through interfacial waves, but too low to overcome the critical shear stress for substrate erosion. Mixing involved the incorporation of flow-derived sediment into the substrate mud without significant downstream transport of the mud, resulting in a deposit that comprised a chaotic, debrite-like, mixture of dispersed mud and mud clasts within flow-derived sediment, separated from the substrate by a scour surface (Baas et al., 2014). Injection in the form of intrabed flow describes the process by which the lower part of a dense turbidity current enters a more dilute substrate that behaves as a fluid mud. Within the substrate, the turbidity

This article is protected by copyright. All rights reserved. 
current keeps its shape and thus continues to flow horizontally, only slowly mixing with the surrounding fluid mud (Baas et al., 2014).

Baas et al. (2014) presented a facies model for intrabed turbidites (their fig. 3), but also concluded that a wider range of boundary conditions is required to delimit the thresholds of intrabed flow, as opposed to bed erosion and mixing. Here, new experimental data are presented that build upon the work of Baas et al. (2014) by investigating the effect of the cohesive strength of the substrate on flow-bed interaction. The specific aims of these experiments were: (i) to define the boundary conditions for different types of interaction between sediment gravity flows and soft muddy substrates; (ii) to extend the facies model for intrabed turbidites to other types of flow-bed interaction; and (iii) to delimit the physical sedimentological conditions for which the development of intrabed flow and intrabed turbidites is feasible in natural environments.

\section{(A) EXPERIMENTAL METHODOLOGY}

Fifteen laboratory experiments were conducted using a rectangular flume $-4.5 \mathrm{~m}$ long, 0.22 m wide and $0.5 \mathrm{~m}$ deep - at the Instituto de Pesquisas Hidráulicas, Universidade Federal do Rio Grande do Sul, Porto Alegre (Fig. 1; Table 1). This facility is tailor-made for turbiditycurrent research, owing to: (i) large header tanks that allow the sustained release of separate sediment types - here cohesive and cohesionless sediment - across the width of the flume; (ii) a large-volume end section connected to a $0.5 \mathrm{~m}$ wide second channel running alongside the observation channel (Fig. 1); this configuration extends the transport path of the turbidity currents and thus minimises flow reflections; and (iii) an adjustable slope gradient. For the experiments described in this paper, small modifications were made to allow for the formation of soft muddy substrates and the release of cohesionless turbidity

This article is protected by copyright. All rights reserved. 
currents across these substrates. Firstly, the slope gradient was set to $0^{\circ}$ for all experiments. Subsequently, a $4.15 \mathrm{~m}$ long reservoir was formed by placing two blocks of polystyrene onto the floor of the flume. The block at the upstream end of the flume was $0.35 \mathrm{~m}$ long and it allowed the turbidity currents to flow over a fixed substrate before moving across the muddy substrate. Another block of polystyrene was placed at the downstream end of the flume to close off the reservoir and prevent spreading of the muddy sediment into the rest of the flume. The thickness of the blocks was $0.08 \mathrm{~m}$ in Runs 1 to 5 and $0.04 \mathrm{~m}$ in Runs 6 to 10 (Table 1). No reservoir was prepared in control Runs 11 to 15 , where the turbidity currents moved across the fixed, smooth floor of the flume.

After filling the flume with fresh water to a depth of $0.50 \mathrm{~m}$, vertical polystyrene walls were placed on top of the blocks to fully isolate the reservoir section from the rest of the flume. A gap in the base of the upstream wall permitted muddy sediment to be added to the reservoir from one of the header tanks. This header tank contained a kaolinite clay suspension with a volumetric concentration of $2.8 \mathrm{vol} \%, 0.220 \mathrm{~m}^{3}$ of which was released into the reservoir at a flow rate of ca $0.050 \mathrm{~m}^{3}$ per minute. The kaolinite had a median diameter, $\mathrm{D}_{50}$, of $7 \mu \mathrm{m}$, with the particle size distribution spanning the clay and silt size classes (Wentworth, 1922); hence the reference to 'mud' in the present paper. Upon entering the reservoir, the kaolinite suspension quickly changed into a turbidity current that reflected repeatedly off of the polystyrene walls, eventually forming a dense mud suspension in the entire body of water. Bulk settling of the kaolinite commenced immediately after the sediment supply was switched off, with progressive release of clean water through the well-defined top of a developing cohesive bed.

Just before the top of the consolidating mud reached the same height as the polystyrene floor in Runs 1 to 10 , usually after several tens of minutes up to 1.5 hours, the polystyrene walls were removed, and the inflow pipe was connected to a second header tank that contained a mixture of fresh water and crushed coal. The crushed coal was cohesionless, had a density of $1190 \mathrm{~kg} \mathrm{~m}^{-3}$ and was poorly sorted, with a $D_{50}$ of $55 \mu \mathrm{m}$. As soon as the This article is protected by copyright. All rights reserved. 
surface of the soft mud was flush with the top of the mud reservoir, the coal suspension was added for $75 \mathrm{~s}$ at $0.050 \mathrm{~m}^{3}$ per minute onto the upstream polystyrene floor, where it quickly evolved into a turbidity current before entering the reservoir. The interaction of the turbidity currents with the fluid mud in Runs 1 to 10 was investigated at initial suspended coal concentrations, $C_{f, i}$, of $1 \%, 5 \%, 10 \%, 15 \%$ and $23 \%$ by volume, for each bed thickness (Table 1). These concentrations are equivalent to initial flow densities, $\rho_{f, i}$, of 1002,1010 , 1019, 1029 and $1044 \mathrm{~kg} \mathrm{~m}^{-3}$, respectively. The same initial densities apply to the turbidity currents in control Runs 11 to 15 . For flows carrying quartz-rich sediment with a sediment density of $2650 \mathrm{~kg} \mathrm{~m}^{-3}$, these densities are equivalent to volumetric suspended sediment concentrations of $0.1 \%, 0.6 \%, 1.8 \%$ and $2.7 \%$, respectively.

Sediment concentrations at selected heights within the kaolinite substrate and within the coal-laden turbidity currents were measured by means of ultra-high concentration meters (UHCM; Fig. 1). The UHCMs measure the attenuation of sound between an acoustic transmitter and receiver pair, placed at a known distance to one another, as a function of suspended particle concentration and particle type (e.g. Felix et al., 2005; Manica, 2012). Because UHCMs have a constant error independent of suspended sediment concentration, these instruments obtain the most accurate concentration data at sediment suspensions above ca 1 vol\%. However, the UHCMs were unable to measure at the levels of highest suspended sediment concentration within the coal-laden turbidity currents with $C_{b, i}=15 \%$ and $C_{b, i}=23 \%$. Before use in the present experiments, the UHCMs were calibrated for a wide range of concentrations of coal and kaolinite in fresh water, and polynomial best-fit functions of degree two were formulated to convert the standard voltage output of the UHCMs to volumetric sediment concentration. These best-fit functions approximated linear relationships between voltage output and sediment concentration, with $R^{2}$ values of at least 0.997. Vertical profiles of mud concentration within the high-density and low-density substrate types, collected when the top of the deposits were flush with the polystyrene floor, are shown in Fig. 2. The $0.08 \mathrm{~m}$ thick substrate exhibited a linear vertical gradient in 
sediment concentration, $C_{b, i}$, from ca 0.8 vol\% (equivalent to a density, $\rho_{b, i}$, of $1013 \mathrm{~kg} \mathrm{~m}^{-3}$ ) near the mud-water interface to ca 5.3 vol\% $\left(1085 \mathrm{~kg} \mathrm{~m}^{-3}\right)$ close to the base of the deposit. The $0.04 \mathrm{~m}$ thick substrate had a steeper vertical gradient, from ca 3.1 vol\% $\left(1050 \mathrm{~kg} \mathrm{~m}^{-3}\right)$ just below the mud-water interface to ca 8.2 vol\% $\left(1131 \mathrm{~kg} \mathrm{~m}^{-3}\right)$ at a height, $z$, of $5 \mathrm{~mm}$ above the base of the deposit (Fig. 2). These densities classify both substrates as fluid muds (Mehta, 2014). The temporal resolution of UHCM data collection during flow was $2 \mathrm{~Hz}$. In Runs 1 to 10 , the UHCMs measured sediment concentrations at $z=-0.005 \mathrm{~m}$ below the fluid mud surface, and at $z=0.02 \mathrm{~m}, 0.07 \mathrm{~m}$ and $0.12 \mathrm{~m}$ above the fluid mud surface. In control Runs 11 to 15 , the measurement heights were $z=0.005 \mathrm{~m}, 0.03 \mathrm{~m}, 0.08 \mathrm{~m}$ and $0.13 \mathrm{~m}$ above the floor of the flume. The UHCMs were positioned at a distance, $x$, of ca $3 \mathrm{~m}$ from the inflow pipe.

Digital video was used to record the head velocity of the turbidity currents, as well as the types of interaction between flow and fluid mud, along the entire length of the reservoir. In order to extend the observations of flow-substrate interaction from the side-wall to the centre of the flume, a medical-grade ultrasound scanner (Brito et al., 2002; Del Rey, 2006) was focussed on the interface between the substrate and the turbidity current at $x=1.45 \mathrm{~m}$ within the flume (Fig. 1). The contrast in acoustic impedance between the coal-water and kaolinite-water mixtures was sufficiently high, especially in Runs 1 to 5 , to track mixing processes between the turbidity currents and the fluid mud.

The laboratory deposits exhibited a myriad of textural and structural sedimentological attributes. The development of these attributes during flow-substrate interaction and after the flow had been halted were described in detail, utilising the digital video recordings, the ultrasound scanner data and direct side-wall observations. These methods were also used to record the final spatial organisation of characteristic textural and structural features.

This article is protected by copyright. All rights reserved. 


\section{(A) RESULTS}

(B) Control experiments with fixed, smooth substrate

(C) Observations

The turbidity currents in Runs 11 to 15 carried coal at initial volumetric concentrations of $1 \%$, $5 \%, 10 \%, 15 \%$ and $23 \%$, respectively (Table 1 ), and moved across the fixed, smooth floor of the measurement channel (Fig. 1). All flows displayed a well-defined, rounded head, and an upper boundary with Kelvin-Helmholtz instabilities both at the side-wall of the flume (Fig. 3) and in the centre of the flume (Fig. 4). The flow thickness, $h_{f}$, decreased from $0.25 \mathrm{~m}$ to 0.12 m, as $C_{f, i}$ was increased from $1 \%$ to $23 \%$.

Figure $5 \mathrm{~A}$ shows spatial changes in the head velocity of the turbidity currents between $x=$ $0.6 \mathrm{~m}$ and $x=3.4 \mathrm{~m}$. After an initial flow acceleration, the head velocities varied slightly but consistent long-term trends were absent. The mean flow velocity increased from ca $0.04 \mathrm{~m}$ $\mathrm{s}^{-1}$ to ca $0.15 \mathrm{~m} \mathrm{~s}^{-1}$, as $C_{f, i}$ was increased from $1 \%$ to $23 \%$ (Fig. 6).

Time-series of suspended sediment concentration, $C_{f}$, collected at $z=0.005 \mathrm{~m}, 0.03 \mathrm{~m}$, $0.08 \mathrm{~m}$ and $0.13 \mathrm{~m}$ above the floor of the flume show a sharp rise in $C_{f}$ upon arrival of the head of the turbidity current (Fig. 7); the time of arrival was progressively earlier with increasing $C_{f, i}$. In most flows, the suspended sediment concentration decreased, as distance from the floor of the flume increased, and $C_{f}$ decreased with time, especially after the supply from the header tank was halted at $75 \mathrm{~s}$. The thickness of the deposits that formed from suspension settling after the turbidity currents were stopped were 0.018 to $0.038 \mathrm{~m}$ in Run $15\left(C_{f, l}=23 \%\right)$ to less than $1 \mathrm{~mm}$ in Run $11\left(C_{f, l}=1 \%\right)$.

This article is protected by copyright. All rights reserved. 
(C) Interpretations

The control Runs 11 to 15 produced non-cohesive turbidity currents that mimic the shape and behaviour of density currents described in numerous previous studies (e.g. Kuenen \& Migliorini, 1950; Middleton, 1966a, 1966b, 1967; Simpson, 1982; Edwards 1993, Gladstone et al., 1998; McCaffrey et al., 2003; Manica, 2012). The mean head velocity increased (Fig. 6) and the flow thickness decreased (Fig. 3), as initial suspended sediment concentration was increased, because excess density is the main driving force of turbidity currents. The increase in mean head velocity caused the flows to arrive progressively earlier at the location of the UHCMs (Fig. 7). Considering that the heads of the turbidity currents did not show any consistent flow deceleration along the length of the flume, it is inferred that the travel distance of the faster-moving higher-density flows is greater than the travel distance of the slower-moving lower-density flows. Settling of sediment from the turbidity currents is inferred to have resulted in the upward decrease in $C_{f}$, and in the temporal decrease in $C_{f}$, which was most prominent upon termination of sediment supply from the header tank (Fig. 7). The lowermost UHCM in the flow with $C_{f, i}=23 \%$ was captured in the deposit that formed almost immediately after the head of this flow passed the UHCM, which explains the inability of the UHCM to measure reliable sediment concentrations after 25 s into Run 15.

\section{(B) Experiments with low-density fluid mud in reservoir}

\section{(C) Observations}

The turbidity currents in Runs 1 to 5 transported sediment at initial volumetric concentrations of $1 \%, 5 \%, 10 \%, 15 \%$ and $23 \%$, respectively (Table 1 ), across the $0.08 \mathrm{~m}$ thick fluid mud (Fig. 2). The shape and behaviour of the turbidity currents in these experiments were similar to those in Runs 11 t 015 with respect to distinct flow fronts, heads and bodies, and Kelvin- 
Helmholtz instabilities at the upper boundary (Figs 8 to 12). Furthermore, the heads of the flows were thinnest for the highest initial suspended sediment concentrations, if the interface between mud and coal on the digital videos is taken as the reference height (cf. Fig. 10A and B, Fig. 10D and E; Table 1). However, the main difference with the control runs was the interaction of the base of the turbidity currents with the underlying fluid mud. Flow-substrate interaction became more pronounced as $C_{f, i}$ was increased, and the type of interaction also varied along the flow path of the turbidity currents.

All the turbidity currents eroded into the fluid mud upon entering the mud reservoir (Figs 8 and 9). The rate and depth of erosion increased, as $C_{f, i}$ was increased, culminating in a final depth of erosion of $0.051 \mathrm{~m}$ for low-concentration Run 1 and $0.062 \mathrm{~m}$ for highestconcentration Run 5, measured at $x=0.6 \mathrm{~m}$. The erosional scours were concave upward and between $0.55 \mathrm{~m}$ and $0.65 \mathrm{~m}$ long. Some of the scoured mud was transported down the channel and deposited together with coal between $x=1 \mathrm{~m}$ and $x=2 \mathrm{~m}$ (Fig. 13B), but most of the mud was captured within the developing scour, where it mixed with coal from the base of the turbidity current and formed coal deposits with dispersed mud and mud clasts (Fig. 13A). The mud clasts originated from fluid mud erosion (sensu Mehta, 2014) and from the disintegration of horizontal streaks of mud, up to $0.01 \mathrm{~m}$ thick, that had been incorporated into the head of the eroding flows (for example, at $x=0.8$ to $1.2 \mathrm{~m}$ in Figs $8 \mathrm{D}, 8 \mathrm{E}, 9 \mathrm{C}$ and 9D).

A convex-upward bed pressure wave developed in front of all the turbidity currents (for example, Fig. 9B to D) and persisted along the channel, especially at high $C_{f, i}$. At $x=2.5 \mathrm{~m}$, the height of the pressure wave was ca $0.006 \mathrm{~m}$ for $C_{t, i}=1 \%$, increasing to $c .0 .037 \mathrm{~m}$ for $C_{f, i}$ $=23 \%$. In the extreme case at $C_{f, i}=23 \%$, the pressure wave was more than $1 \mathrm{~m}$ long and it had multiple crests (Fig. 11A).

This article is protected by copyright. All rights reserved. 
The head of the turbidity current with $C_{f, i}=1 \%$ bypassed the intermediate and distal sections of the flume with minor erosion (Fig. 12A). Locally, the fluid mud was plastically deformed, forming small interfacial waves (cf. Verhagen et al., 2013; for example, at $x=1.9$ $m$ in Fig. 10A). The body of the flow was depositional and left a graded coal-rich bed, 0.007 $\mathrm{m}$ thick in the intermediate section of the flume, which contained some dispersed mud near the base (Fig. 13C). Part of this mud appeared in plumes above flame structures, but this relationship was more pronounced in the deposits of higher-density flows. The flame structures and closely associated load structures dominated the base of the deposit along the entire flume; these structures reached a maximum height at around $x=1.4 \mathrm{~m}$ (Fig. 13). The flame and load structures started to form during the final phase of flow and kept growing for several tens of minutes after the flow had stopped. The most distal deposits in Run 1 were less than $0.005 \mathrm{~m}$ thick, and composed mainly of coal particles (Fig. 13D).

The most conspicuous characteristic of Run $2\left(C_{f, i}=5 \%\right)$ was that $41 \%$ of the frontal part of the turbidity current moved underneath the fluid mud surface below the ultrasound scanner (Fig. 12B); this increased to $84 \%$ in Run $3\left(C_{f, i}=10 \%\right.$; Fig. 12C). Remarkably, the entire front of the turbidity current travelled inside the fluid mud over a length of ca $0.03 \mathrm{~m}$ in Run $4\left(C_{f, i}=15 \%\right.$; Fig. 12D) and ca $0.10 \mathrm{~m}$ in Run 5 ( $C_{f, i}=23 \%$; Fig. 12E), before emerging above the fluid mud. These intrabed currents (sensu Baas et al., 2014) had the same shape as ordinary turbidity currents; hence fluid mud was displaced over the front of the head, as if it was ambient water in classic bottom-hugging turbidity currents. This mud was incorporated into the flow at the point of emergence of the intrabed turbidity currents, forming long and persistent, horizontal, coal-bearing, mud layers encapsulated by the intrabed and suprabed flow portions (Figs 10E, 11B and 11C).

Despite the distinct longitudinal variations in flow-substrate interaction, the head velocities of the turbidity currents in Runs 1 to 5 lacked consistent long-term accelerations or decelerations between $x=1.2 \mathrm{~m}$ and $x=3.4 \mathrm{~m}$ (Fig. 5C). The mean head velocity of the 
turbidity currents increased from ca $0.06 \mathrm{~m} \cdot \mathrm{s}^{-1}\left(C_{f, i}=1 \%\right)$ to $c a 0.12 \mathrm{~m} \cdot \mathrm{s}^{-1}\left(C_{f, i}=10 \%\right.$ and $C_{f, i}$ $=15 \%)$, before decreasing to ca $0.11 \mathrm{~m} \cdot \mathrm{s}^{-1}\left(C_{t, i}=23 \%\right)($ Fig. 6$)$.

Figure 14 shows time-series of suspended sediment concentration, $C_{f}$, within and above the fluid mud. The lowermost UHCM probe yielded the initial near-surface fluid mud concentration of ca $1 \mathrm{vol} \%$, before the turbidity currents arrived below the ultrasound scanner. In Runs 2 to 5, a sudden jump in $C_{f}$-values to ca $2 \%$ at $z=-0.005 \mathrm{~m}$ corresponded to the arrival of the bed pressure wave in front of the turbidity currents. A second jump in $C_{f}$ at $z=-0.005 \mathrm{~m}$ in Runs 2 to 5 signified the arrival of the head of the turbidity currents. Figure $14 \mathrm{~A}$ shows only the arrival of the turbidity current with $C_{f, i}=1 \%$, as the vertical spacing of the UHCMs was too large to record the small pressure wave in Run 1. After the arrival of the head of the turbidity currents, the $C_{f}$ values for the lowermost UHCM remained at a raised level at $C_{f, i} \leq 10 \%$ until the supply from the header tank was halted, and the suspended sediment concentration started to decrease exponentially. The lowermost UHCM was unable to measure suspended coal concentrations in the head and body of the turbidity currents with $C_{f, i} \geq 15 \%$, but the UHCM time-series for these flows do reveal the exponential decrease in suspended sediment concentration after the supply from the header tank was stopped. As in the control experiments, the $C_{f}$-values measured within the turbidity currents decreased with increasing distance above the substrate, and the suspended sediment concentrations decreased at all levels in the flows upon termination of supply from the header tank. The UHCM at $z=0.10 \mathrm{~m}$ in Runs 4 and 5 measured $C_{f}$ values in clear water above the top of the turbidity current, while the UHCMs at $z=0.08 \mathrm{~m}$ in Run 5 just touched the top of the current's body.

The deposits of the turbidity currents in Runs 2 to 5 decreased in thickness from several centimetres to several millimetres along the flow path. Downflow of the chaotic coal-mud deposits close to the point of inflow, which were similar to the proximal deposits in Run 1 (cf. Figs $13 \mathrm{~A}$ and $15 \mathrm{~A}$ ), the deposits of the flows with $C_{f, i} \geq 5 \%$ had reproducible properties that were related genetically to the observed flow-substrate interaction. The mud incorporated at This article is protected by copyright. All rights reserved. 
the point of emergence of the intrabed turbidity currents was gradually, yet incompletely, mixed with coal within the body of the flows. This resulted in intrabed turbidites (denoted by 'I') that comprised, from base to top: (I1) coaly mud, with both dispersed mud and mud clasts, formed by local mixing and erosion as well as minor supply from the proximal scour; (I2) muddy coal, representing the 'intrabed' flow portion; (I3) coal-bearing mud with a speckled appearance, representing the encapsulated mud layer; and (14) mud-poor coal, representing the 'suprabed' flow portion and post-flow suspension settling (Fig. 15C). The I1 division pinched out between $x=1 \mathrm{~m}$ and $x=2 \mathrm{~m}$ (Fig. 15C and D). The I2 and I3 divisions were also wedge-shaped, but continuous over a larger distance. The 14 division persisted to the end of the mud reservoir, sitting on top of the mud substrate at $x>$ ca $3 \mathrm{~m}$.

The deposits of Runs 2 to 5 revealed a myriad of soft sediment deformation structures. Load structures (Fig. 15D), separated by flame structures (Fig. 15E), developed at the base of the turbidites near the end of the experiments. These deformation structures continued to grow after the flows had stopped, eventually reaching heights of up to $0.01 \mathrm{~m}$. Mud particles were ejected into the overlying turbidite via fluid-escape pipes or sheets (Fig. 15B). This injected mud formed 'frozen' mud plumes in the 12 , 13 and 14 divisions, and the mud often accumulated at the same level as the encapsulated mud in 12 to 14 beds. Some flame structures and overlying mud plumes leaned into the flow direction (Fig. 15E).

(C) Process interpretations

Physical reasoning dictates that differences in excess density drive the turbidity currents in the low-density fluid mud runs in the same way as in the control runs. However, flowsubstrate interaction, and in particular the development of intrabed flow, led to distinct differences in flow behaviour and deposit properties. The mean head velocity was higher and increased more rapidly with increasing $C_{f, i}$ in Runs 1 to 3 than in Runs 11 to 13 , which This article is protected by copyright. All rights reserved. 
carried sediment at similar initial concentrations (Fig. 6). In contrast, the rate of increase in mean head velocity from $C_{f, i}=10 \%$ (Run 3 ) to $C_{f, i}=15 \%$ (Run 4) was lower than in the corresponding control Runs 13 and 14 . Moreover, the mean head velocity of the turbidity current in Run $5\left(C_{t, i}=23 \%\right)$ was lower than in Run 4 , whereas the mean head velocity continued to rise from control Run $14\left(C_{f, i}=15 \%\right)$ to $15\left(C_{f, i}=23 \%\right)($ Fig. 6). It is inferred that these differences are caused by substrate erosion and intrabed flow, which prevailed downflow of the proximal location of in situ mixing with substrate sediment. Erosion of mud from the substrate increased the density difference with the ambient water in Runs 1 to 3 , thus increasing the head velocity relative to Runs 11 to 13 . The excess density for intrabed flows moving through mud should be lower than for flows moving through ambient water. This might explain why the mean head velocities for Runs 4 and 5 were lower than for Run 14 and 15. Intrabed flow was most prominent in Run 5 (Fig. 12), which caused this flow to move slower than the turbidity current in Run 4. Substrate erosion might have increased the excess density also in Runs 4 and 5, but the resultant increase in the head velocity was probably lower than the decrease in the head velocity from intrabed flow. The present authors hypothesise from the observed trends in head velocity that the travel distance of turbidity currents increases with the ability to entrain sediment from the fluid mud, but that the development of intrabed flow results in a shorter travel distance. A longer flume is required to test this hypothesis.

The spatio-temporal trends in the suspended sediment concentrations for the UHCMs that measured above the substrate in Runs 1 to 5 mimic the trends observed in control Runs 11-15. The UHCM that measured within the fluid mud at $z=-0.005 \mathrm{~m}$ recorded the arrival of the bed pressure waves and the intrabed portion of the turbidity currents in Runs 2 to 5 . It is unclear why the mud concentration in the bed pressure waves was twice as high as in the original substrate. This increase in mud concentration cannot be explained by admixture of coal, because the pressure waves travelled consistently in front of the turbidity currents. An alternative cause for the increase in concentration within the bed pressure wave is sourcing 
of extra mud from deeper within the substrate, thus essentially generating a much lower vertical density gradient within the fluid mud, but the experimental data do not enable verification of this.

The low-density fluid mud interacted with the coal-laden turbidity currents through four main processes: (i) substrate erosion and mixing at proximal locations; (ii) bypass and minor erosion at intermediate and distal locations in Run 1; (iii) intrabed flow and the development of a bed pressure wave at intermediate and distal locations in Runs 2 to 5; and (iv) soft sediment deformation at the base of developing turbidite deposits. These processes are inferred to be closely related to the rheological properties of the mud. Unlike sand, fluid mud has a bulk strength that depends on cohesive bonds between individual mud particles. This cohesive strength increases with increasing substrate mud concentration. Entrainment of cohesive mud is possible through the erosion of individual mud particles or small floccules ('surface' erosion of Mehta, 2014), the detachment of parcels of fluid mud from the crest of interfacial waves ('fluid mud' erosion of Mehta, 2014) and the erosion of pieces of mud from a firm bed ('mass' erosion of Mehta, 2014). Surface erosion and fluid mud erosion were observed at proximal locations in the present experiments, with the mud clasts denoting fluid mud erosion and the dispersed mud representing surface erosion and disintegration of the mud clasts by flow shear. The fact that the proximal deposits contained a large amount of mud clasts (for example, Fig. 15A), and that some mud clasts were transported along the flow path without disintegrating, suggests that the kaolinite was cohesive enough to produce strong clasts, despite their water content of up to $99 \%$. Yet, the yield stress of the clay must have been lower than the bed shear stress of the flows to initiate fluid mud erosion. All turbidity currents in Runs 1 to 5 were visibly turbulent, although it cannot be ruled out that the higher-density flows were transient turbulent (sensu Baas et al., 2009), given the low Reynolds numbers of these flows (Table 1). This turbulent flow behaviour implies that mixing of mud and coal was possible from a hydrodynamic point of view. Further evidence for the considerable cohesive strength of the mud was the presence of long streaks of mud injected

This article is protected by copyright. All rights reserved. 
into the turbidity currents (Figs 8D, 8E, 9C and 9D), the preservation of encapsulated mud in the $\mathrm{I} 3$ divisions of the intrabed turbidites (Fig. 15C and D) and the abundance of load and flame structures (Figs 13B, 15D and 15E). Together with the common presence of interfacial waves at the base of the turbidity currents and bed pressure waves in front of the turbidity currents, the load and flame structures indicate that the mud was plastically deformable under relatively weak horizontal shear or overburden pressure. The height of the flame and load structures appeared to have been controlled by the depth of erosion into the densitystratified fluid mud (Fig. 2) and the thickness of the overlying deposit. The deposits at around $x=1.4 \mathrm{~m}$ were relatively thick and most of the original mud was preserved. Hence, the overburden pressure was relatively high and the substrate mud concentration immediately below the base of the deposits was relatively low; this explains the large flame and load structures at around $x=1.4 \mathrm{~m}$. More distal deposits were thinner, and more proximal deposits were thicker, but rested on deeply eroded, firmer mud, hence the presence of smaller flame and load structures at these locations. A gradual increase in overburden pressure caused by continued deposition of suspended sediment explains why the flame and load structures kept growing after the sediment supply from the header tank had stopped.

Intrabed flow is inferred to take place only if the density of the turbidity current is larger than the density of the muddy substrate, and if the cohesive strength of the mud is high enough to withstand, or at least delay, mixing the mud into the flow. This reasoning is supported by the observations. In Runs 4 and 5, where intrabed flow was most pronounced, the turbidity currents had initial densities that were significantly higher than the density of the mud just below the substrate (1044 $\mathrm{kg} \mathrm{m}^{-3}$ for Run 5 and $1029 \mathrm{~kg} \mathrm{~m}^{-3}$ for Run 4 versus 1013 $\mathrm{kg} \mathrm{m}^{-3}$ for the mud substrate). The initial density of $1002 \mathrm{~kg} \mathrm{~m}^{-3}$ for the turbidity current in Run 1 was too low to trigger intrabed flow. The initial densities of the turbidity currents in Run 2 and 3 were close to the density of the substrate $\left(1010 \mathrm{~kg} \mathrm{~m}^{-3}\right.$ and $1019 \mathrm{~kg} \mathrm{~m}^{-3}$ versus 1013

This article is protected by copyright. All rights reserved. 
$\mathrm{kg} \mathrm{m}^{-3}$ ) which explains why these flows moved partly below the top of the fluid mud, but lacked distinct intrabed flow.

(C) Facies models

The deposits of the experimental intrabed turbidity currents informed a facies model for intrabed turbidites, proposed by Baas et al. (2014), scaled to deposits that contain natural sand and mud instead of coal and kaolinite. Herein, this facies model is extended by including a proximal facies for mixed flow-derived and substrate-derived sediment (Fig. 16B and C). Also, a new facies model for non-intrabed turbidity currents moving across soft mud, based on Run 1, is proposed (Fig. 16A). The facies model for the turbidity currents that remained on top of the substrate is dominated by evidence for combined erosion and deposition in proximal locations, bypass, minor erosion and deposition in intermediate and distal locations, and basal soft sediment deformation along the entire flow path (Fig. 16A). The proximal facies comprises a scoured and loaded base, a lower division of thick, chaotically mixed sand, mud clasts and dispersed mud, and an upper division of normally graded sand. The lower division should not be mistaken for a debris-flow deposit; the mixed sand-mud was formed below a fully turbulent gravity flow by incomplete disintegration of eroded mud clasts and weak downflow transport of the eroded sediment. The upper division resembles a Bouma-type turbidite (Bouma, 1962), with evidence for gradual flow deceleration and suspension settling. The mixed sand-mud division wedges out in a downflow direction, with the mud clasts becoming increasingly smaller and less frequent. In the same direction, the flame and load structures tend to increase in size first, but then become smaller in parallel with gradually decreasing bed thickness. A division of muddy sand, which records the effect of minor erosion of the fluid mud, may be present between the mixed sand-mud division and the normally graded sand at intermediate locations. This 
division rests directly upon the fluid mud beyond the point of termination of the mixed sandmud division. The muddy sand division eventually also pinches out, so that the most distal locations are characterised by thin, graded sand beds.

The most proximal facies of turbidity currents that show intrabed behaviour (Fig. 16B and C) is similar to the proximal facies shown in Fig $16 \mathrm{~A}$, but the mixed mud-sand and normally graded sand divisions may be thicker, because intrabed flow is expected to be more common in relatively high-concentration and high-velocity turbidity currents. Complete intrabed turbidite 11 to 14 sequences prevail in locations where the turbidity current moves into the substrate and the distal extension of the proximal mixed sand-mud facies is preserved. As in the experimental deposits, an encapsulated mud layer (I3 division) separates the intrabed portion (I2 division) from the suprabed portion (14 division) of the turbidite (Fig. 16C). The 12 division resembles a turbidite with abundant evidence of soft sediment deformation. The 14 division is expected to be a normally graded Bouma-type turbidite. Beyond the influence of substrate erosion, the full intrabed turbidite is replaced by a thinner, base-missing 12 to 14 turbidite. The most distal 14 facies (Fig. 16C) signifies termination of intrabed flow, possibly owing to re-emergence of the flow above the fluid mud surface or immobilization inside the fluid mud.

\section{(B) Experiments with high-density fluid mud in reservoir}

\section{(C) Observations}

The turbidity currents in Runs 6 to 10 carried sediment at initial volumetric concentrations of $1 \%, 5 \%, 10 \%, 15 \%$ and $23 \%$, respectively (Table 1), across the $0.04 \mathrm{~m}$ thick fluid mud (Fig. 2). In general, the dynamics of these flows, and their interaction with the fluid mud, can be described as intermediate between the flows over the fixed bed (Runs 11 to 15) and the 
flows over the low-density fluid mud (Runs 1 to 5 ). Flow thickness decreased from $0.16 \mathrm{~m}$ to ca $0.08 \mathrm{~m}$, as $C_{t, i}$ was increased from $1 \%$ to $23 \%$ (Table 1 ). Head velocity showed some variations over short distances, but none of the turbidity currents experienced significant flow decelerations or accelerations between $x=1.2 \mathrm{~m}$ and $x=3.4 \mathrm{~m}$ (Fig. 5B). The mean head velocities increased from ca $0.06 \mathrm{~m} \mathrm{~s}^{-1}$ for Run $6\left(C_{t, i}=1 \%\right)$ to ca $0.14 \mathrm{~m} \mathrm{~s}^{-1}$ for Run $10\left(C_{f, i}=\right.$ 23\%) (Fig. 6). This rate of increase was slightly lower than for the fixed-bed runs, and the decrease in mean head velocity between $C_{f, i}=15 \%$ and $C_{f, i}=23 \%$ for the intrabed flows in Runs 4 and 5 was absent from Runs 9 and 10. Indeed, none of the side-wall videos (Fig. 17), the ultrasound recordings (Fig. 18) and the UHCM data (Fig. 19) showed evidence for intrabed flow in Runs 6 to 10. Nonetheless, the turbidity current with $C_{f, i}=23 \%$ (Run 10) tried to move into the fluid mud in a few places (for example, Fig. 20A), but it only managed to disturb the mud for short distances, thereby forming short horizontal streaks of mud, before continuing on top of the substrate (Fig. 20). This process was rare compared to fluid mud erosion (sensu Mehta, 2014) at proximal locations and surface-type erosion (sensu Mehta, 2014) to a depth of several millimetres elsewhere along the flow path. Erosion close to the point of entry also took place at $C_{t, i} \leq 15 \%$, but the depths of the scoop-shaped scours $(0.001$ to $0.005 \mathrm{~m}$ at $x=0.6 \mathrm{~m}$; for example, Fig. $21 \mathrm{~A}$ ) were shallower than in Runs 1 to 5 . Bypass of the head and deposition from the body and tail of the turbidity currents prevailed elsewhere in Runs 6 to 9 . Bed pressure waves were confined to the turbidity currents with $C_{f, i} \geq 10 \%$ (Fig. 18). These waves were between $0.001 \mathrm{~m}$ and $0.0045 \mathrm{~m}$ high and less than $0.1 \mathrm{~m}$ long, thus considerably smaller than in Runs 1 to 5 .

Figure 19 shows the time-series of suspended sediment concentration within and above the fluid mud for Runs 6 to 10. The lowermost UHCM probe remained within the substrate throughout Runs 6 to 9 (blue lines in Fig. 19A to D), where the mud concentration gradually increased with time. This increase was largest in Run 9, with the top of the fluid mud reaching a suspended sediment concentration of $4.6 \%$ after ca 8 minutes (Fig. 19D). In contrast, the UHCM data for the highest-concentration turbidity current in Run 10 shows a 
rapid increase in sediment concentration at $z=-0.005 \mathrm{~m}$ upon arrival of the head of the flow. The remaining UHCMs, positioned within the water column in Runs 6 to 10, also recorded the arrival of the turbidity currents. As in the other series of experiments, the turbidity currents became more dilute with time, especially after the sediment supply for the header tank had stopped, and as the height above the substrate increases.

The deposits of the turbidity currents in Runs 6 to 10 resembled the turbidites formed in Run 1. However, the mixed coal-mud beds that formed within the proximal erosional scours were thinner, and the mud clasts were smaller, than in the low-density fluid mud Runs 1 to 5 (Fig. 21A). Thin coal-rich beds prevailed at intermediate and distal locations. Proximal deposits had a thickness of 0.011 to $0.030 \mathrm{~m}$, while the most distal deposits were less than $0.005 \mathrm{~m}$ thick. Load structures, and some flame structures, were confined to locations where flow-substrate interaction was most pronounced, i.e. at proximal locations in all runs (Fig. 21C), at intermediate and distal locations below the higher-concentration, higher-velocity Runs 8 to 10 (Fig. 21B), and below failed intrabed flow in Run 10 (Fig. 20B). These soft sediment deformation structures were up to $0.01 \mathrm{~m}$ high. Towards the end of several experiments, clouds of mud started to appear at the side-wall of the flume at a level just below the top of the coal deposits. These clouds continued to grow to a diameter of up to $0.01 \mathrm{~m}$, thereby merging with adjacent clouds, after sediment supply from the header tank had stopped. This process formed an almost continuous layer of pure mud and mixed mudcoal, which was separated from the loaded mud fluid by a layer of pure coal (Fig. 21B and C). These mud clouds were different from the clouds found in Runs 1 to 5 , in that they were not directly coupled to flame structures in the underlying mud. Instead, the mud seemed to have moved from the centre of the flume to the side-wall.

This article is protected by copyright. All rights reserved. 
(C) Interpretations

The increase in near-surface mud concentration from 1\% in Runs 1 to 5 to $3 \%$ in Runs 6 to 10 rendered the $4 \mathrm{~cm}$ thick fluid mud more cohesive than the $8 \mathrm{~cm}$ thick fluid mud and therefore significantly changed the flow-substrate interaction. It is inferred that the fluid mud was too dense to permit intrabed flow, because the initial densities of all turbidity currents in Runs 6 to $10\left(1002\right.$ to $\left.1044 \mathrm{~kg} \mathrm{~m}^{-3}\right)$ were lower than the density of the mud at $z=-0.005 \mathrm{~m}$ $\left(1050 \mathrm{~kg} \mathrm{~m}^{-3}\right)$. However, the initial density of the flow in Run 10 was sufficiently close to the density of the fluid mud to exhibit failed intrabed flow (Fig. 20). Instead of producing intrabed flow, the turbidity currents eroded the fluid mud, particularly upon entering the mud reservoir, and deposited coal onto the relatively firm substrate. However, the substrate was not firm enough to withstand soft sediment deformation by the overburden pressure of the gradually thickening coal deposits. Load structures were most common, and started to form near the end of the experiments, presumably when the deposits had reached a thickness large enough to cause an unstable inverse pressure gradient at its lower boundary. As in Runs 1 to 5 , settling of suspended coal was a slow process, explaining why the load structures kept on growing well after the flows had been halted. The clouds of mud within the turbidite deposits are interpreted as mud injections that were also related to overburden pressure. These injections were most likely to be initiated in the centre of the flume and then spread sideways towards the side-wall of the flume. The mud accumulated at a specific level within the coal deposits, where the density of the mud and the density of the coal deposits were approximately equal. The lower permeability of the relatively fine-grained sediment near the top of the graded coal deposits might have prevented the mud from extruding onto the bedwater interface.

The fluid mud experienced consolidation after the passage of and deposition from the turbidity currents in Runs 6 to 9, as suggested from the increase in sediment concentration measured by the UHCM at $z=-0.005 \mathrm{~m}$ within the substrate (Fig. 19A to D). The rate of consolidation was highest in Run 9, which renders it likely that the overburden pressure of This article is protected by copyright. All rights reserved. 
the turbidite deposits not only caused soft sediment deformation, but also sped up the consolidation process. In run 10 with $C_{f, i}=23 \%$, the turbidity current eroded down to a depth of at least $0.005 \mathrm{~m}$, considering that the lowermost UHCM recorded the arrival of the head of this flow.

The facies model for turbidites formed from the non-intrabed turbidity currents, shown in Fig. 16A, also applies to the flows in Runs 6 to 10 . However, the chaotically mixed sandmud is expected to be thinner than for the softer fluid mud, because the flow cannot erode as far into the relatively firm mud. For the same reason, the length of the mixed sand-mud layer should be shorter than for facies associated with softer mud. Mud clasts within this division are expected to be relatively small and infrequent, because fluid mud erosion is confined to shallower depths. Locally, streaks of mud may be present near the base of sandy divisions at intermediate and distal locations, but relatively clean sand resembling Bouma-type turbidites should be dominant, because entrainment of mud from the firm substrate is limited. Load structures are common in this facies, but perhaps not as widespread as in equivalent facies for lower-density fluid muds.

\section{(A) DISCUSSION}

\section{(B) Classification of types of flow-substrate interaction}

The present experiments reveal that laboratory-scale turbidity currents experience a marked variety of types of interaction with a soft muddy substrate, ranging from erosion, bypass and deposition to local mixing, intrabed flow, and soft sediment deformation. Based on fundamental physical principles, we propose that five main factors determine the type of interaction (Fig. 22): (i) the erosive capability of the turbidity current versus the resistance to This article is protected by copyright. All rights reserved. 
erosion of the muddy substrate; (ii) the ability of the turbidity current to keep particles in suspension; (iii) the difference in density between the turbidity current and the soft muddy substrate; (iv) the stability of the turbidity current; and (v) the difference in density between the turbidite deposit and the substrate.

The erosive capability of the turbidity current is governed by the bed shear stress, $\tau_{0}$, and the resistance to erosion of the fluid mud depends on the cohesive forces within the mud, which can be quantified by the yield stress, $\tau_{y}$. The fluid mud is exposed to erosion, if the bed shear stress is higher than the yield stress. Conversely, the fluid mud is stable, except possibly for plastic deformation, if the bed shear stress is lower than the yield stress. Figure 22 uses the excess bed shear stress, $T$, to parameterise these conditions:

$$
T=\frac{\tau_{0}-\tau_{y}}{\tau_{y}}
$$

where $T>0$ denotes plastic deformation at relatively low $T$-values and erosion at relatively high $T$-values, (sector I in Fig. 22) and $T<0$ represents the stable substrate (sector II in Fig. 22). The bed shear stress can be calculated from the mean flow velocity, $U$, and the density of the flow, $\rho_{f}$, via the quadratic stress law:

$$
\tau_{0}=\frac{\rho_{f} g U^{2}}{C^{z^{2}}}
$$

where $g$ is the gravitational constant and $C^{\prime}$ is the Chézy coefficient. The Chézy coefficient depends on the grain roughness and the form roughness of the substrate. For invariably flat fluid muds, it can be assumed that $C^{\prime}$ is governed by the grain roughness of the silt-sized and clay-sized particles within the mud. In the present study, $C^{\prime}$ is kept constant at $100 \mathrm{~m}^{0.5}$ $\mathrm{s}^{-1}$, which was calculated using procedures described by Van Rijn (1990). Furthermore, it is This article is protected by copyright. All rights reserved. 
assumed that the flow density and the mean flow velocity in Eq. 2 can be approximated by the initial density of the turbidity current, $\rho_{f, i}$, and the head velocity of the turbidity current, $U_{h}$, respectively. Empirical data are required to calculate the yield stress from the volumetric concentration of clay in the fluid mud. Wan (1982) proposed the following empirical relationship for kaolinite:

$$
\tau_{y}=1280\left(\frac{C_{b}}{100}\right)^{3}
$$

where $C_{b}$ is the volumetric sediment concentration within the substrate. The stable fluid mud at $T<0$ might experience bypass or deposition of suspended sediment, depending on whether the turbidity current is sufficiently turbulent to support this sediment. These types of flow-substrate interaction are controlled by the ratio between the shear velocity of the flow, $u_{*}$, and the particle settling velocity, $w_{s}$. Bypass requires $u_{*} \geq w_{s}$, and deposition takes place at $u *<w_{s}$ (sector II in Fig. 22).

The turbidity current exhibits intrabed behaviour or mixing between flow-derived and substrate-derived sediment, if the density near the base of the flow is higher than the density close to the surface of the fluid mud. Conversely, the flow remains on top of the substrate, if the flow is less dense than the substrate mud. Figure 22 uses the non-dimensional excess density, $P$, to parameterise these conditions:

$$
P=\frac{\rho_{f, i}-\rho_{b}}{\rho_{b}}
$$

where $\rho_{b}$ is the near-surface density of the fluid mud. The initial flow density, $\rho_{f, i}$, is assumed to be representative for the density near the base of the turbidity current. Hence, $P>0$ represents intrabed flow or mixing (sector III in Fig. 22) and $P<0$ signifies flow on top of the This article is protected by copyright. All rights reserved. 
substrate (sectors I and II in Fig. 22). The difference between intrabed flow and mixing is inferred to depend on the stability of the flow inside the fluid mud. Intrabed flow is stable only if the mud that is swept over the top of the submerged flow is mixed into the flow slowly (for example, Fig. 12E), whereas intrabed flow is unlikely if this mixing process is rapid, as at proximal locations in the experiments with low-density fluid mud. The degree of stability of the upper boundary of turbidity currents is governed by the gradient Richardson number, $R i_{g}$ :

$$
R i_{g}=\frac{\frac{d \rho}{d z}}{\rho_{f^{i} i}} \frac{g}{\left(\frac{d u}{d z}\right)^{2}}
$$

where $d \rho$ is the density difference between the flow and the fluid mud acting over a vertical distance $d z, g$ is the gravitational constant $\left(g=9.8 \mathrm{~m} \mathrm{~s}^{-1}\right)$ and $d u$ is the difference in velocity between the flow and the displaced mud. $R i_{g} \geq 0.25$ denotes a stable boundary, whereas $R i_{g}$ $<0.25$ signifies an unstable boundary (e.g. Stacey \& Bowen, 1988; Buckee et al., 2001). Equation 5 shows that the stability of the boundary increases as a function of increasing density gradient and decreasing velocity gradient. Therefore, intrabed flow should dominate in lower right corner of sector III in Fig. 22, and mixing should prevail in the upper left corner of the same sector.

Soft sediment deformation by way of the development of load, flame and injection structures requires that the density of the turbidite deposit is higher than the density of the upper part of the substrate mud. This late depositional to post-depositional process forms an integral part of the facies models shown in Fig. 16, but it may obscure sedimentological evidence for other types of interactions, for example where extruded substrate mud accumulates in the 13 division of intrabed turbidites (Fig. 15E), and load structures deform overlying stratification (Fig. 21B).

This article is protected by copyright. All rights reserved. 
The type of flow-substrate interaction for $T<0$ and $P>0$ (sector IV in Fig. 22) is unclear. The experiments did not cover this condition, but intrabed flow is probably not possible for bed shear stresses that are lower than the yield strength of the soft, muddy substrate. Instead, the flow may bypass the site and loading may start earlier than in sectors I and II, because a deposit is not required to develop the inverse density gradient.

The experimental data comply with the classification of the flow-substrate interaction types in Fig. 22. As shown above, all turbidity currents that moved into the high-density fluid mud reservoir, as well as the flow with $C_{t, i}=1 \%$ that moved into the low-density fluid mud reservoir, lacked intrabed flow, because the flow density was lower than the substrate density (Table 1; Figs $12 \mathrm{~A}$ and 18). Moreover, the front of the turbidity currents with $C_{f, i} \geq$ $15 \%$ moved inside the low-density fluid mud (Fig. 12D and E), because the density of these flows was significantly higher than the near-surface density of the fluid mud. The bed shear stress of all the turbidity currents that negotiated the low-density fluid mud reservoir, and the flow with $C_{f, i}=23 \%$ that encountered the high-density fluid mud reservoir, were higher than the yield stress of the fluid mud, which explains the dominance of erosion, even in the slowmoving currents (Table 1). The absence of erosion of the high-density fluid mud at intermediate and distal locations in the turbidity currents with $C_{t, i} \leq 15 \%$ also complies with the calculated $T$-values (Runs 6 to 9 in Table 1). Turbulence production at the abrupt transition from the fixed polystyrene substrate to the soft mud may have promoted the erosion of the fluid mud at the proximal location in these flows.

Equation 5 was used to estimate the stability of the intrabed portions of the turbidity currents in Runs 4 and 5 (Fig. 12D and E). The density gradient $d \rho / d z$ was based on the difference in the mean density of the flow and the mean density of the overlying fluid mud over a vertical distance of $0.025 \mathrm{~m}$, assuming that no mud was mixed into the intrabed flow. The same vertical distance was applied to $d u / d z$, where the velocity of the intrabed flow was obtained from the ultrasound recordings and it was assumed that the velocity of the displaced mud was very small, hence $d u \approx u$. The intrabed portion of the turbidity current in This article is protected by copyright. All rights reserved. 
Run $4\left(C_{t, i}=15 \%\right)$ was only $0.03 \mathrm{~m}$ long (Fig. 12D), suggesting that the upper boundary quickly entrained the mud displaced over the top of the flow. This interpretation is supported by the low gradient Richardson number $\left(R i_{g}=0.07\right)$, which implies an unstable upper boundary of the flow. The gradient Richardson for Run $5\left(C_{f, i}=23 \%\right)$ was just above the threshold value of 0.25 for a stable upper boundary $\left(\mathrm{R} i_{g}=0.26\right)$, which is reflected in a relatively long intrabed portion for this turbidity current (Fig. 12E).

\section{(B) Intrabed flow in natural turbidity currents}

\section{(C) Rationale}

The flume experiments were conducted with low-velocity turbidity currents and dilute substrates. Fluid mud can reach densities of up to ca $1250 \mathrm{~kg} \mathrm{~m}^{-3}$ (e.g. Winterwerp \& van Kesteren, 2004; Mehta, 2014), which is equivalent to a volumetric kaolinite concentration of ca $15.5 \%$ and a yield stress of $4.8 \mathrm{~N} \mathrm{~m}^{-2}$ (Eq. 3; Wan,1982). Because muddy substrates start to behave as solids above $1250 \mathrm{~kg} \mathrm{~m}^{-3}$ (Mehta, 2014), it is assumed here that intrabed flow is not possible under these conditions, and that mass erosion (sensu Mehta, 2014) should prevail instead. The velocity of natural turbidity currents can reach up to several tens of metres per second (Talling et al., 2013), which is two orders of magnitude larger than the head velocity of the experimental turbidity currents described in the present paper. These distinct differences between natural turbidity currents and the experimental turbidity currents bring into question: (i) how common fluid muds are in the natural environment; (ii) how feasible intrabed flow is for natural turbidity currents; and (iii) provided that intrabed flow is possible, how stable it is in the natural environment?

This article is protected by copyright. All rights reserved. 
(C) Fluid mud in natural environments

Widespread evidence exists for the presence of fluid mud, formed by rapid sedimentation of mud or liquefaction of mud deposits, in natural environments (e.g. Whitehouse et al., 2000; Winterwerp \& van Kesteren, 2004). Fluid mud has been found mostly in harbours and navigation channels (e.g. Verlaan \& Spanhoff, 2000; McAnnally et al., 2007a,b), at river mouths (e.g. Kineke et al., 1996; Traykovski et al., 2000) and on the shoreface and continental shelf (e.g. Wells \& Coleman, 1981; Wheatcroft \& Borgeld, 2000; Anthony et al., 2010), and also in deep ocean basins (e.g. Cacchione et al., 2006; Amy et al., 2007; Ito et al., 2014; Stevenson et al., 2014a). Here, it is assumed that fluid mud in the natural environment covers a similar density range as fluid mud in the laboratory, and that, at first order, empirical relationships between mud concentration and yield stress are valid for scale models in the laboratory and prototypes in the natural environment. However, fluid mud is subjected to consolidation by gradual loss of pore water, which causes the fluid mud to evolve into a solid mud. Characteristic time-scales are hours to days for forming freshly consolidated, dilute, fluid mud $\left(\rho_{b}=1000\right.$ to $1050 \mathrm{~kg} \mathrm{~m}^{-3}$ ), weeks for forming weakly consolidated fluid mud $\left(\rho_{\mathrm{b}}=1050\right.$ to $\left.1150 \mathrm{~kg} \mathrm{~m}^{-3}\right)$, months for forming moderately consolidated, dense fluid mud $\left(\rho_{b}=1150\right.$ to $1250 \mathrm{~kg} \mathrm{~m}^{-3}$ ), and years to hundreds of years for forming highly consolidated mud, stiff mud and hard mud $\left(\rho_{b}>1250 \mathrm{~kg} \mathrm{~m}^{-3}\right.$ ) (Mehta, 2014). These timescales for the maintenance of fluid mud are short compared with most other timescales in sedimentary geology. Therefore, special circumstances are required to make fluid mud available for interaction with turbidity currents. More or less continuous supply of fine-grained sediment by bottom currents, such as on the continental shelf adjacent to the modern Amazon River (Anthony et al., 2010), and deposition of clay-rich sediment from different types of sediment gravity flow at a high recurrence rate within deep marine basins, may maintain substrates with fluid-mud properties for prolonged periods of time. Liquefaction of mud deposits, by, for example, earthquakes, storm waves, tsunamis and This article is protected by copyright. All rights reserved. 
shear imposed by bottom currents and sediment gravity flows, also produces soft muddy substrates that might be susceptible to intrabed flow behaviour (e.g. de Wit \& Kranenburg, 1997; Manica 2012; Jia et al., 2014; Baas et al., 2016). Contained and confined basins are particularly suitable for the development of thick fluid muds, because clay-sized sediment tends to be trapped within these basin types (Amy et al., 2007). The presence of a sill across which the sediment gravity flows enter such basins may further promote the initiation of intrabed flow, especially where an onlap relationship between the soft basin mud and the firmer sediment of the sill is present. It should be emphasised, however, that any depression in the basin floor serves as a possible container for fluid mud, whereas sloping basin floors are less likely to sustain the highly mobile fluid mud.

Under the assumption that conditions suitable for fluid mud development are available, the feasibility of intrabed flow in natural turbidity currents is assessed by taking a three-way approach. Firstly, Eq. 4 is used to show that natural turbidity currents are capable of moving inside fluid muds. Secondly, Eq. 1 is used to determine which types of flow-substrate interaction are most likely for full-scale turbidity currents of different density and velocity. Thirdly, Eq. 5 is used to estimate the thresholds of intrabed flow behaviour versus flowsubstrate sediment mixing for natural turbidity currents.

(C) Feasibility of intrabed flow

Figure 23 compares the density of turbidity currents with the density of soft muddy substrates. The substrate density covers the entire stability range of fluid mud and extends into relatively low-density solid substrates at $>1250 \mathrm{~kg} \mathrm{~m}^{-3}$. The flow density covers low to high-concentration turbidity currents carrying an arbitrarily chosen maximum of $24 \%$ quartzrich sediment. Figure 23 also shows lines of equal head velocity, for which the bed shear stress is equal to the yield stress of the fluid mud, following the quadratic stress law (Eq. 2). This article is protected by copyright. All rights reserved. 
For turbidity currents that are less dense than the muddy substrate, each line of equal velocity separates eroding flow to the left $\left(\tau_{0}>\tau_{y}\right)$ from non-eroding flow to the right $\left(\tau_{0}<\tau_{y}\right)$. For example, a turbidity current with a head velocity of $0.8 \mathrm{~m} \mathrm{~s}^{-1}$ and a density of $1100 \mathrm{~kg} \mathrm{~m}^{-3}$ erodes the substrate only if the substrate density is lower than $1131 \mathrm{~kg} \mathrm{~m}^{-3}$. Erosion can also be achieved by increasing the flow density, but the near-vertical orientation of the lines of equal head velocity suggests that such a change has a significantly smaller effect on the excess bed shear stress than reducing the substrate density, or increasing the head velocity. The bold dashed line in Fig. 23 represents the conditions for which the flow density is equal to the substrate density. Intrabed flow and mixing of flow-derived and substrate-derived sediment are possible only above this line, i.e. at $\rho_{f}>\rho_{b}$, provided that $\tau_{0}>\tau_{y}$. As expected, dense flows are particularly prone to intrabed flow or mixing when flowing across a fluid mud. In fact, all high-density turbidity currents that carry quartz-rich sediment at a volumetric concentration of $15 \%$ or higher should have the tendency to flow inside freshly, weakly or moderately consolidated fluid mud. The lines of equal head velocity for turbidity currents that move faster than ca $2 \mathrm{~m} \mathrm{~s}^{-1}$ are outside the density range of fluid mud composed of kaolinite (Fig. 23). This implies that such fast-flowing currents are able to enter any fluid mud, provided that the flow is denser than the substrate. The lines of equal velocity in Fig. 23 are valid only for kaolinite, which is a relatively weakly cohesive clay mineral. Bentonite, on the other hand, is strongly cohesive, and therefore has a higher yield stress than kaolinite (Wan, 1982):

$$
\tau_{y}=22.3 \cdot 10^{3}\left(\frac{C_{b}}{100}\right)^{3.69}
$$

This higher yield stress would shift the line of $4 \mathrm{~m} \mathrm{~s}^{-1}$ into the fluid-mud regime in Fig. 23 . Hence, turbidity currents that move at 2 to $4 \mathrm{~m} \mathrm{~s}^{-1}$ should no longer be capable of entering moderately consolidated bentonite mud. In general, however, the above conclusions on the 
capability of turbidity currents to enter fluid muds composed of kaolinite also apply to bentonite and presumably to more moderately cohesive clay minerals, such as illite, as well.

(C) Stability of intrabed flow

It thus appears from the above theoretical considerations that a wide range of natural turbidity currents is susceptible to sector-III type interaction with fluid muds. However, stable intrabed flow, as opposed to mixing of sediment from the flow with mud from the substrate, requires that the gradient Richardson number across the upper boundary of intrabed flow is higher than 0.25 . Equation 5 indicates that a stable boundary is more likely in slower flows. Because the head velocity of natural turbidity currents can be much higher than the head velocity of laboratory currents, it is hypothesised here that stable intrabed behaviour in sector-III turbidity currents is less common in prototypes than in scale models and, therefore, I1 to 14 facies models (Fig. 16B) are confined to relatively weak turbidity currents. This hypothesis was tested by calculating $R i_{g}$-values for typical ranges of $d \rho / d z, \rho_{f}$, and $d u / d z$. It seems unlikely that turbidity currents can enter a muddy substrate down to more than a couple of metres, primarily because overburden pressure in fluid muds will cause the density and strength of the substrate to increase rapidly with depth below the sediment surface until a solid bed (sensu Mehta, 2014) is established, for which intrabed flow has been discarded. Values of $d z$ in natural flows are therefore assumed to range from ca $0.1 \mathrm{~m}$ to ca $1.0 \mathrm{~m}$ in the $R i_{g}$-calculations, whereas laboratory flows should be limited to $0.01<d z<0.1 \mathrm{~m}$. Based on the available data for turbidity currents in modern environments, accumulated by Talling et al. (2013), flow velocities in the range of $0.5 \mathrm{~m} \mathrm{~s}^{-1}$ to $40 \mathrm{~m} \mathrm{~s}^{-1}$ were tested. The substrate densities used in the calculations covered the entire range of freshly, weakly and moderately consolidated fluid mud, and flow densities ranged from $1005 \mathrm{~kg} \mathrm{~m}^{-3}$ to $1400 \mathrm{~kg} \mathrm{~m}^{-3}$, as in Fig. 23. The results of the $R i_{g}$ analysis for $d z$-values of $1.0,0.1$ and $0.01 \mathrm{~m}$ are summarised in This article is protected by copyright. All rights reserved. 
Fig. 24A, B and C, respectively. Each graph shows curves that represent $R i_{g}=0.25$, based on $\rho_{f}-\rho_{b}, u_{f}-u_{b}$, and $\rho_{f}$-values of $1025,1100,1200,1300$ and $1400 \mathrm{~kg} \mathrm{~m}^{-3}$, and extend only to conditions where the substrate density is higher than $1000 \mathrm{~kg} \mathrm{~m}^{-3}$, the density of fresh water. These curves separate a flow regime with a stable upper flow boundary and intrabed flow for lower $u_{f}-u_{b}$ and higher $\rho_{f}-\rho_{b}$ from a flow regime with an unstable flow boundary and mixing of flow-derived and substrate-derived sediment for higher $u_{f}-u_{b}$ and lower $\rho_{f}-\rho_{b}$. As in the experiments described above, it was assumed that the velocity of the mud swept over the top of the intrabed flows is close to zero, hence $u_{f}-u_{b}$ effectively reduces to $u_{f}$.

Figure 24 shows that the threshold velocity for intrabed flow is governed mainly by $d z$, but there is also a considerable dependence on the difference between flow density and substrate density, especially for low values of $\rho_{f}-\rho_{b}$. In contrast, the threshold velocity for intrabed flow varies only slightly with the absolute density of the flow. The main conclusion drawn from Fig. 24 is that stable intrabed flow requires relatively low flow velocities, despite the fact that most natural turbidity currents are well able to enter fluid muds (Fig. 23). Mixing of flow-derived and substrate-derived sediment should prevail in all turbidity currents that move faster than $3.5 \mathrm{~m} \mathrm{~s}^{-1}$, assuming that $d z=1 \mathrm{~m}$ is a reasonable upper limit for the density and velocity gradients. The upper limit of intrabed flow decreases, as $\rho_{f}-\rho_{b}$ is decreased, because a smaller density gradient renders the upper flow boundary less stable. For example, a decrease in the density gradient from $400 \mathrm{~kg} \mathrm{~m}^{-3}$ per metre to $150 \mathrm{~kg} \mathrm{~m}^{-3}$ per metre reduces the upper limit of intrabed flow from $3.5 \mathrm{~m} \mathrm{~s}^{-1}$ to ca $2.0 \mathrm{~m} \mathrm{~s}^{-1}$ (Fig. 24A). As changes in the velocity gradient lead changes in the density gradient [i.e. $(d u / d z)^{2}$ versus $d \rho / d z$ in Eq. 5], a steeper velocity gradient reduces the maximum velocity for intrabed flow even further. For $d z=0.1$, which is likely to apply to relatively large laboratory currents and relatively small natural currents, stable intrabed flow is predicted at flow velocities below ca 1 $\mathrm{m} \mathrm{s}^{-1}$ for large density gradients and down to several tenths of $\mathrm{m} \mathrm{s}^{-1}$ for small density gradients. Turbidity currents at a scale similar to the experimental flows presented herein, for This article is protected by copyright. All rights reserved. 
which $d z$ is of the order of 0.01 , are predicted to show stable intrabed behaviour only at flow velocities below 0.1 to $0.3 \mathrm{~m} \mathrm{~s}^{-1}$, again depending on the density gradient. These calculations of intrabed flow thresholds are based on densities just below the top of the mud substrate. However, the experiments showed that intrabed flow tends to find a level within the fluid mud where the substrate density is closer to the flow density. The $R i_{g}$-analysis might therefore overestimate the values of $\rho_{f}-\rho_{b}$, and the maximum velocities for stable intrabed flow might be somewhat lower than those shown in Fig. 24.

The results of the $R i_{g}$-analysis thus support the hypothesis here that stable intrabed behaviour in sector III turbidity currents is restricted to relatively weak flows. None of the 'powerful' currents in the dataset of Talling et al. (2013) (for example, in the Grand Banks area, in the Zaire and Goaping Canyons, and off Nice airport in the Mediterranean) would be able to produce stable intrabed flow, if such flows enter a fluid mud. On the other hand, the 'weak' flows, and possibly some of the flows of 'intermediate' strength $(u<c a 1.5 \mathrm{~m}$ $\mathrm{s}^{-1}$; Talling et al., 2013), would have the potential to produce stable intrabed flow, especially for large positive gradients in density.

(C) Estimating flow properties from deposit properties of an intrabed turbidite

Baas et al. (2014) described an inferred 12 to 14 intrabed turbidite from Clarach Bay in the Silurian Aberystwyth Grits Group in West Wales, United Kingdom (Fig. 25A). The 12 division of this turbidite consists of a 0.07 m thick muddy sandstone with small load and flame structures at its base and pervasive convolute lamination. This muddy sandstone is overlain by an irregular, $0.01 \mathrm{~m}$ thick, sandy mudstone, interpreted as the 13 division, and a $0.015 \mathrm{~m}$ thick 14 division, consisting of normally graded sandstone loaded into the underlying mudstone. This bed stands out from a sedimentary sequence that is dominated by hybrid 
event beds (Fig. 25B; Talling et al., 2004; Haughton et al., 2009,) in that: (i) the intrabed turbidite consists of a thin, continuous, mudstone enveloped by thicker sandstones, whereas the hybrid event beds comprise a thick mud-clast rich contorted sandstone (formed by a debris flow) sandwiched between thin cleaner sandstones (formed by turbidity currents); (ii) the intrabed turbidite lacks the clasts and rafts present near the top of the mud-rich sandstone in the hybrid event beds; (iii) the intrabed turbidite has load and flame structures at its base, where the hybrid event beds often have flutes and grooves, suggesting a firm local substrate, unsuitable for intrabed flow; and (iv) the 13 division of the intrabed turbidite is continuous upflow for at least $17 \mathrm{~m}$ until it bends upward to the former bed-water interface interpreted as the point where the turbidity currents entered the substrate - so it is more likely that this division represents a mud injection rather than an elongate mud clast.

Considering that this intrabed turbidite was ca $0.1 \mathrm{~m}$ thick, of which the intrabed flow portion was $0.07 \mathrm{~m}$, the present authors infer that the turbidity current that entered the substrate and produced the 12 to 14 deposit had a relatively low velocity, and it was probably somewhat larger than the experimental turbidity currents described herein. It is not possible to determine a precise velocity and a precise density difference with the muddy substrate for this turbidity current, but estimates can be made from the properties of the deposit. The load and flame structures within the natural intrabed turbidite were smaller than within the experimental intrabed turbidites, while the deposit was roughly twice as thick as the experimental deposits. This combination of a lower depth of loading and a higher overburden pressure suggests that the fluid mud had a relatively high density, perhaps within the 'intermediate strength' category of Mehta (2014). In turn, this implies that the density difference between the flow and the muddy substrate was relatively low. Furthermore, $d z-$ values for the intrabed portion of the turbidity current were probably well below $0.1 \mathrm{~m}$, even if post-depositional consolidation is taken into account. By applying the above $R i_{g}$-analysis (Fig. 24), these low values for $\rho_{f}-\rho_{b}$ and $d z$ can be shown to restrict the maximum velocity at which intrabed flow is stable for this turbidity current to approximately 0.3 to $0.8 \mathrm{~m} \mathrm{~s}^{-1}$.

This article is protected by copyright. All rights reserved. 
(C) Further advances

Further field examples of intrabed turbidites, together with more detailed and larger-scale experimental research, are clearly needed to test the present, largely theoretical, approach of delimiting the thresholds of intrabed flow and the other types of interaction between sediment gravity flows and soft muddy substrates. In particular the effect of density stratification (i.e. with $R i_{g}>0.25$ ) on the development and maintenance of intrabed flow in high-density turbidity currents, transitional flows (sensu Baas et al., 2009, 2011) and debris flows, is an important avenue for further research, because such highly stratified flows have been inferred to result from flow deceleration in distal parts of submarine fans (e.g. McCave \& Jones, 1988; Talling et al., 2013). Despite the fact that the scaling model presented herein predicts the behaviour of the experimental flows well, further development of the scaling model is required. Firstly, the flow velocity in Eqs 2 and 5 is based on the head velocity of the turbidity currents. It would be more accurate to use the height-averaged velocity in the head of the current. However, the front of the head of the intrabed turbidity currents was seen to plunge into the substrate. It can therefore be assumed that the flow velocity, and thus the bed shear stress, immediately behind the front of the head controls the plunging process. For reasons of continuity, this velocity should be similar to the head velocity. Secondly, the excess bed shear stress parameter in Eq. 1 relies on the yield strengths calculated with Eqs 3 and 6 . These equations ignore differences in the rheological properties of kaolinite and bentonite caused by differences in chemical composition and external parameters, such as water temperature, salinity and pH. In Fig. 23, the boundary velocities for fluid mud that contains kaolinite (near-vertical black curves) and bentonite (near-vertical red curves) may therefore move to the left or right, depending on whether these clays are more cohesive or less cohesive than the clay minerals on which Eqs 3 and 6 were based. However, these changes should not change the principal conclusion that, based on density differences between flow and substrate, a large range of turbidity currents are able to move This article is protected by copyright. All rights reserved. 
into fluid mud. Thirdly, the gradient Richardson number (Eq. 5) has been developed for Newtonian fluids. However, fluid muds may behave as non-Newtonian fluids, with yield strengths of up to $5 \mathrm{~N} \mathrm{~m}^{-2}$ for kaolinite and $22 \mathrm{~N} \mathrm{~m}^{-2}$ for bentonite. For these yield strengths, mixing between substrate-derived and flow-derived sediment may be more difficult than predicted by the gradient Richardson number, thus effectively expanding the range of flow velocities at which intrabed flow could be stable. Fourthly, the preservation of the 13 division in intrabed turbidites depends on the degree of turbulent mixing within the encapsulating flow and the cohesive strength of the encapsulated mud before final deposition. For relatively low-density and fast-moving sediment gravity flows, in which turbulence is fully developed, as well as for weakly cohesive clay types and low-concentration encapsulated mud suspensions, the encapsulated mud may mix with sediment from the suprabed and intrabed portions of the flow. This would render the preservation of 13 divisions within intrabed turbidites less likely than for high-density, turbulence-attenuated flows and turbulence-free debris flows, and for strongly cohesive clay types and highly concentrated encapsulated mud suspensions. Effectively, this mixing process might reduce the range of velocities for which recognisable 11 to 14 facies are able to form. The $\mathrm{I} 3$ divisions shown in Fig. $15 \mathrm{C}$ and $\mathrm{D}$ were composed of coal-bearing mud, which suggests that some mixing occurred while the substrate mud was encapsulated by these experimental flows. In contrast, mixing between the encapsulated mud and the intrabed and suprabed portions of the flow that formed the deposit in the Aberystwyth Grits (Fig. 25A), may have been weaker, because the I3 division is composed mainly of fine-grained sediment.

Notwithstanding these limitations, the facies model presented in Fig. 16 can be used as a guide to recognising intrabed turbidites in core and outcrop. By building a database of intrabed turbidites of different size, different internal organisation and from different basin types, it should be possible to further investigate the relationship between deposit signature and flow forcing, and determine the sedimentary environments where intrabed turbidites are most likely to be generated and preserved.

This article is protected by copyright. All rights reserved. 


\section{(A) CONCLUSIONS}

The results of the laboratory-scale experiments with turbidity currents moving into soft muddy reservoirs reveal predictable changes in the interaction between flow and muddy substrate. The types of interaction, which include bypass, erosion, deposition, intrabed flow, mixing and soft sediment deformation, are governed by the properties of the flow, the sediment and the substrate. Bypass and deposition depend on the ratio between shear velocity and particle settling velocity, whereas erosion requires that the bed shear stress is larger than yield stress of the mud in the substrate. Soft sediment deformation, in particular the formation of load, flame and injection structures, depends on the weight of the developing turbidite bed and the density of the muddy substrate. The novel processes of intrabed flow and mixing between flow-derived and substrate-derived sediment are governed by the difference in density between the flow and the substrate and by the difference in velocity between the flow and the mud displaced by the flow when it enters the substrate. A theoretical framework for defining the physical sedimentological thresholds of the various interaction types, and resultant deposit signatures, was validated using the experimental data and then used to scale flow-substrate interaction to turbidity currents under natural conditions. This analysis shows that: (i) many natural turbidity currents are expected to either erode or enter into muddy substrates that behave like fluid mud; (ii) intrabed flow is unlikely to occur in firm substrates; (iii) intrabed flow is stable only in relatively weak natural turbidity currents that move at a speed well below $3.5 \mathrm{~m} \mathrm{~s}^{-1}$; and (iv) the head velocity of a natural turbidity current that formed an inferred intrabed turbidite in the deep-marine Aberystwyth Grit Group of West Wales, United Kingdom, may have been between $0.3 \mathrm{~m}$ and $0.8 \mathrm{~m} \mathrm{~s}^{-1}$.

This article is protected by copyright. All rights reserved. 


\section{(A) ACKNOWLEDGEMENTS}

We are grateful to the technicians, staff, and students at NECOD for invaluable assistance (by permission from Prof. R.D. Maestri in 2012). The detailed comments by the journal reviewers Ian Kane and Joris Eggenhuisen, and by the Associate Editor, were stimulating and very helpful in clarifying the content of this paper. The research was kindly funded by Petrobras, and the UK Natural Environment Research Council also contributed to the project through grant NE/I027223/1. The initial work on the interaction between sediment gravity flows and soft muddy substrates, without which the present experiments could not have been conducted, was led by Iris Verhagen and sponsored by the Turbidite Research Group (University of Leeds, United Kingdom) through William D. McCaffrey.

\section{(A) REFERENCES}

Amy, L.A., Kneller, B.C. and McCaffrey, W.D. (2007) Facies architecture of the Grès de Peïra Cava, SE France: Landward stacking patterns in ponded turbiditic basins. Journal of the Geological Society of London, 164, 143-162.

Anthony, E.J., Gardel, A., Gratiot, N., Proisy, C., Allison, M.A., Dolique, F. and Fromard, F. (2010) The Amazon-influenced muddy coast of South America: A review of mud-bankshoreline interactions. Earth-Science Reviews, 103, 99-121.

This article is protected by copyright. All rights reserved. 
Baas, J.H. and Best, J.L. (2002) Turbulence modulation in clay-rich sediment-laden flows and some implications for sediment deposition. Journal of Sedimentary Research, 72, 336340.

Baas, J.H., Best, J.L., Peakall, J. and Wang, M. (2009) A phase diagram for turbulent, transitional, and laminar clay suspension flows. Journal of Sedimentary Research, 79, 162183.

Baas, J.H., Best, J.L. and Peakall, J. (2011) Depositional processes, bedform development and hybrid bed formation in rapidly decelerated cohesive (mud-sand) sediment flows. Sedimentology, 58, 1953-1987.

Baas, J.H., Manica, R., Puhl, E. and Borges, A.L.O. (2014) Processes and products of turbidity currents entering soft muddy substrates. Geology, 42, 371-374.

Baas, J.H., Best, J.L. and Peakall, J. (2016) Predicting bedforms and primary current stratification in cohesive mixtures of mud and sand. Journal of the Geological Society, 173, $12-45$

Bagnold, R.A. (1962) Auto-suspension of transported sediment; turbidity currents. Proceedings of the Royal Society of London, A265, 315-319.

This article is protected by copyright. All rights reserved. 
Bouma, A.H. (1962) Sedimentology of Some Flysch Deposits: A Graphic Approach to Facies Interpretation. Amsterdam, Elsevier, 168 pp.

Brito, D.U., Medeiros, D.S., Manica, R., Borges, A.L. de O. and Maestri, R.D. (2002) Emprego de equipamento de visualização (ecógrafo médico) para o estudo de correntes de densidade não conservativas. Revista Técnica de Energia Petróleo e Gás, Rio de Janeiro, 2, 54-59.

Buckee, C.M., Kneller, B.C. and Peakall, J. (2001) Turbulence structure in steady, solutedriven gravity currents. In: Particulate Gravity Currents (Ed. by W.D. McCaffrey, B.C. Kneller and J. Peakall), IAS Special Publications, 31, 173-187.

Cacchione, D.A., Sternberg, R.W. and Ogston, A.S. (2006) Bottom instrumented tripods: History, applications, and impacts. Continental Shelf Research, 26, 2319-2334.

Cornamusini, G. (2004) Sand-rich turbidite systems of the Late Oligocene Northern Apennines foredeep: Physical stratigraphy and architecture of the 'Macigno costiero' (coastal Tuscany, Italy). In: Confined Turbidite Systems (Ed. by S.A. Lomas and P. Joseph), Geological Society, London, Special Publications, 222, 261-283.

de Wit, P.J. and Kranenburg, C. (1997) The wave-induced liquefaction of cohesive sediment beds. Estuarine, Coastal and Shelf Science, 45, 261-271. 
Del Rey, A.C. (2006) Simulação física de processos gravitacionais subaquosos: Uma aproximação para o entendimento da sedimentação marinha profunda. Tese de Doutorado, Universidade Federal do Rio Grande do Sul, Instituto de Geociências, Programa de PósGraduação em Geociências, Porto Alegre (RS), 229 pp.

Edwards, D.A. (1993) Turbidity currents: Dynamics, deposits and reversals. Lecture Notes in Earth Sciences, 44, 1-174.

Felix, M., Sturton, S. and Peakall, J. (2005) Combined measurements of velocity and concentration in experimental turbidity currents. Sedimentary Geology, 179: 31-47.

Gladstone, C., Phillips, J.C. and Sparks, R.S.J. (1998) Experiments on bidisperse, constant-volume gravity currents: Propagation and sediment deposition. Sedimentology, 45, 833-843.

Guth, E. and Simha, R. (1936) Über die Viskosität von Kugelsuspensionen (Zur Berechnung des Wandeinflusses und der Wechselwirkung bei der Viskosität, sowie bei rotierenden Kugeln), Kolloid-Zeitschrift, 77, 266-275.

Haughton, P., Davis, C., McCaffrey, W. and Barker, S. (2009) Hybrid sediment gravity flow deposits - Classification, origin and significance. Marine and Petroleum Geology, 26, 19001918.

This article is protected by copyright. All rights reserved. 
Ito, M., Ishikawa, K. and Nishida, N. (2014) Distinctive erosional and depositional structures formed at a canyon mouth: A lower Pleistocene deep-water succession in the Kazusa forearc basin on the Boso Peninsula, Japan. Sedimentology, 61, 2042-2062.

Jia, Y., Zhang, L., Zheng, J., Liu, X., Jeng, D.-S. and Shan, H. (2014) Effects of waveinduced seabed liquefaction on sediment re-suspension in the Yellow River Delta. Ocean Engineering, 89, 146-156.

Kineke, G.C., Sternberg, R.W., Trowbridge, J.H. and Geyer, W.R. (1996) Fluid-mud processes on the Amazon continental shelf. Continental Shelf Research, 16, 667-696.

Kuenen, P.H. and Migliorini, C.I. (1950) Turbidity currents as a cause of graded bedding. Journal of Geology, 58, 91-127.

Manica, R. (2012) Sediment gravity flows: Study based on experimental simulations. In: Hydrodynamics - Natural Water Bodies (Ed. by H.E. Schulz, A.L.A. Simões and R.J. Lobosco), Rijeka, Croatia, InTech, 263-286, doi:10.5772/28794.

McAnally, W.H., Friedrichs, C., Hamilton, D., Hayter, E., Shrestha, P., Rodriguez, H., Sheremet, A. and Teeter, A. (2007a) Management of fluid mud in estuaries, bays, and lakes. I: Present state of understanding on character and behavior. Journal of Hydraulic Engineering, 133, 9-22.

This article is protected by copyright. All rights reserved. 
McAnally, W.H., Teeter, A., Schoellhamer, D., Friedrichs, C., Hamilton, D., Hayter, E., Shrestha, P., Rodriguez, H. , Sheremet, A. and Kirby R. (2007b) Management of fluid mud in estuaries, bays, and lakes. II: Measurement, modeling, and management. Journal of Hydraulic Engineering, 133, 23-38.

McCaffrey, W.D., Choux, C.M., Baas, J.H. and Haughton, P.D.W. (2003) Spatio-temporal evolution of velocity structure, concentration and grain-size stratification within experimental particulate gravity currents. Marine and Petroleum Geology, 20, 851-860.

McCave, I.N. and Jones, K.P.N. (1988) Deposition of ungraded muds from high-density non-turbulent turbidity currents. Nature, 333, 250-252.

Mehta, A.J. (2014) An Introduction To Hydraulics Of Fine Sediment Transport. World Scientific Publishing Company, Advanced Series on Ocean Engineering, 38, 1060 pp.

Middleton, G.V. (1966a) Experiments on density and turbidity currents. I. Motion of the head. Canadian Journal of Earth Sciences, 3, 523-546.

Middleton, G.V. (1966b) Experiments on density and turbidity currents. II. Uniform flow of density currents. Canadian Journal of Earth Sciences, 3, 627-637.

Middleton, G.V. (1967) Experiments on density and turbidity currents. III. Deposition of sediment. Canadian Journal of Earth Sciences, 4, 475-505.

This article is protected by copyright. All rights reserved. 
Mutti, E. (1985) Turbidite systems and their relations to depositional sequences. In: Provenance of Arenites (Ed. by G.G. Zuffa), NATO-ASI Series, D. Reidel Publishing Co., Amsterdam, 65-93.

Mutti, E. and Normark, W.R. (1987) Comparing examples of modern and ancient turbidite systems: Problems and concepts. In: Marine Clastic Sedimentology (Ed. by J.K. Leggett and G.G. Zuffa), Springer Verlag, Netherlands, 1-38.

Simpson, J.E. (1982) Gravity currents in the laboratory, atmosphere, and ocean. Annual Review of Fluid Mechanics, 14, 213-234.

Stacey, M.W. and Bowen, A.J. (1988) The vertical structure of density and turbidity currents: Theory and observations. Journal of Geophysical Research, 93, 3528-3542.

Stevenson, C.J., Talling, P.J., Masson, D.G., Sumner, E.J., Frenz, M. and Wynn, R.B. (2014a) The spatial and temporal distribution of grain-size breaks in turbidites. Sedimentology, 61, 1120-1156.

Stevenson, C.J., Talling, P.J., Sumner, E.J., Masson, D.G., Frenz, M. and Wynn, R.B. (2014b) On how thin submarine flows transported large volumes of sand for hundreds of kilometres across a flat basin plain without eroding the sea floor. Sedimentology, 61, 19822019.

This article is protected by copyright. All rights reserved. 
Stevenson, C.J., Jackson, C.A.L., Hodgson, D.M., Hubbard, S.M. and Eggenhuisen, J.T. (2015) Deep-water sediment bypass. Journal of Sedimentary Research, 85, 1058-1081

Sumner, E.J., Talling, P.J. and Amy, L.A. (2009) Deposits of flows transitional between turbidity current and debris flow. Geology, 37, 991-994.

Talling, P.J., Amy, L.A., Wynn, R.B., Peakall, J. and Robinson, M. (2004) Beds comprising debrite sandwiched within co-genetic turbidite: Origin and widespread occurrence in distal depositional environments. Sedimentology, 51, 163-194.

Talling, P.J., Wynn, R.B., Masson, D.G., Frenz, M., Cronin, B.T., Schiebel, R., Akhmetzhanov, A.M., Dallmeier-Tiessen, S., Benetti, S., Weaver, P.P.E., Georgiopoulou, A., Zuhlsdorff, C. and Amy, L.A. (2007) Onset of submarine debris flow deposition far from original giant landslide. Nature, 450, 541-544.

Talling, P.J., Wynn, R.B., Schmmidt, D.N., Rixon, R., Sumner, E. and Amy, L. (2010) How did thin submarine debris flows carry boulder-sized intraclasts for remarkable distances across low gradients to the far reaches of the Mississippi Fan? Journal of Sedimentary Research, 80, 829-851.

Talling, P.J., Masson, D.G., Sumner, E.J. and Malgesini, G. (2012) Subaqueous sediment density flows: Depositional processes and deposit types. Sedimentology, 59, 1937-2003.

This article is protected by copyright. All rights reserved. 
Talling, P.J., Paull, C.K., and Piper, D.J.W. (2013) How are subaqueous sediment density flows triggered, what is their internal structure and how does it evolve? Direct observations from monitoring of active flows. Earth-Science Reviews, 125, 244-287.

Talling, P.J., Allin, J., Armitage, D.A., Arnott, R.W.C., Cartigny, M.J.B., Clare, M.A., Felletti, F., Covault, J.A., Girardclos, S., Hansen, E., Hill, P.R., Hiscott, R.N., Hogg, A.J., Clarke, J.H., Jobe, Z.R., Malgesini, G., Mozzato, A., Naruse, H., Parkinson, S., Peel, F.J., Piper, D.J.W., Pope, E., Postma, G., Rowley, P., Sguazzini, A., Stevenson, C.J., Sumner, E.J., Sylvester, Z., Watts, C. and Xu, J.P. (2015). Key future directions for research on turbidity currents and their deposits. Journal of Sedimentary Research, 85, 153169.

Traykovski, P., Geyer, W.R., Irish, J.D. and Lynch, J.F. (2000) The role of wave-induced density-driven fluid mud flows for cross-shelf transport on the Eel River continental shelf. Continental Shelf Research, 20, 2113-2140.

Van Rijn, L.C. (1990) Principles of Fluid Flow and Surface Waves in Rivers, Estuaries, Seas and Oceans. Aqua Publications, Amsterdam, 335 pp.

Verhagen, I.T.E., Baas, J.H., McCaffrey, W.D. and Davies, A.G. (2013) A first classification scheme of flow-bed interaction for clay-laden density currents and soft substrates. Ocean Dynamics, 63, 385-397. 
Verlaan, P.A.J. and Spanhoff, R. (2000) Massive sedimentation events at the mouth of the Rotterdam Waterway. Journal of Coastal Research, 16, 458-469.

Wan, Z. (1982) Bed material movement in hyperconcentrated flow. Institute of Hydrodynamics and Hydraulic Engineering, Lyngby, Technical University of Denmark, Series Paper, 16-24.

Wentworth, C.K. (1922) A scale of grade and class terms for clastic sediments. Journal of Geology, 30, 377-392.

Weimer, P. and Pettingill, H.S. (2007) A global overview of fields and discoveries in deepwater deposits. In: Atlas of Deepwater Outcrops (Ed. by T. Nielsen, R.D. Shew, G.S. Steffens and J.R.J. Studlick), AAPG Studies in Geology 56, Shell Exploration and Production and American Association of Petroleum Geologists, 12-16.

Wells, J.T. and Coleman, J.M. (1981) Physical processes and fine-grained sediment dynamics, coast of Surinam, South America. Journal of Sedimentary Petrology, 51, 10531068.

Wheatcroft, R.A. and Borgeld, J.C. (2000) Oceanic flood deposits on the northern California shelf: Large-scale distribution and small-scale physical properties. Continental Shelf Research, 20, 2163-2190.

This article is protected by copyright. All rights reserved. 
Whitehouse, R., Soulsby, R., Roberts, W. and Mitchener, H. (2000) Dynamics of Estuarine Muds. Thomas Telford Publishing, London, 210 pp.

Winterwerp, J.C. and van Kesteren, W.G.M. (2004) Introduction to the Physics of Cohesive Sediment Dynamics in the Marine Environment. Developments in Sedimentology, 56, Elsevier, Oxford, UK.

\section{FIGURE CAPTIONS}

Table 1. Experimental parameters.

Fig. 1. Schematic diagram of the experimental set-up. UHCM = ultra-high concentration meter.

Fig. 2. Vertical distribution of volumetric sediment concentration in the $8 \mathrm{~cm}$ thick low-density fluid mud substrate and the $4 \mathrm{~cm}$ thick high-density fluid mud substrate.

Fig. 3. Video images of the turbidity currents that moved across the fixed smooth bed in the control Runs 11 to 15 . Horizontal scale is in centimetres. Flow was from right to left.

Fig. 4. Series of ultrasound images of the front of the turbidity currents that moved across the fixed smooth bed in the control Runs 11 to 15: (A) Run 11, $C_{f, i}=1 \%$; (B) Run 12, $C_{f, i}=$ 5\%; (C) Run $13 C_{f, i}=10 \%$; (D) Run 14, $C_{f, i}=15 \%$; and (E) Run 15, $C_{f, i}=23 \%$. Each component image is $0.062 \mathrm{~m}$ wide. Black horizontal lines denote the floor of flume. Flow was from right to left.

This article is protected by copyright. All rights reserved. 
Fig. 5. Head velocity of turbidity currents against distance along flume for: (A) control Runs 11 to 15; (B) high-density fluid mud Runs 6 to 10; and (C) low-density fluid mud Runs 1 to 5.

Fig. 6. Mean head velocity of all turbidity currents against initial suspended sediment concentration. Note the decrease in mean head velocity for the $23 \%$ flow that moved inside the low-density fluid mud (blue curve).

Fig. 7. Time-series of UHCM-derived sediment concentrations at different heights above the bed in the control experiments: (A) Run 11, $C_{f, i}=1 \%$; (B) Run 12, $C_{f, i}=5 \%$; (C) Run $13 C_{f, i}=$ $10 \%$; (D) Run 14, $C_{f, i}=15 \%$; and (E) Run 15, $C_{f, i}=23 \%$.

Fig. 8. Video images of the turbidity currents that moved into the low-density fluid mud reservoir, $x=0.4$ to $1.6 \mathrm{~m}$ : (A) Run 1, $C_{f, i}=1 \%$; (B) Run 2, $C_{f, i}=5 \%$; (C) Run $3 C_{f, i}=10 \%$; (D) Run 4, $C_{f, i}=15 \%$; and (E) Run 5, $C_{f, i}=23 \%$. Flow was from right to left.

Fig. 9. Series of video images showing the progression of the turbidity current with $C_{t, i}=$ 23\% (Run 5) upon entering the low-density fluid mud reservoir: (A) $t=6.9 \mathrm{~s}$; (B) $t=9.6 \mathrm{~s}$; (C) $t=12.7 \mathrm{~s}$; (D) $t=16.5 \mathrm{~s}$; and (E) $t=27.3 \mathrm{~s}$, where $t$ denotes time since the start of the experiment. Flow was from right to left.

Fig. 10. Characteristic profiles and flow-substrate interactions for the turbidity currents that moved in the low-density fluid mud reservoir, $x=1.8$ to $2.9 \mathrm{~m}$ : (A) Run 1, $C_{t, i}=1 \%$; (B) Run 2, $C_{f, i}=5 \%$; (C) Run $3 C_{f, i}=10 \%$; (D) Run 4, $C_{f, i}=15 \%$; and (E) Run 5, $C_{f, i}=23 \%$. Flow was from right to left.

This article is protected by copyright. All rights reserved. 
Fig. 11. Series of video images showing the progression of the turbidity current with $C_{f, i}=$ $23 \%$ (Run 5) in the middle of the low-density fluid mud reservoir: (A) $t=14.3 \mathrm{~s}$; (B) $t=24.3 \mathrm{~s}$; and $(\mathrm{C}) t=39.0 \mathrm{~s}$, where $t$ denotes time since the start of the experiment. The arrows point to multiple crests in the bed pressure wave. Flow was from right to left.

Fig. 12. Series of ultrasound images of the front of the turbidity currents that interacted with the low-density fluid mud in Runs 1 to 5 . (A) Run 1, $C_{f, i}=1 \%$; (B) Run 2, $C_{f, i}=5 \%$; (C) Run 3 $C_{f, i}=10 \%$; (D) Run 4, $C_{f, i}=15 \%$; and (E) Run 5, $C_{f, i}=23 \%$. Note the intrabed flow in Runs 4 and 5. Each component image is $0.062 \mathrm{~m}$ wide. Black horizontal lines denote the original bed level before the arrival of the bed pressure wave. Flow was from right to left.

Fig. 13. Final deposit of Run $1\left(C_{f, i}=1 \%\right)$. (A) Proximal scour fill of incompletely mixed coal and mud. (B) Pronounced load and flame structures around $x=1.4 \mathrm{~m}$. (C) Relatively thin deposit with small load and flame structures and small amounts of dispersed mud and mud clasts at around $x=2.7 \mathrm{~m}$. (D) Distal, thin, coal-rich, deposit with small-scale soft sediment deformation. Scale bars are $0.02 \mathrm{~m}$ long in all pictures.

Fig. 14. Time-series of UHCM-derived sediment concentrations at different heights below and above the top of the fluid mud in: (A) Run 1, $C_{f, i}=1 \%$; (B) Run 2, $C_{f, i}=5 \%$; (C) Run $3 C_{f, i}$ $=10 \% ;$ (D) Run 4, $C_{f, i}=15 \%$; and (E) Run 5, $C_{f, i}=23 \%$.

Fig. 15. Characteristic properties of the final deposits in Runs 2 to 5. (A) Coal with dispersed mud and mud clasts deposited on the erosional mud surface in the proximal section of the reservoir in Run 2. (B) Fluid escape structures supplying flame structures below the base of 
the turbidite in Run 5. (C) Complete 11 to 14 intrabed turbidite sequence (right) evolving to base-missing sequences by progressive pinching out of the $I 1$ and $I 2$ to $I 3$ divisions (left) in Run 3. Note the mud clasts at the top of the 11 division. (D) Poorly developed 12 to 14 sequence, where loading folded the overlying sediment layers (Run 2). (E) Flame structures and load structures at the base of the turbidite in Run 5 . Note the plumes of mud above the flame structures. Scale bars are $0.02 \mathrm{~m}$ long in all pictures.

Fig. 16. (A) Facies model for the deposits of turbidity currents that interact with a soft muddy substrate, but flow on top of the substrate. (B) Model for intrabed turbidity current dynamics. Note that the mud (in grey) is encapsulated by the intrabed portion (in orange) and the suprabed portion (in yellow) of the turbidity current, forming the layer of sandy mud (in brown). (C) Facies model for intrabed turbidites. See text for explanation.

Fig. 17. Selected images of turbidity currents that moved across the high-density fluid mud reservoir: (A) Run 7, $C_{f, i}=5 \%$; and (B) Run 9, $C_{f, i}=15 \%$. Flow was from right to left.

Fig. 18. Series of ultrasound images of the front of the turbidity currents that interacted with the high-density fluid mud in Runs 6 to 10: (A) Run 6, $C_{f, i}=1 \%$; (B) Run 7, $C_{f, i}=5 \%$; (C) Run $8 C_{f, i}=10 \%$; (D) Run 9, $C_{f, i}=15 \%$; and (E) Run 10, $C_{f, i}=23 \%$. Each component image is $0.062 \mathrm{~m}$ wide. Black horizontal lines denote the original substrate level. Flow was from right to left.

Fig. 19. Time-series of UHCM-derived sediment concentrations at different heights below and above the top of the fluid mud in: (A) Run 6, $C_{f, i}=1 \%$; (B) Run 7, $C_{f, i}=5 \%$; (C) Run $8 C_{f, i}$ $=10 \% ;(\mathrm{D})$ Run $9, C_{f, i}=15 \% ;$ and $(\mathrm{E})$ Run 10, $C_{f, i}=23 \%$. 
Fig. 20. Failed intrabed flow in high-density fluid mud Run $10\left(C_{f, i}=23 \%\right)$. (A) Instead of moving into the fluid mud, the flow only disturbs the mud for short distances, thereby forming short horizontal streaks of mud, as shown in the fourth image from the top. (B) Pronounced soft sediment deformation structures associated with failed intrabed flow. Flow was from right to left.

Fig. 21. Characteristic properties of the final deposits of Runs 6 to 10. (A) Proximal scour surface with load structures in Run 7. (B) and (C) Mud injections in the upper part of coalrich deposits in Run 8.

Fig. 22. Schematic graph summarising different types of interaction between turbidity currents and soft muddy substrates, based on the excess bed shear stress parameter, $T$, and the excess density parameter, $P$. See text for explanation.

Fig. 23. Graph showing the thresholds of different types of interaction between the base of turbidity currents and the top of muddy substrates for different substrate densities, flow densities and head velocities. Bold dashed line represents $\rho_{\text {flow }}=\rho_{\text {bed. }}$ Vertical dashed line and open circles denote boundary between fluid mud and solid bed, and experimental Runs 1 to 10 , respectively. Continuous black and red lines represent $\tau_{b}=\tau_{y}$ for different head velocities for kaolinite and bentonite, respectively. Roman numerals refer to different types of interaction, as in Fig. 22.

Fig. 24. Stability diagrams for stable intrabed flows versus mixing between flow-derived and substrate-derived sediment, based on the density difference between flow and mud swept over the top of the flow, $\rho_{f}-\rho_{b}$, the velocity difference across the upper boundary of the flow, 
$\mathrm{u}_{f}-\mathrm{u}_{b}$, the vertical distance $d z$, and the density of the flow, $\rho_{f:}$ (A) $d z=1 \mathrm{~m}$; (B) $d z=0.1 \mathrm{~m}$; and $(\mathrm{C}) d z=0.01 \mathrm{~m}$. Note that stable intrabed flow is possible only at velocity differences of $3.5 \mathrm{~m} \mathrm{~s}^{-1}$ or smaller.

Fig. 25. (A) Field example and interpretative drawing of an 12 to 14 intrabed turbidite in the Aberystwyth Grits Formation (Clarach Bay, Wales, UK). The picture on the right shows the same bed as the picture on the left, but $17 \mathrm{~m}$ upflow, where the 13 division (between the thin black lines) bends upward and then meets the former sea floor. Note that this picture shows a vertical section and a bedding-plane section of the turbidite, so in the upper right, the I3 division has an apparent dip angle that is higher than the real dip angle of ca $10^{\circ}$. (B) Examples of hybrid event beds in the Aberystwyth Grits Formation (Clarach Bay, Wales, UK). $\mathrm{H} 1$ to $\mathrm{H} 5$ refer to the hybrid event bed model of Haughton et al. (2009), where the $\mathrm{H} 1$ and H4/H5 divisions were formed by high-density and low-density turbidity currents, respectively, and the H3 division represents a debris flow. Modified after Baas et al. (2014).

This article is protected by copyright. All rights reserved. 
Table 1. Experimental parameters.

\begin{tabular}{rrrrrrrrrrrr}
\hline Run & $\begin{array}{r}C_{f, i} \\
(\mathrm{vol} \%)\end{array}$ & $\begin{array}{r}\rho_{f, i} \\
\left(\mathrm{~kg} \mathrm{~m}^{-}\right)\end{array}$ & $\begin{array}{r}U_{h} \\
\left(\mathrm{~m} \mathrm{~s}^{-1}\right)\end{array}$ & $\begin{array}{r}h_{f} \\
(\mathrm{~m})\end{array}$ & $\begin{array}{r}R e_{h} \\
(-)\end{array}$ & $\begin{array}{r}I P \\
(\%)\end{array}$ & $\begin{array}{r}\tau_{y} \\
\mathrm{~N} \mathrm{~m}^{-2}\end{array}$ & $\begin{array}{r}\tau_{0} \\
\mathrm{~N} \mathrm{~m}^{-2}\end{array}$ & $\begin{array}{r}T \\
(-)\end{array}$ & $\begin{array}{c}\text { Substrate } \\
(-)\end{array}$ \\
\hline 1 & 1 & 1002 & 0.062 & 0.120 & 7262 & 0 & 0.001 & 0.015 & 11.04 & -0.010 & LD fluid mud \\
2 & 5 & 1010 & 0.093 & 0.140 & 11328 & 41 & 0.001 & 0.035 & 36.43 & -0.003 & LD fluid mud \\
3 & 10 & 1019 & 0.117 & 0.100 & 8571 & 84 & 0.001 & 0.056 & 42.59 & 0.007 & LD fluid mud \\
4 & 15 & 1029 & 0.119 & 0.075 & 5424 & 100 & 0.001 & 0.058 & 61.43 & 0.016 & LD fluid mud \\
5 & 23 & 1044 & 0.114 & 0.055 & 2820 & 100 & 0.001 & 0.054 & 41.39 & 0.031 & LD fluid mud \\
6 & 1 & 1002 & 0.056 & 0.160 & 8746 & 0 & 0.039 & 0.013 & -0.68 & -0.046 & HD fluid mud \\
7 & 5 & 1010 & 0.076 & 0.140 & 9258 & 0 & 0.055 & 0.023 & -0.58 & -0.039 & HD fluid mud \\
8 & 10 & 1019 & 0.094 & 0.110 & 7575 & 0 & 0.046 & 0.036 & -0.22 & -0.030 & HD fluid mud \\
9 & 15 & 1029 & 0.106 & 0.080 & 5154 & 0 & 0.055 & 0.046 & -0.16 & -0.021 & HD fluid mud \\
10 & 23 & 1044 & 0.141 & 0.085 & 5390 & 0 & 0.065 & 0.083 & 0.28 & -0.006 & HD fluid mud \\
11 & 1 & 1002 & 0.040 & 0.250 & 9761 & - & - & 0.006 & - & - & Smooth, fixed \\
12 & 5 & 1010 & 0.060 & 0.240 & 12529 & - & - & 0.015 & - & - & Smooth, fixed \\
13 & 10 & 1019 & 0.074 & 0.180 & 9758 & - & - & 0.022 & - & - & Smooth, fixed \\
14 & 15 & 1029 & 0.132 & 0.130 & 10429 & - & - & 0.072 & - & - & Smooth, fixed \\
15 & 23 & 1044 & 0.146 & 0.120 & 7879 & - & - & 0.089 & - & - & Smooth, fixed \\
\hline
\end{tabular}

$C_{f, i}=$ initial coal concentration in turbidity current

$\rho_{f, i}=$ initial density of turbidity current

$U_{h}=$ mean head velocity of turbidity current over muddy substrate at $x=0.12$ to $0.34 \mathrm{~m}$

$h_{f}=$ thickness of head of turbidity current at $x=0.25 \mathrm{~m}$, excluding intrabed flow

$R e_{h}=$ Reynolds number, based on $U_{h}, h_{f}$ and viscosity for solid suspensions (Guth \& Simha,

1936)

$I P=$ proportion of intrabed flow at front of turbidity current

$\tau_{y}=$ yield stress

$\tau_{0}=$ bed shear stress

$T=$ excess bed shear stress parameter

$P=$ excess density parameter

$\mathrm{LD}=$ low-density, $\mathrm{HD}=$ high-density

This article is protected by copyright. All rights reserved. 


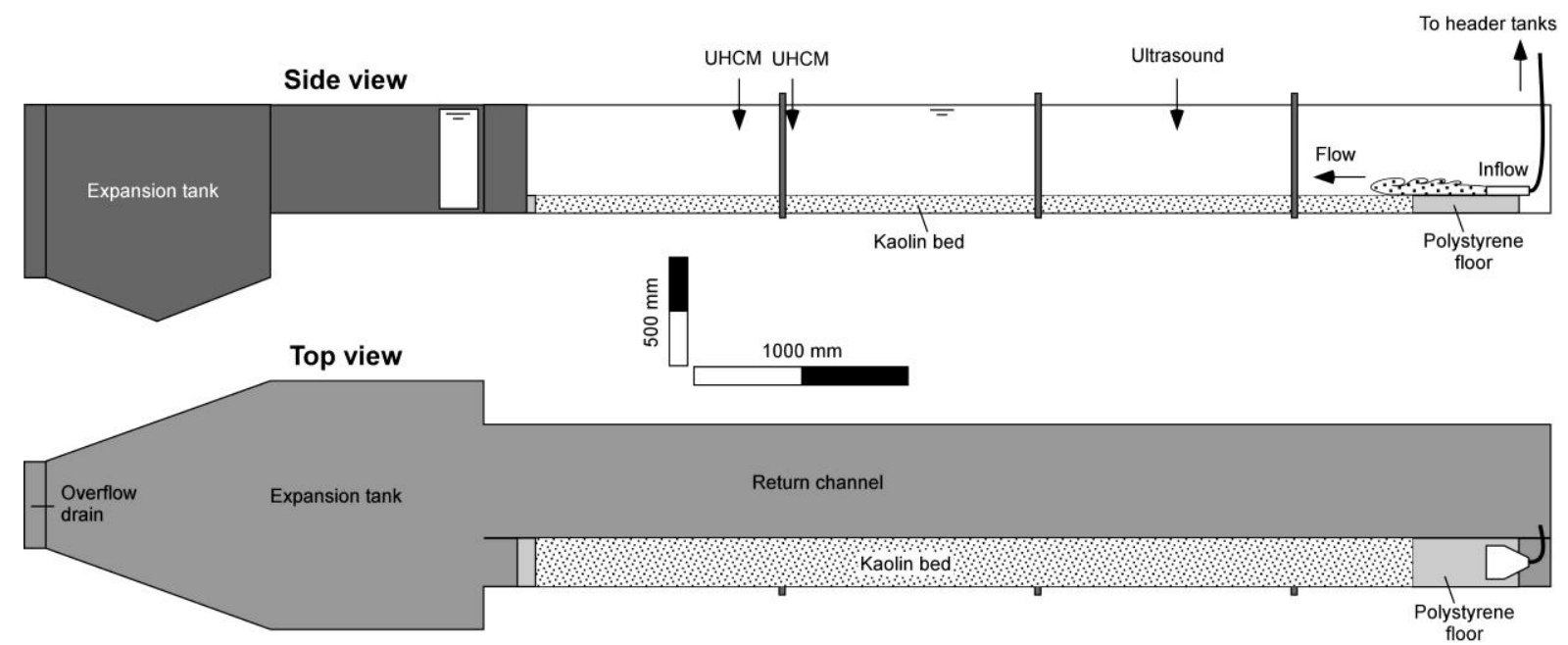

This article is protected by copyright. All rights reserved. 


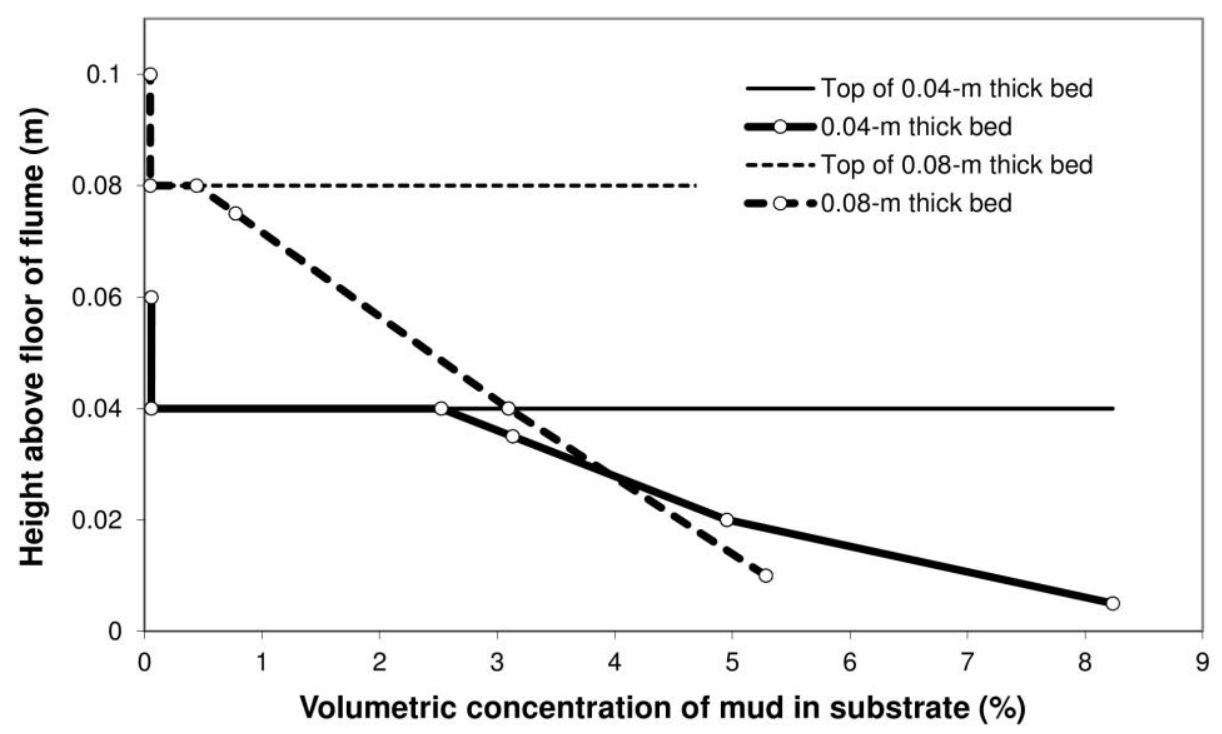

This article is protected by copyright. All rights reserved. 

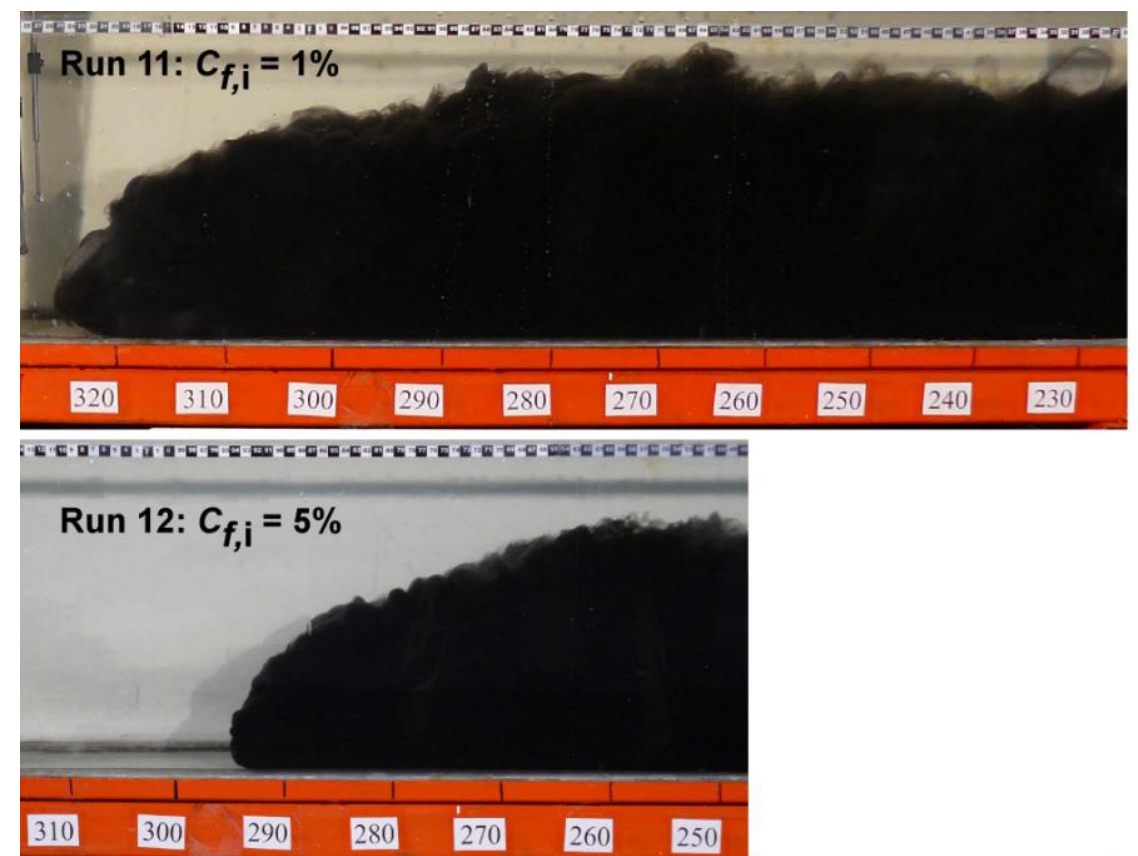

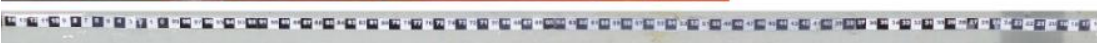
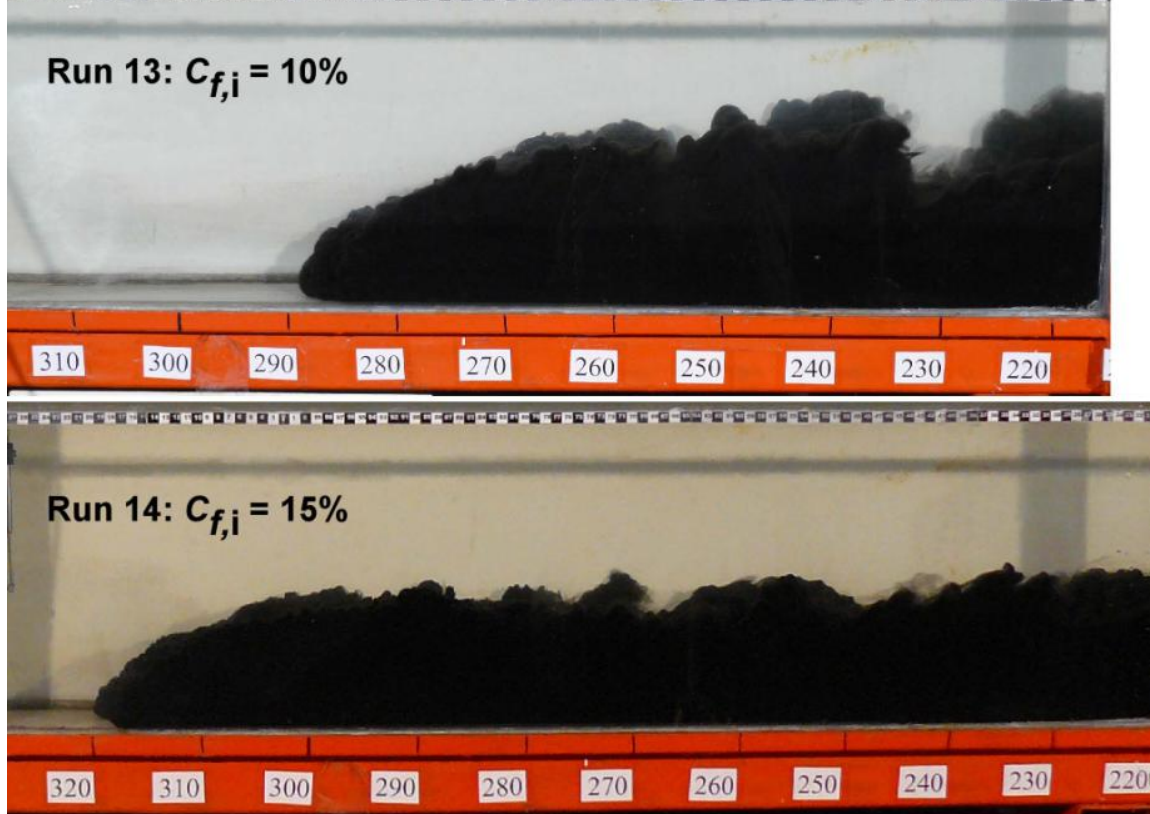

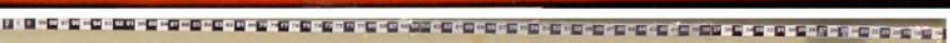

Run 15: $C_{f, \mathrm{i}}=23 \%$

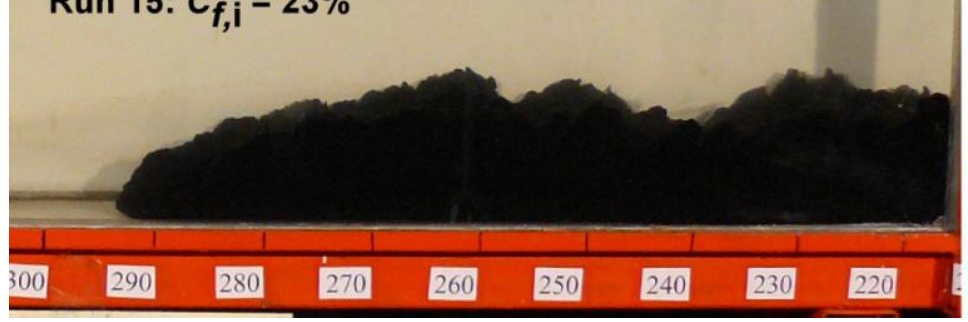

This article is protected by copyright. All rights reserved. 


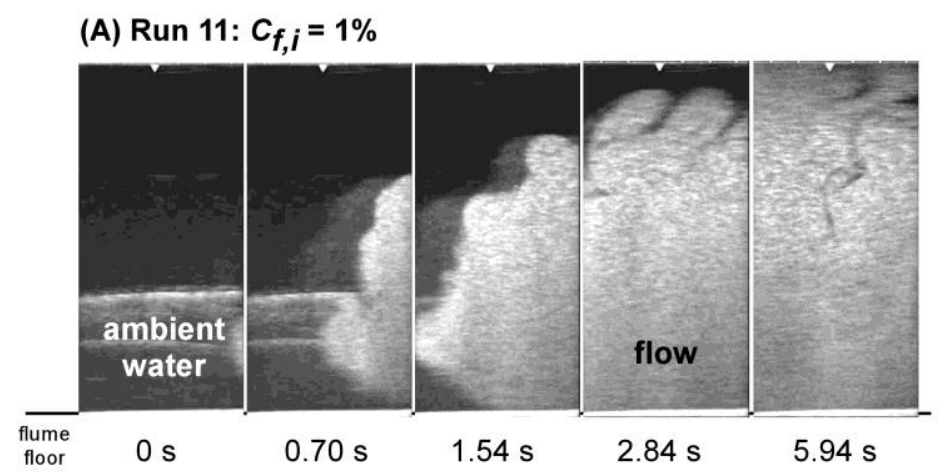

(B) Run 12: $C_{f, i}=5 \%$

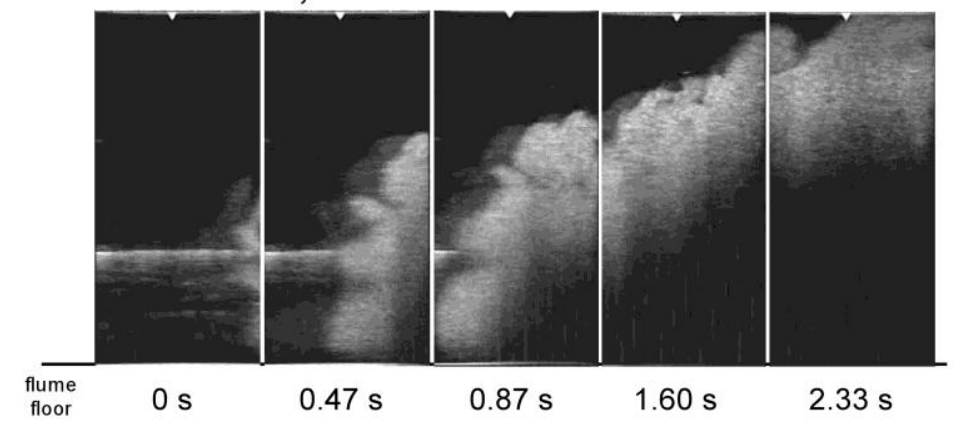

(C) Run 13: $C_{f, i}=10 \%$

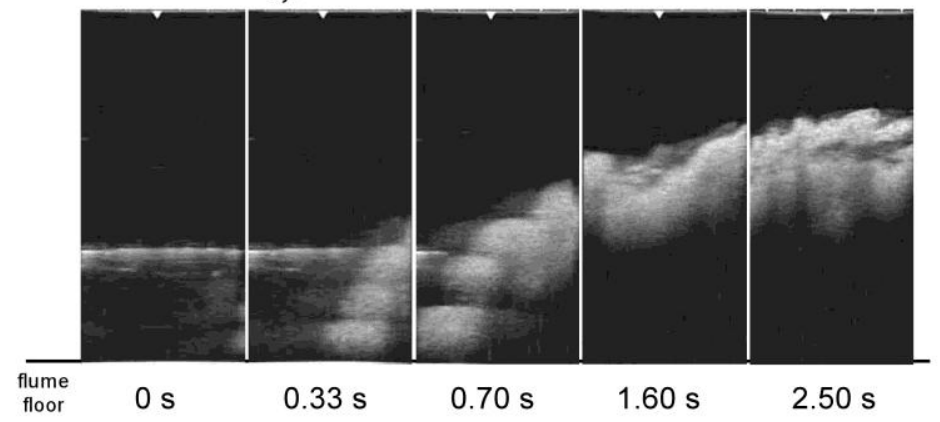

(D) Run 14: $C_{f, i}=15 \%$

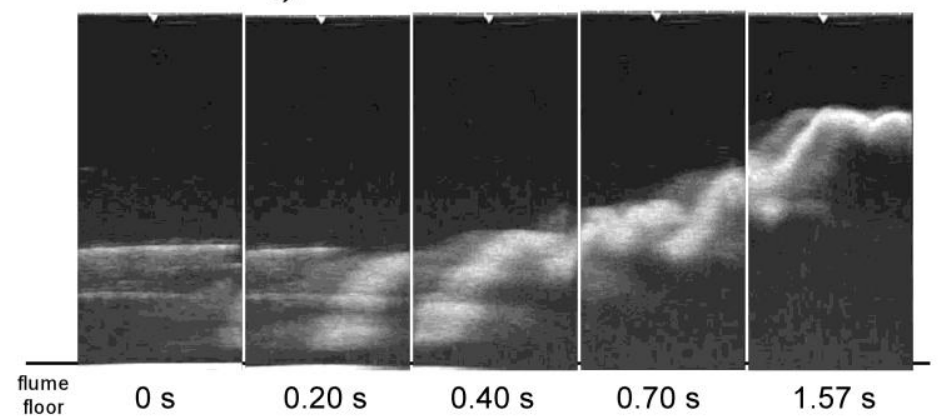

(E) Run 15: $C_{f, i}=23 \%$

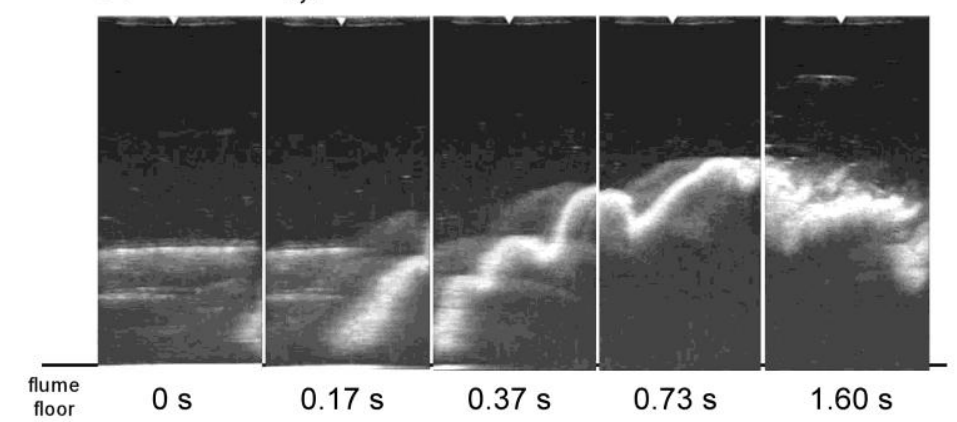

This article is protected by copyright. All rights reserved. 

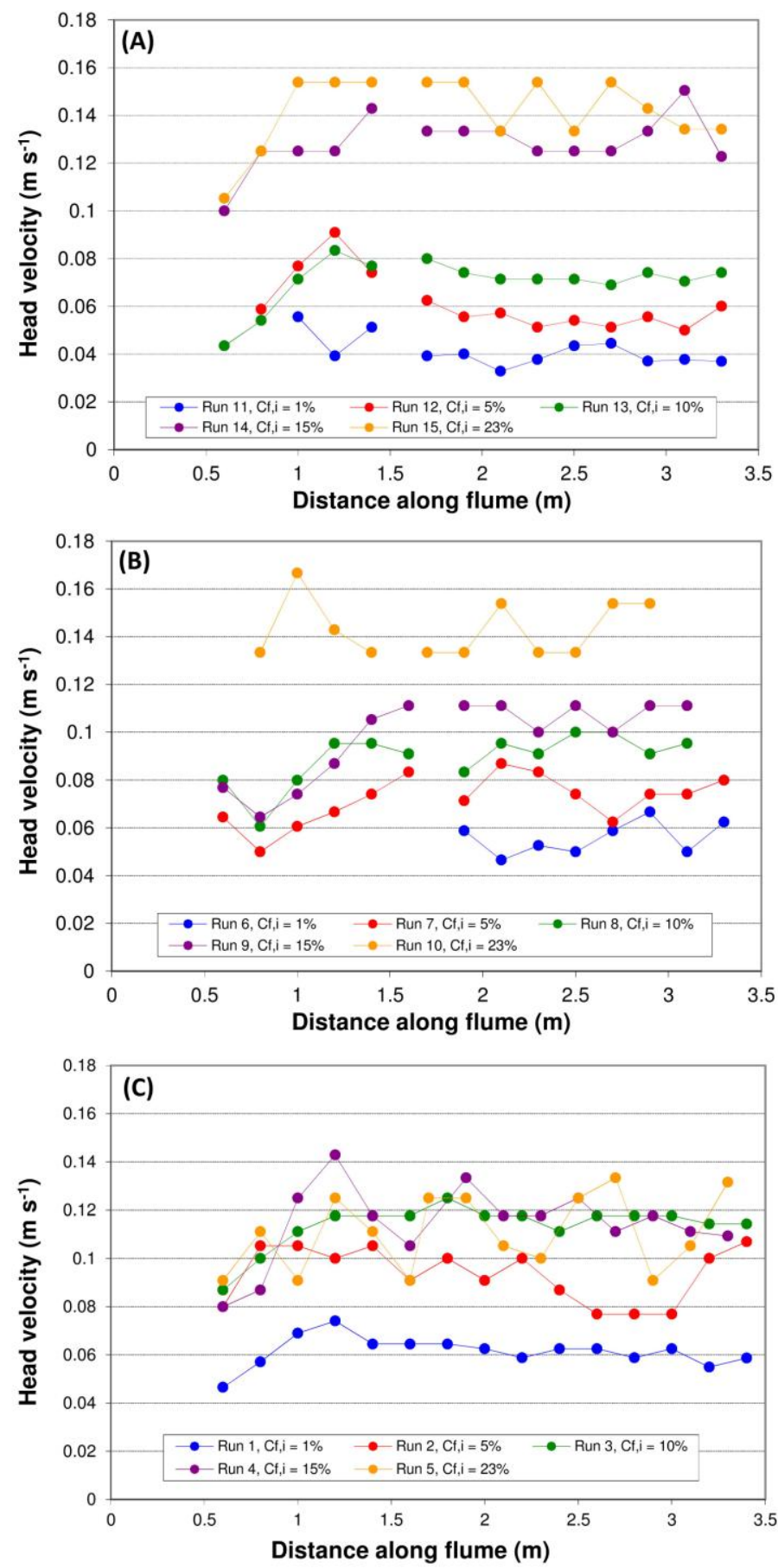

This article is protected by copyright. All rights reserved. 


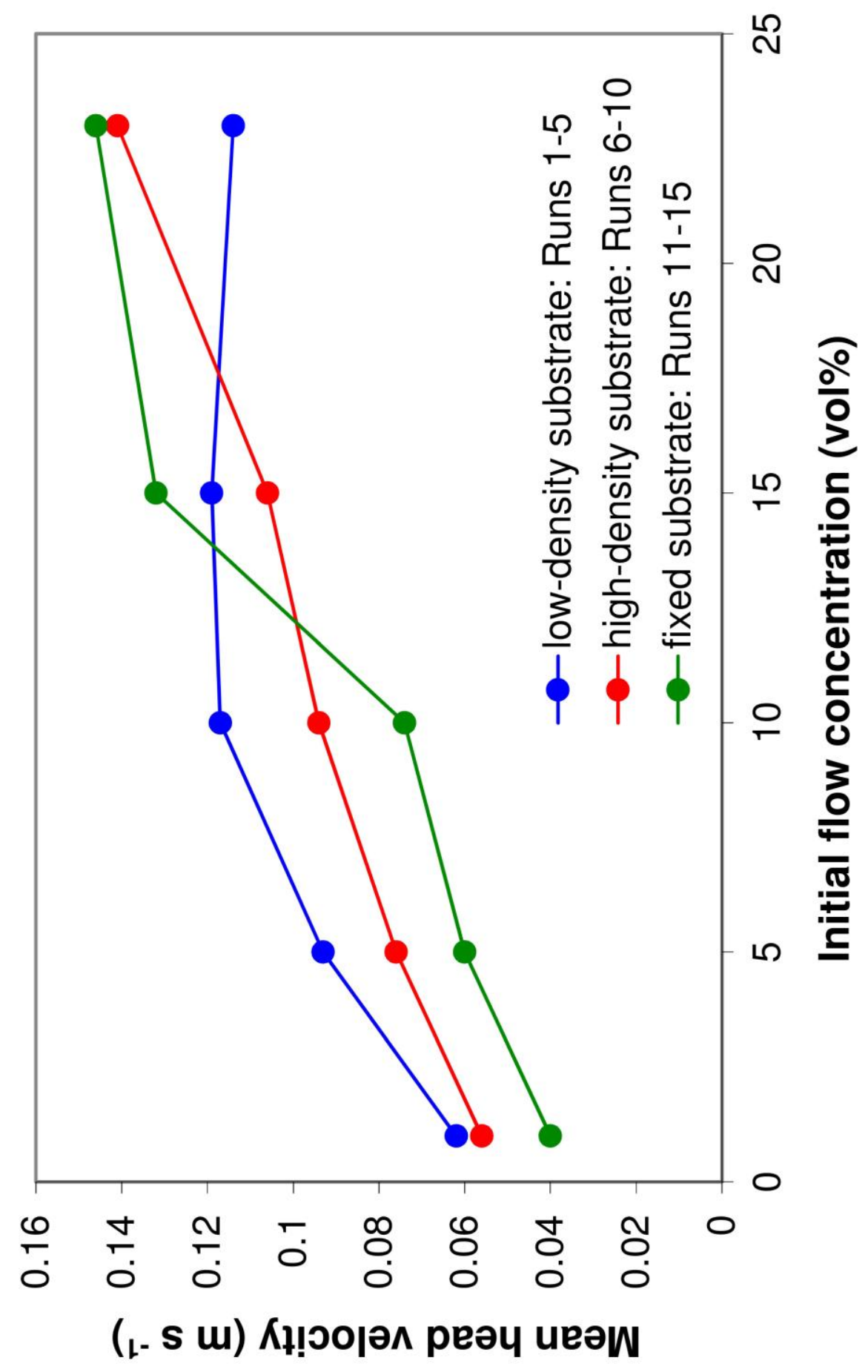

This article is protected by copyright. All rights reserved. 

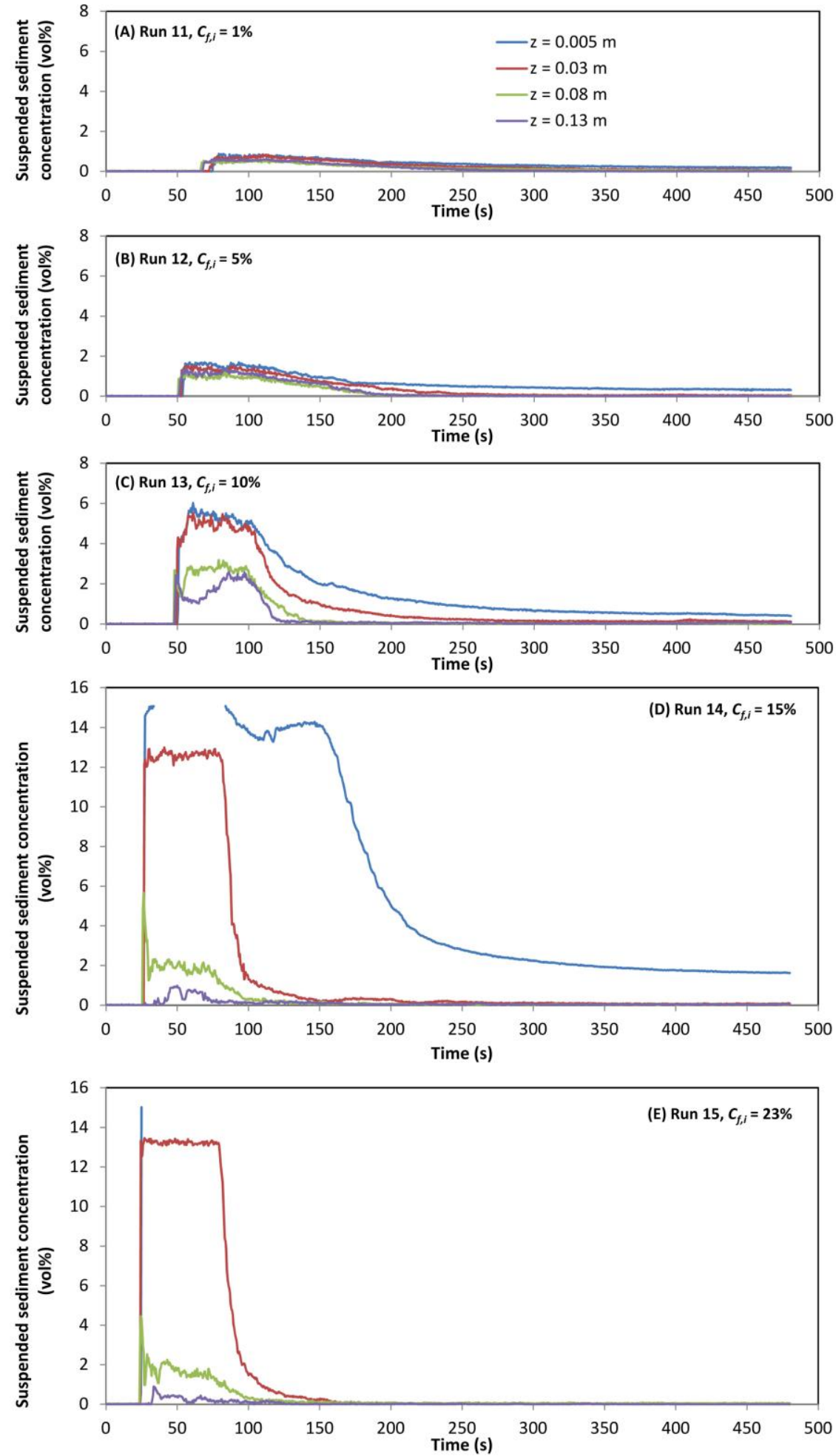

This article is protected by copyright. All rights reserved. 

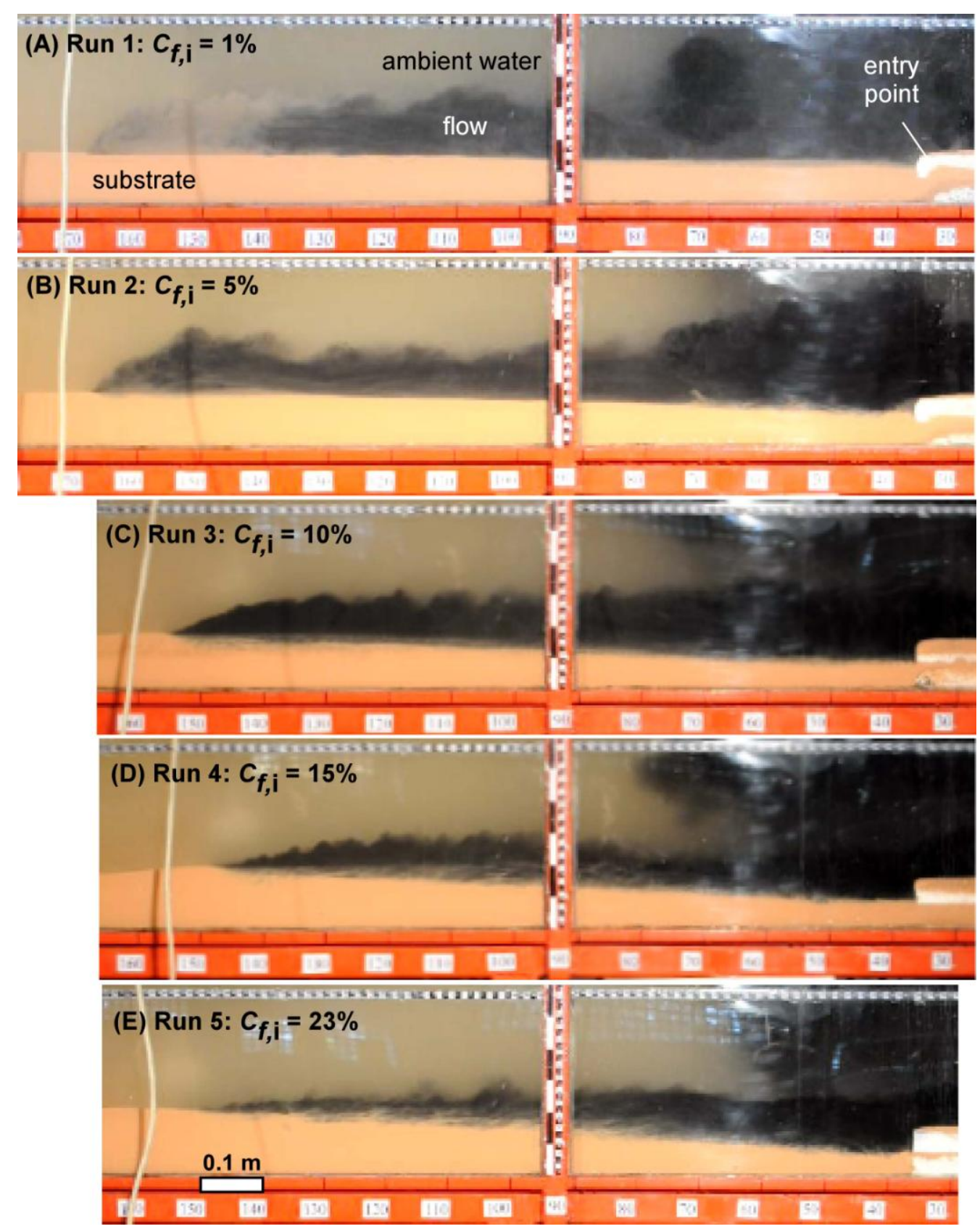

This article is protected by copyright. All rights reserved. 

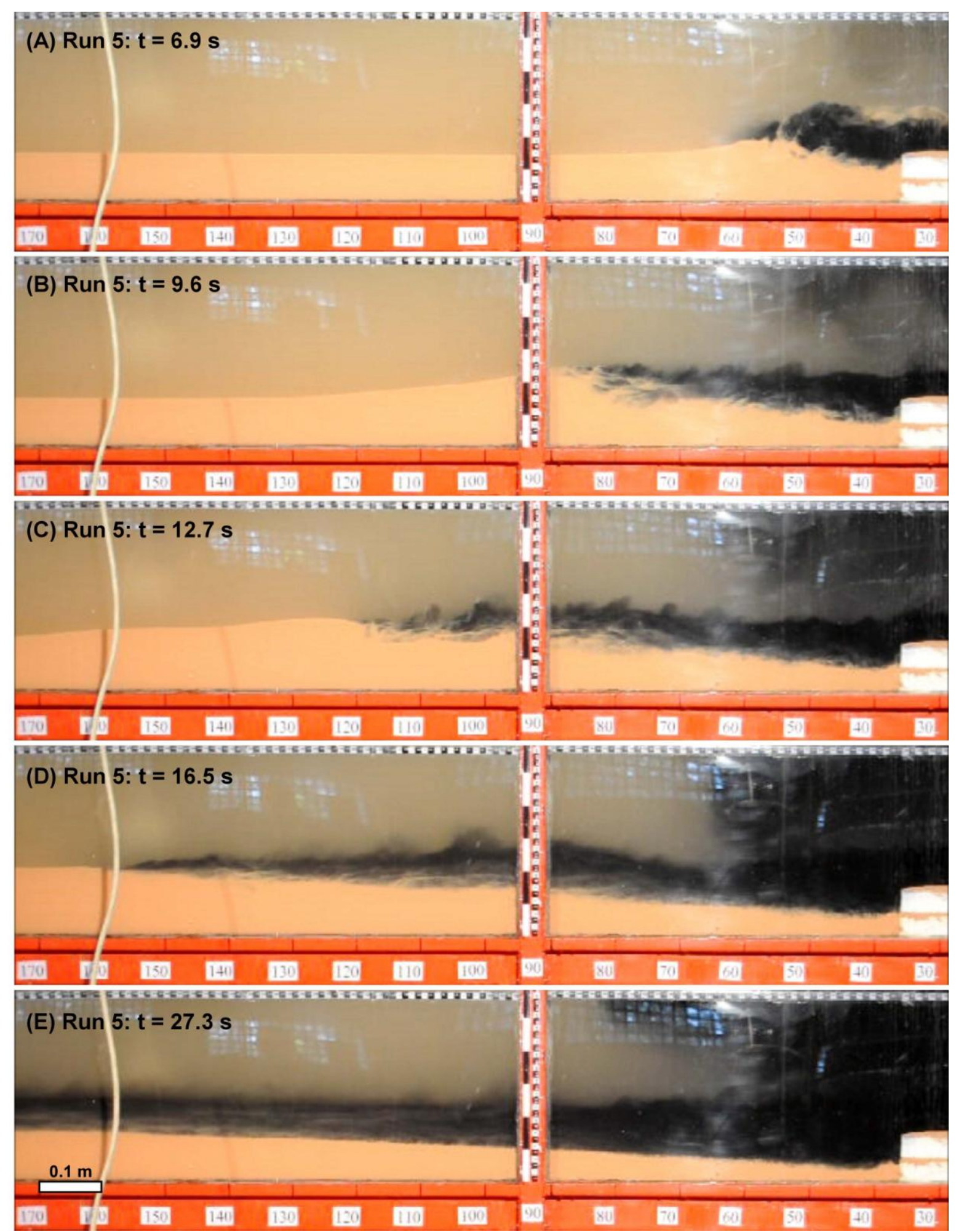

This article is protected by copyright. All rights reserved. 

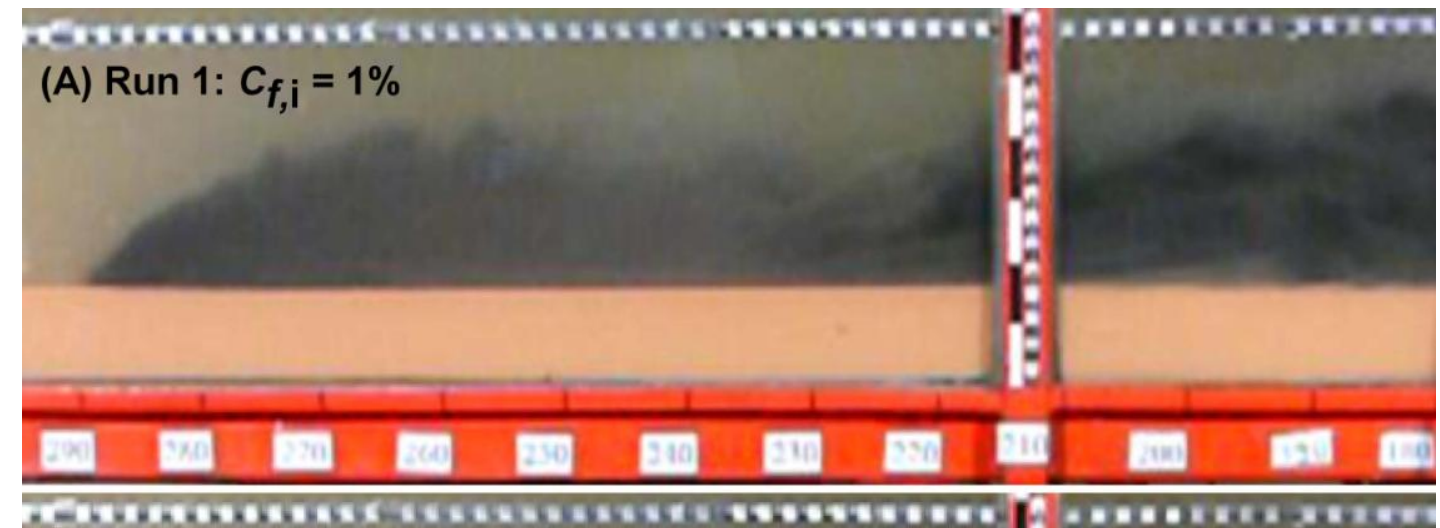

(B) Run 2: $C_{f, i}=5 \%$
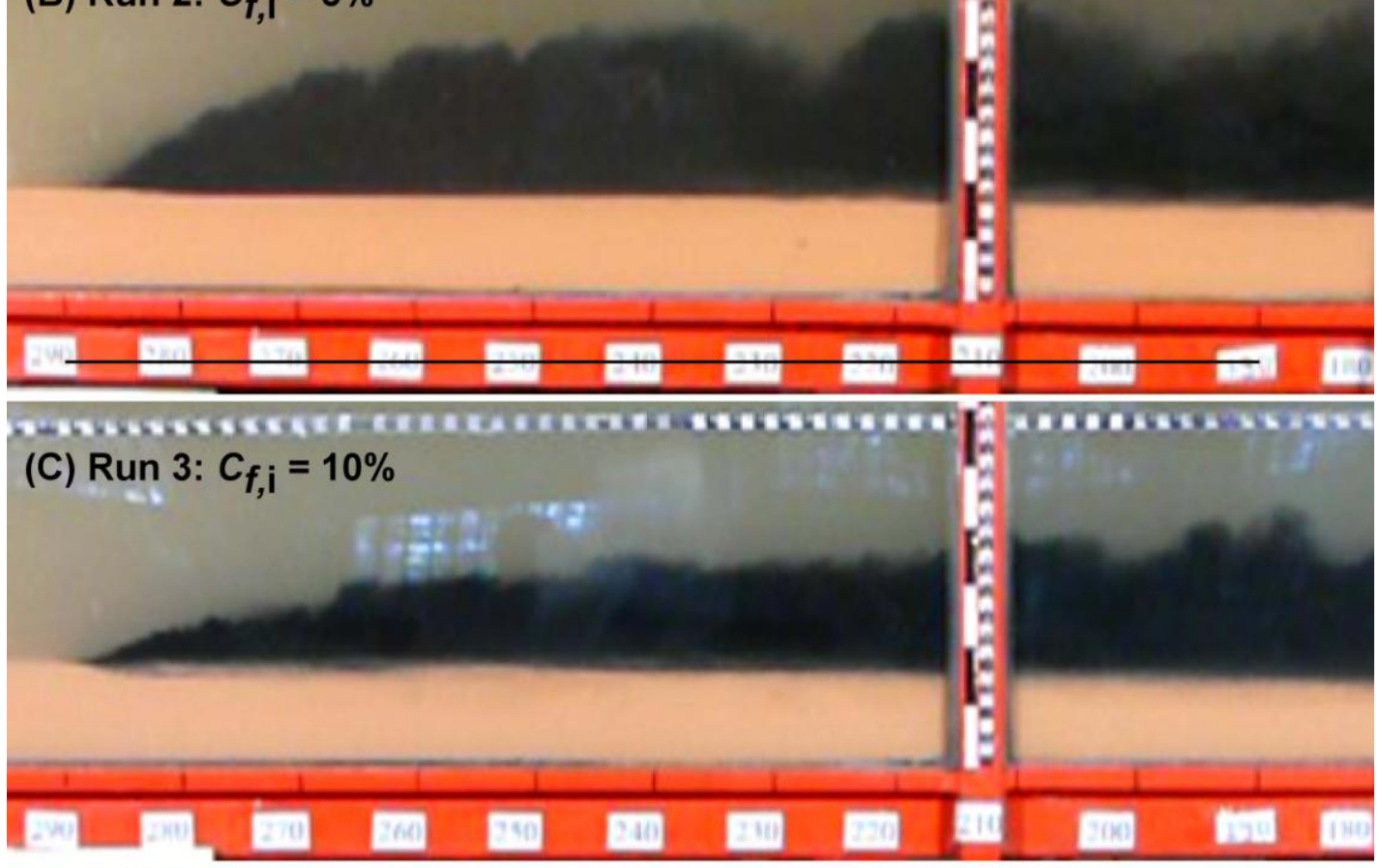

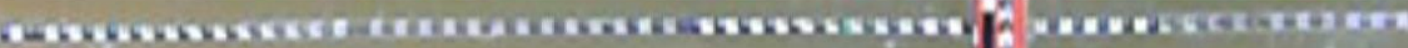

(D) Run 4: $C_{f, i}=15 \%$
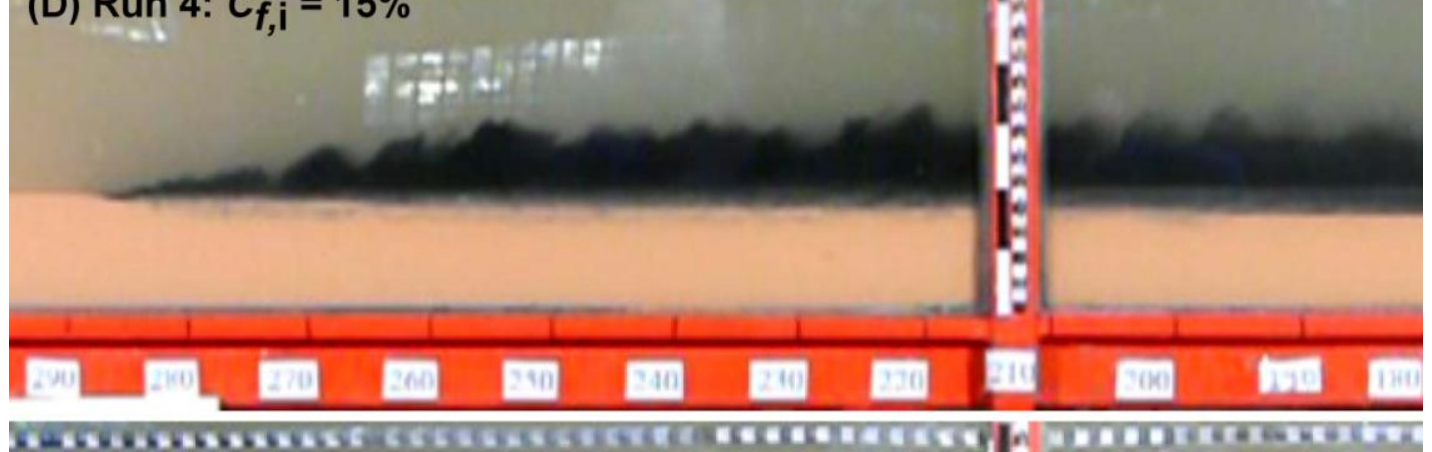

(E) Run 5: $C_{f, i}=23 \%$

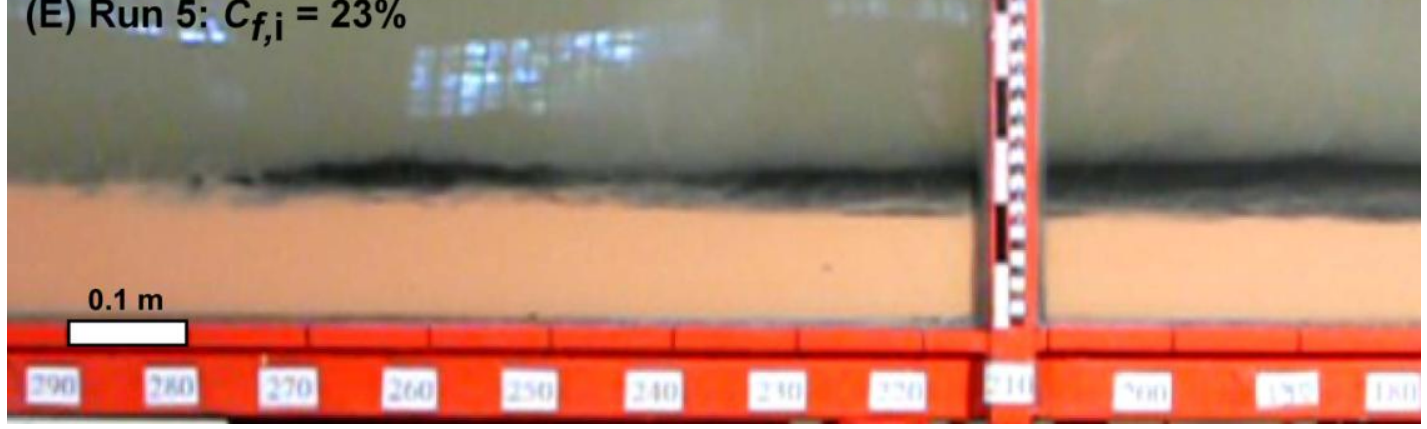

This article is protected by copyright. All rights reserved. 

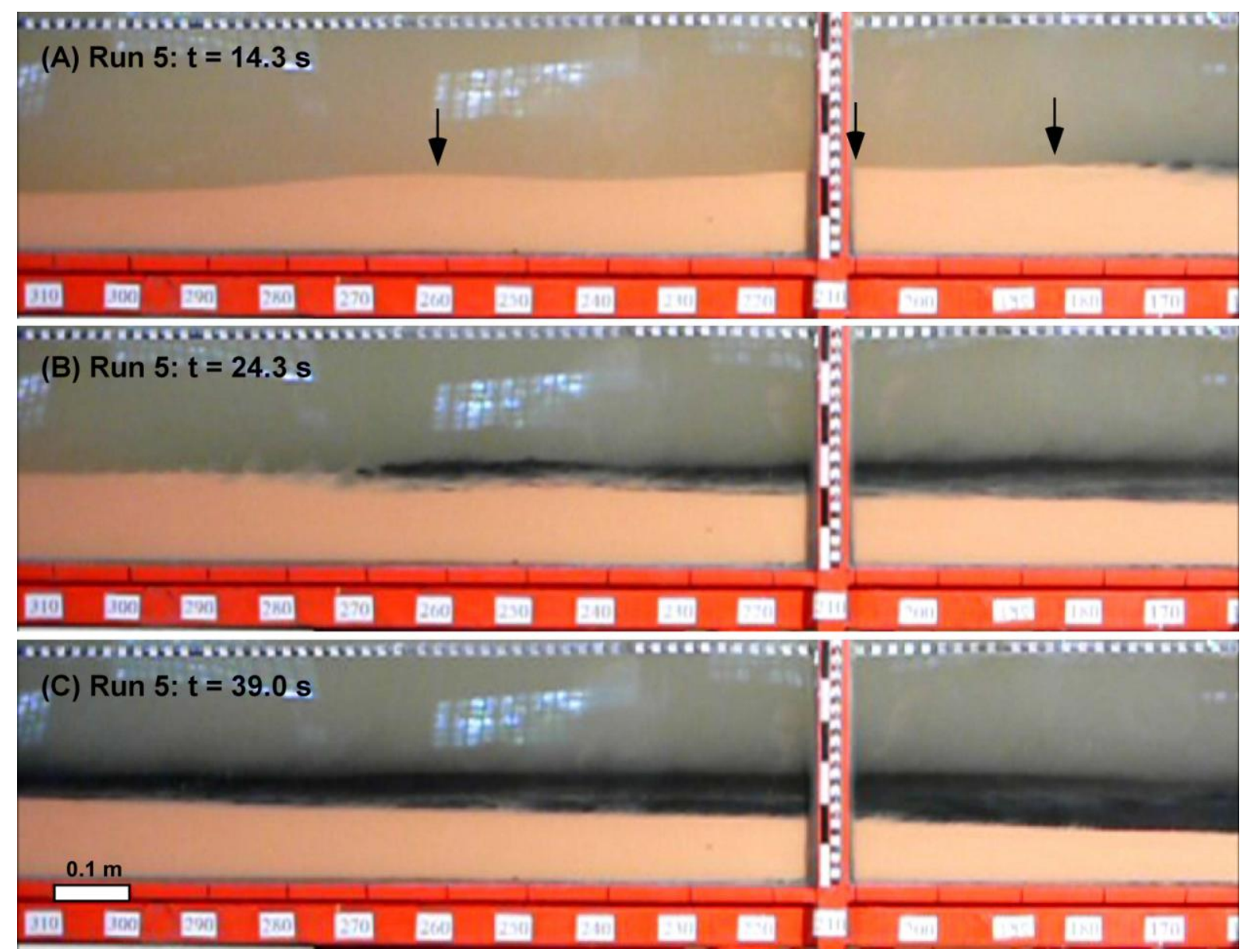

This article is protected by copyright. All rights reserved. 


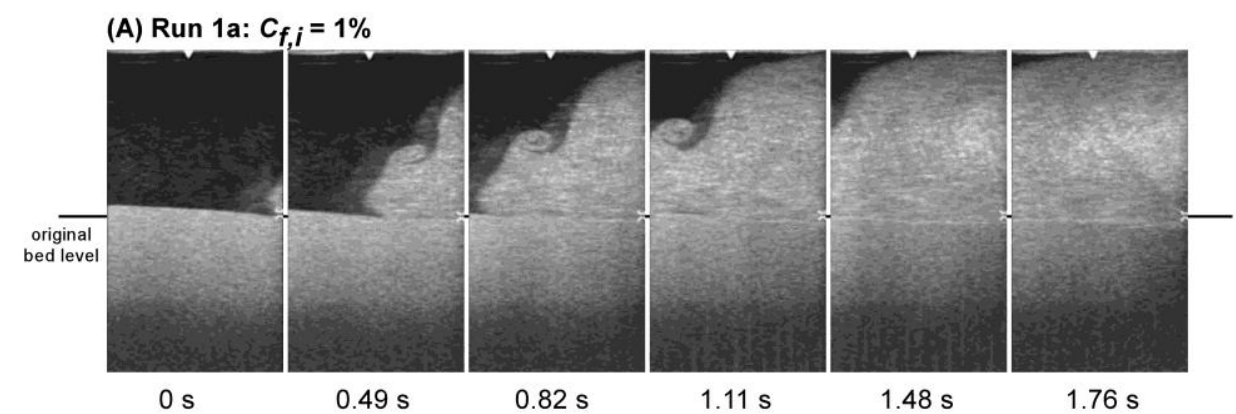

(B) Run 2: $C_{f, i}=5 \%$

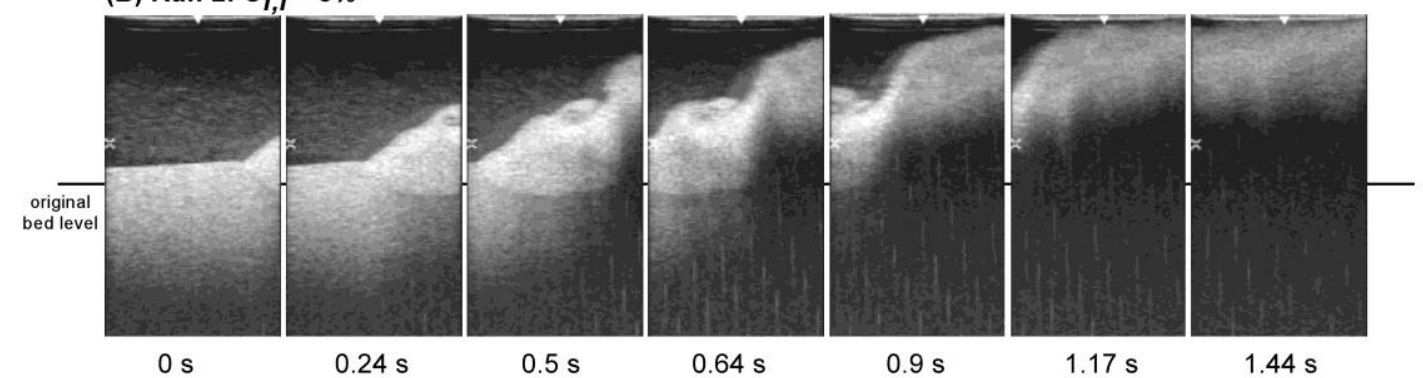

(C) Run 3: $C_{f, i}=10 \%$

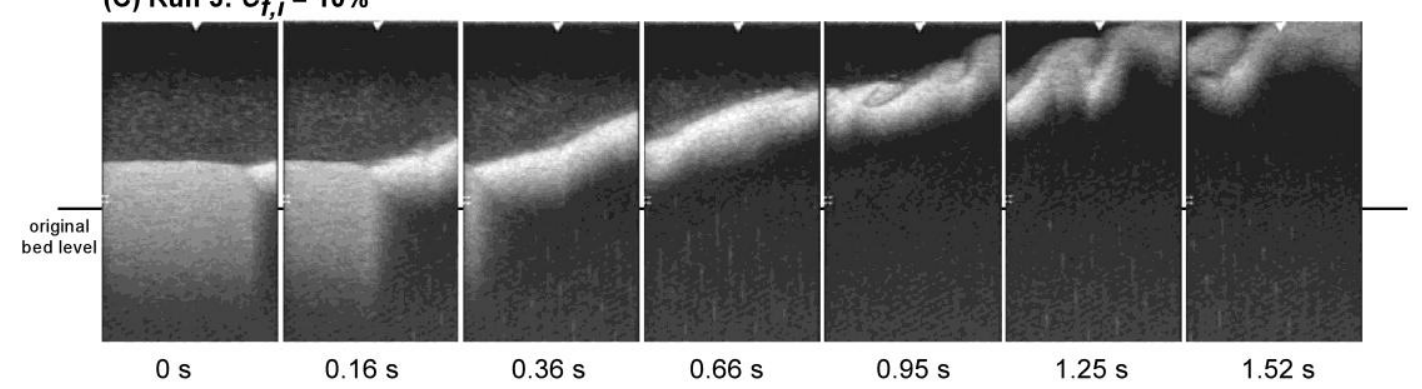

(D) Run 4: $C_{f, i}=15 \%$

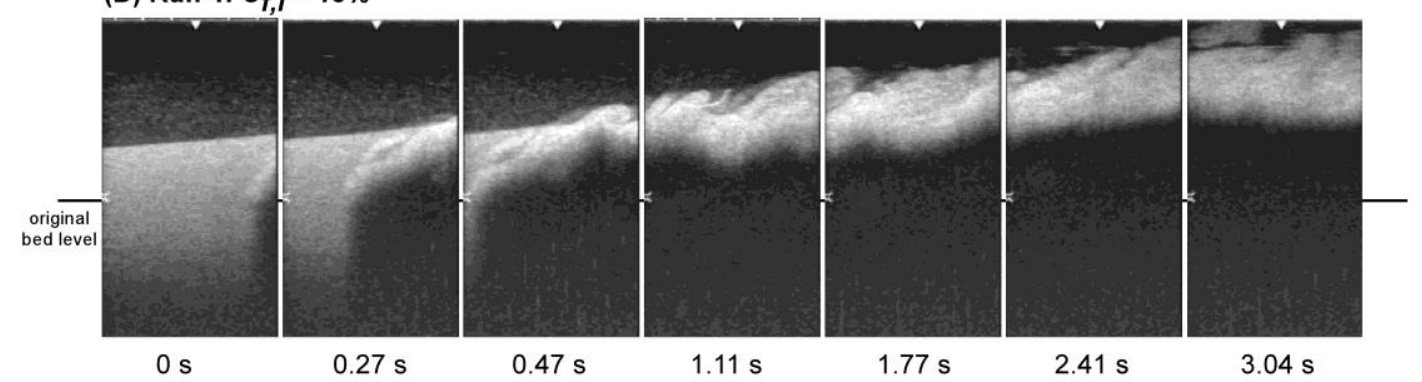

(E) Run 5: $C_{f, i}=23 \%$

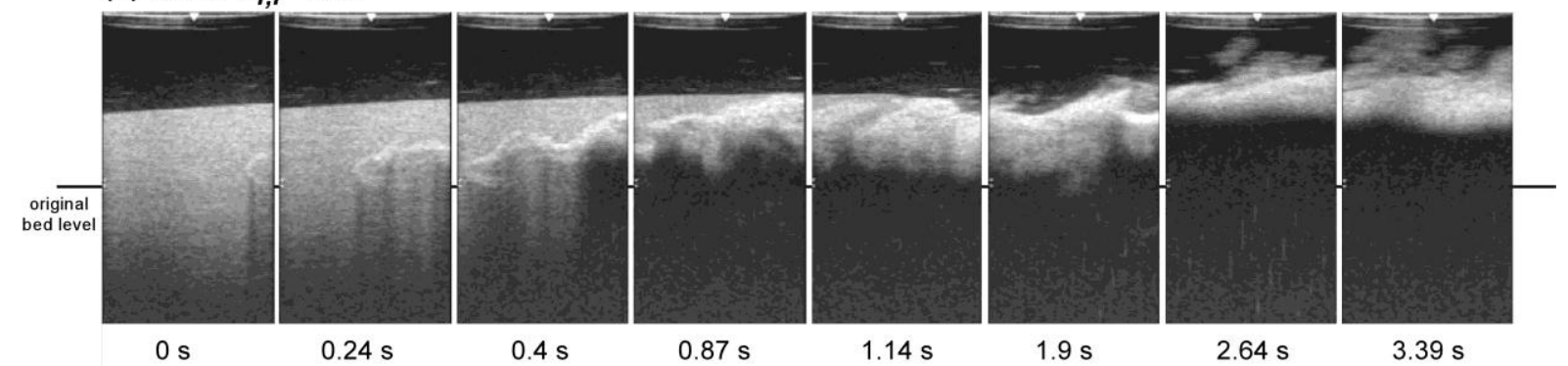

This article is protected by copyright. All rights reserved. 


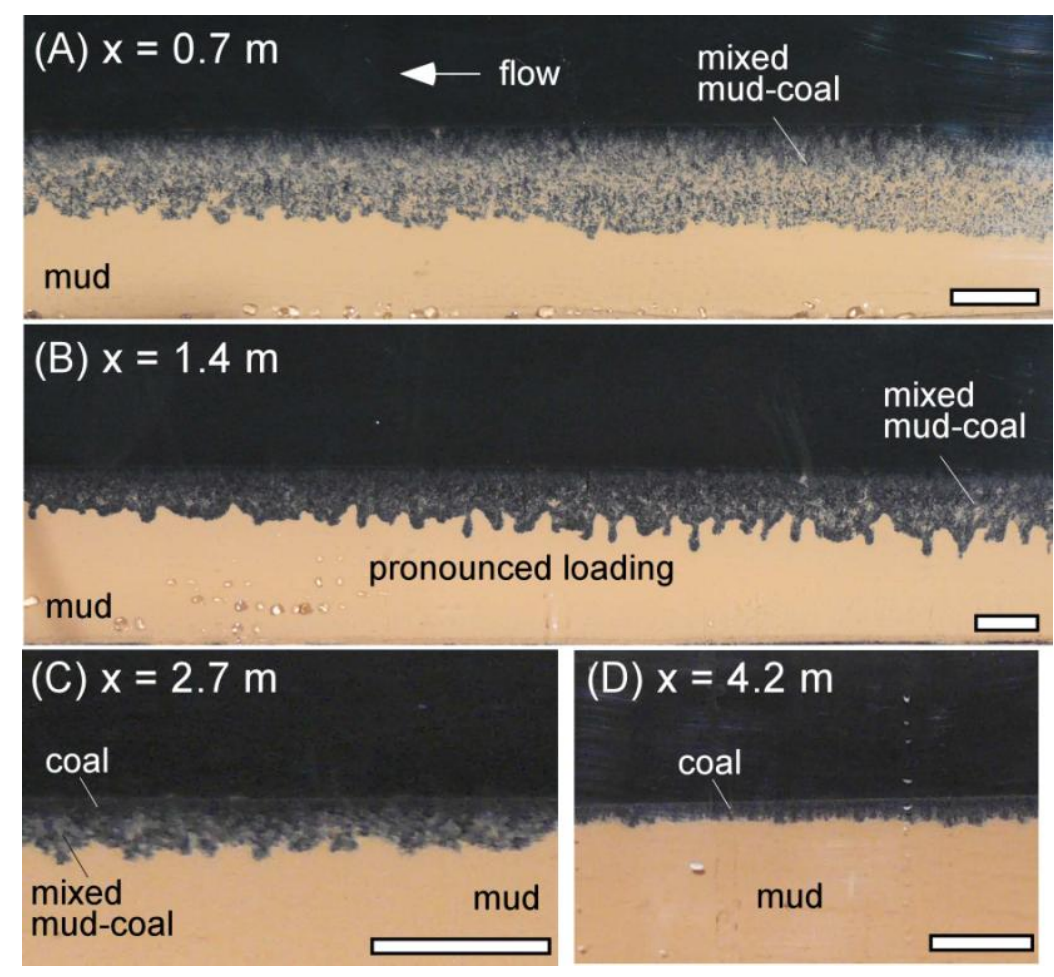

This article is protected by copyright. All rights reserved. 

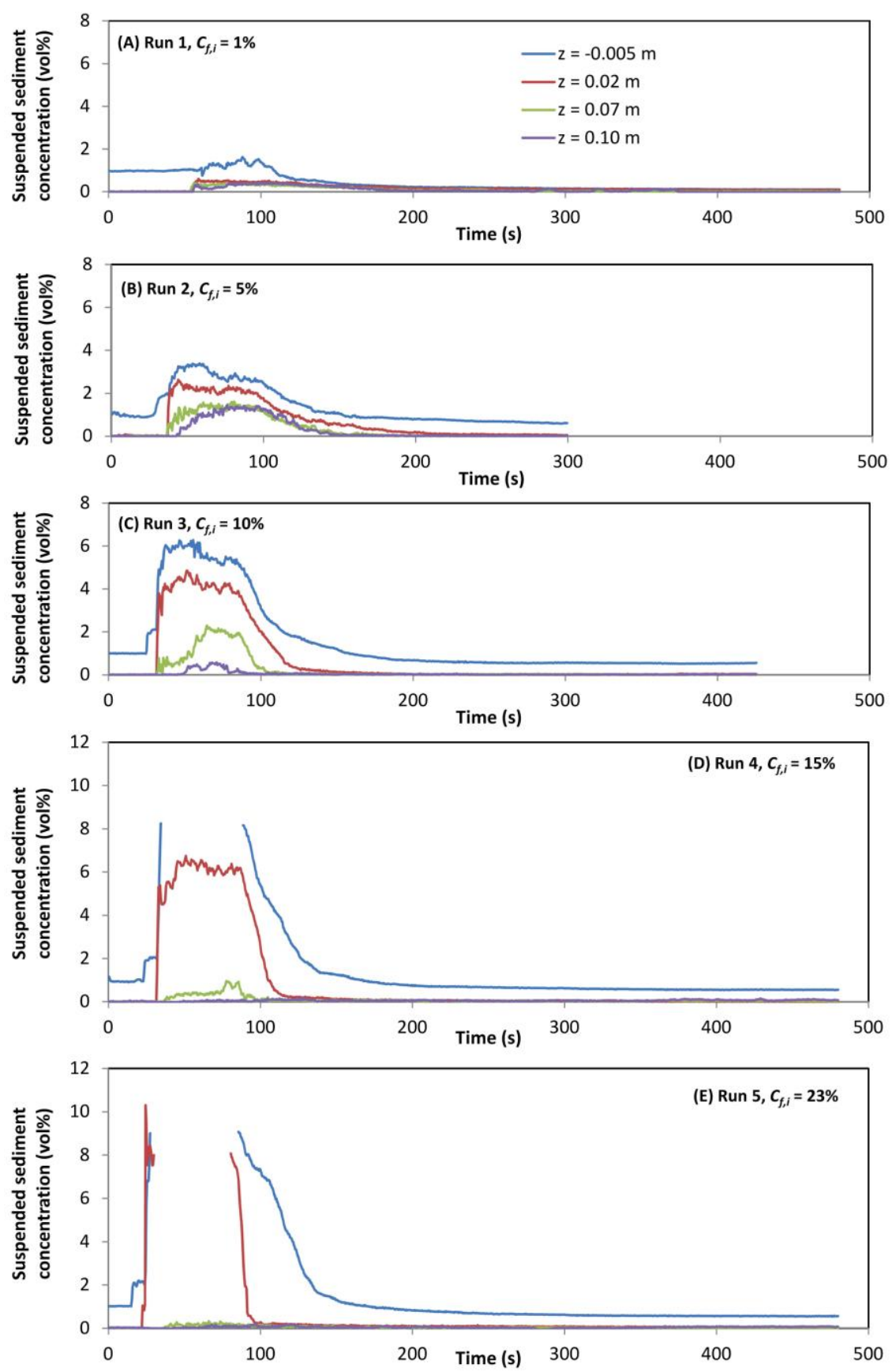

This article is protected by copyright. All rights reserved. 


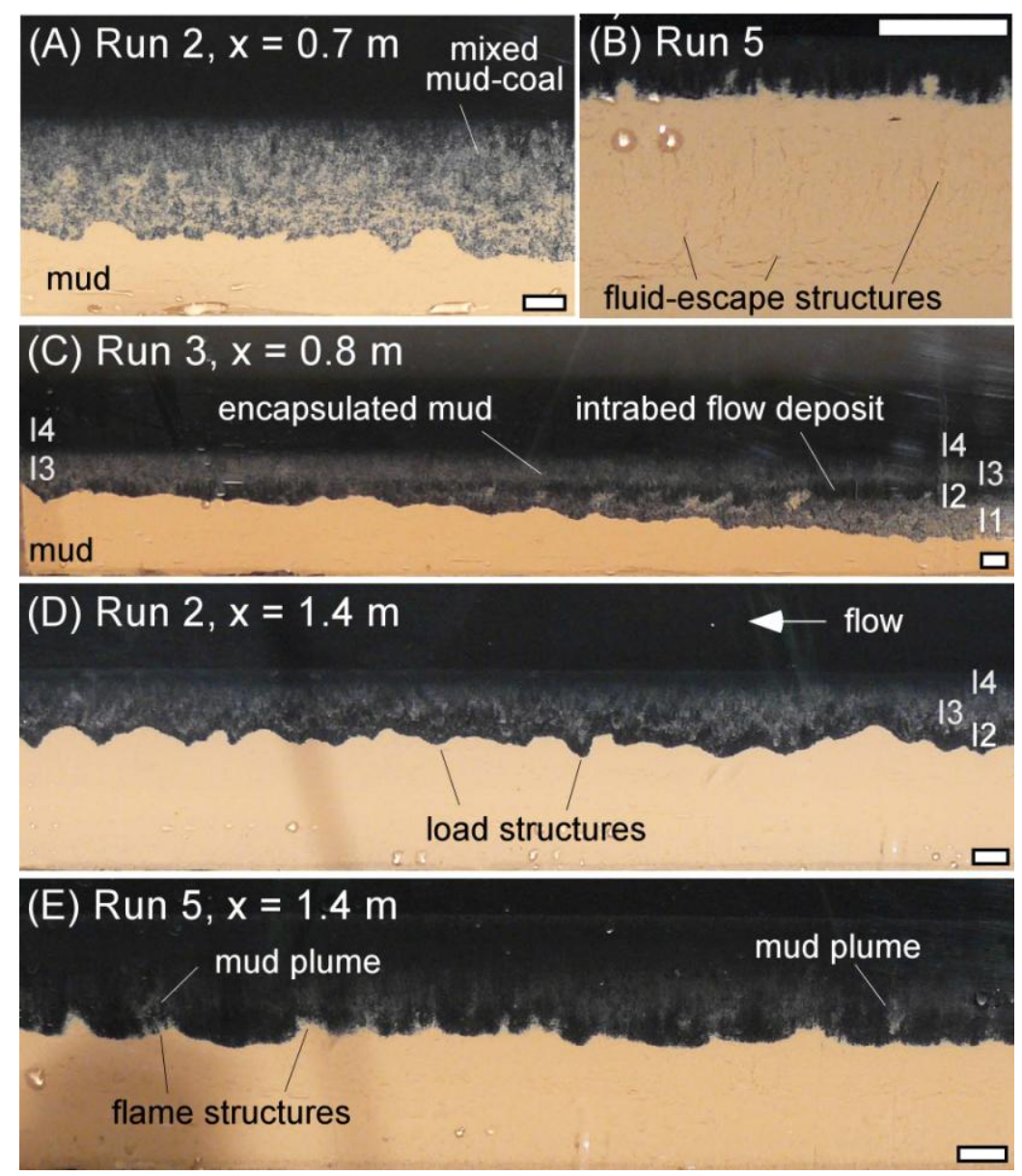

This article is protected by copyright. All rights reserved. 


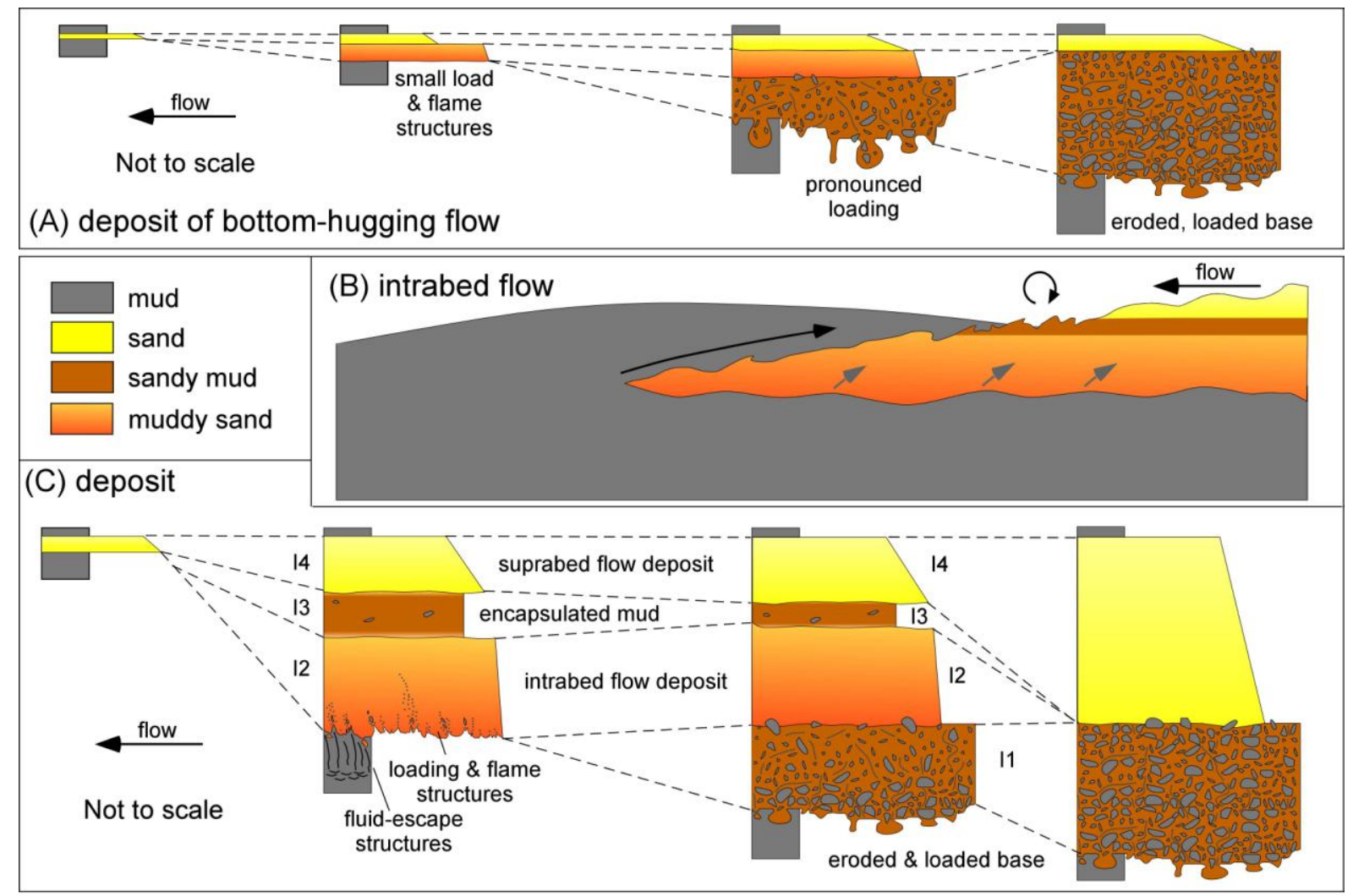

This article is protected by copyright. All rights reserved. 


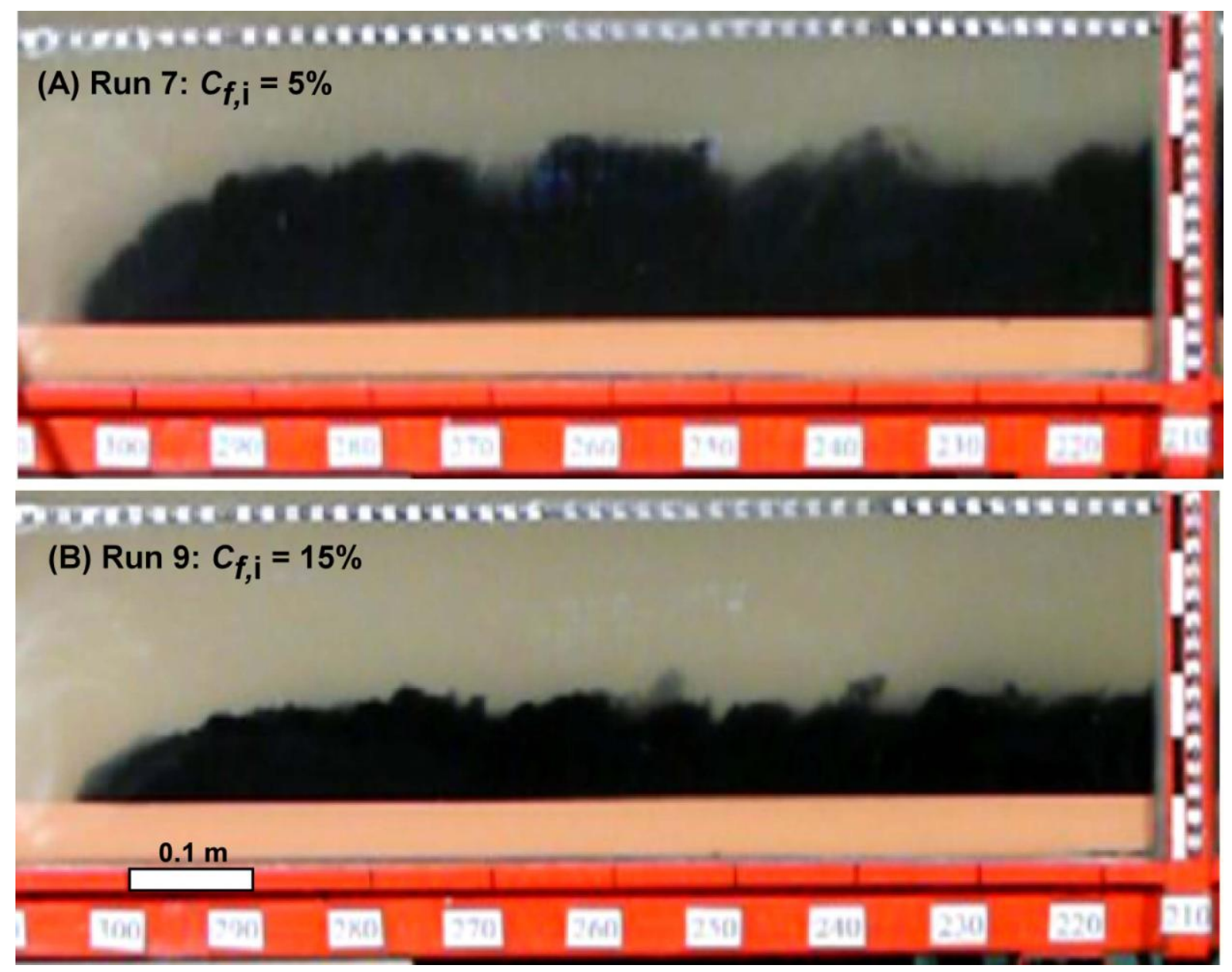

This article is protected by copyright. All rights reserved. 
(A) Run 6: $C_{f, i}=1 \%$

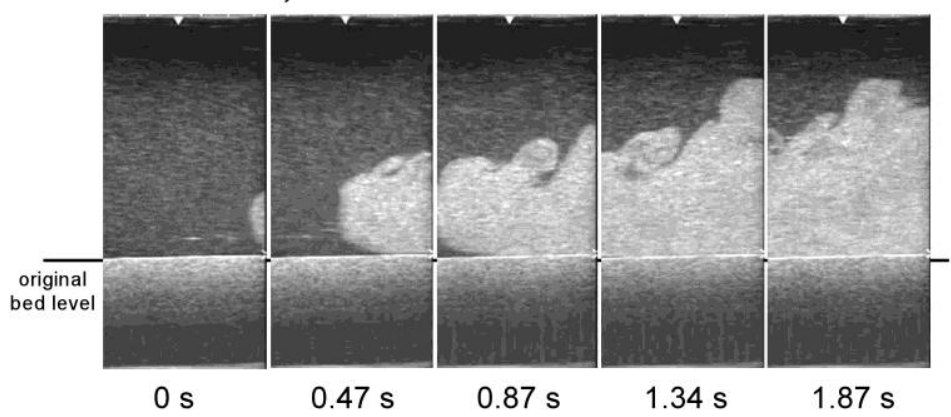

(B) Run 7: $c_{f, i}=5 \%$

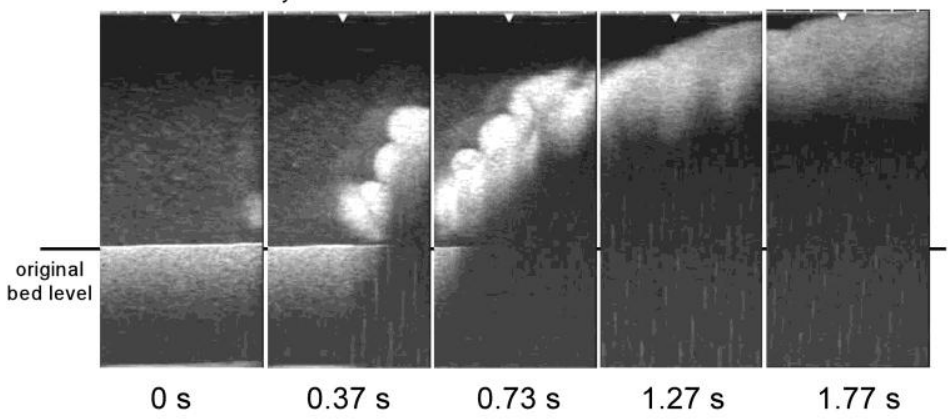

(C) Run 8: $C_{f, i}=10 \%$

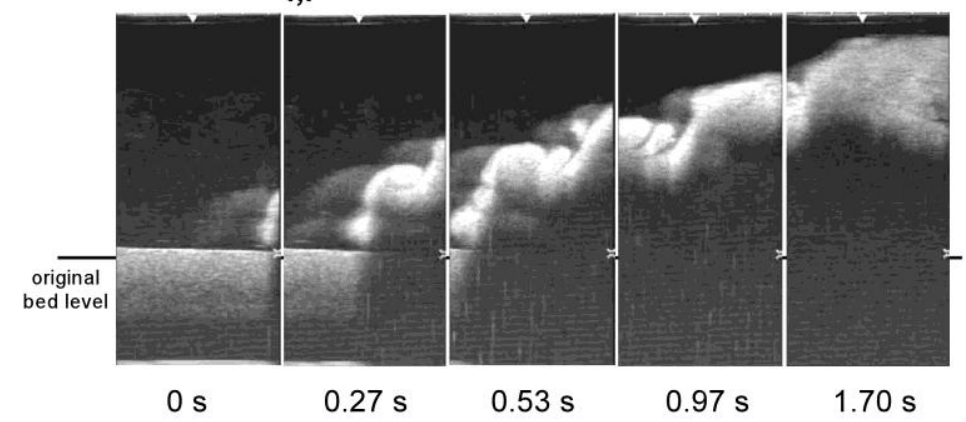

(D) Run 9: $C_{f, i}=15 \%$

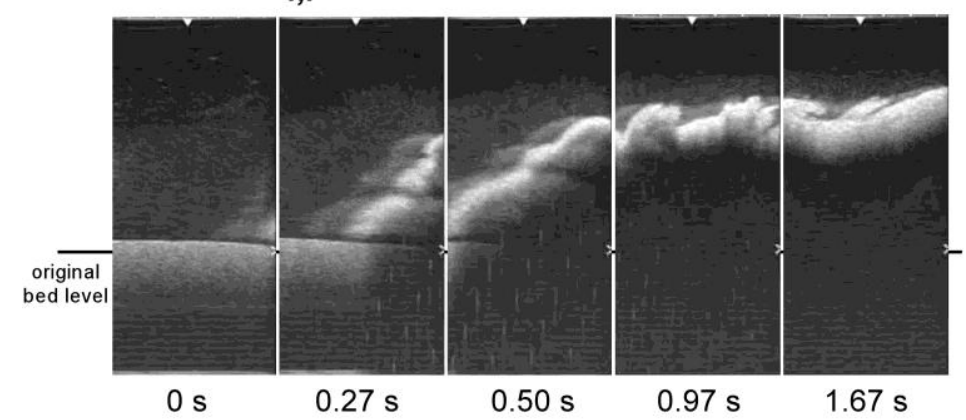

(E) Run 10: $C_{f, i}=23 \%$

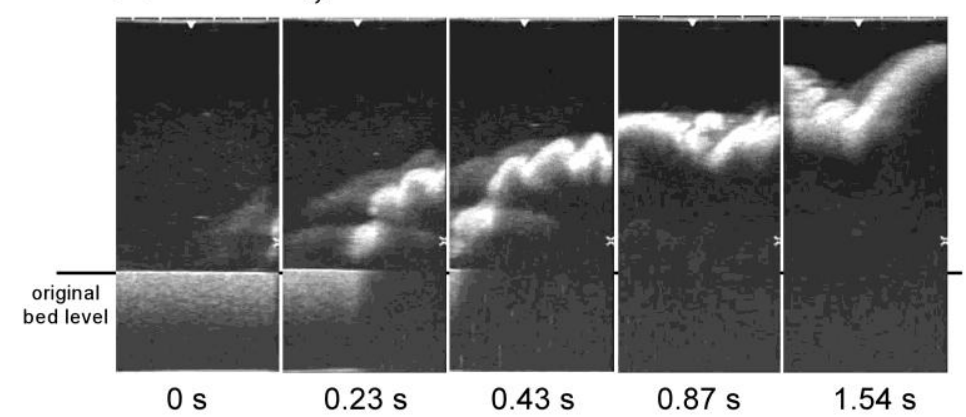

This article is protected by copyright. All rights reserved. 

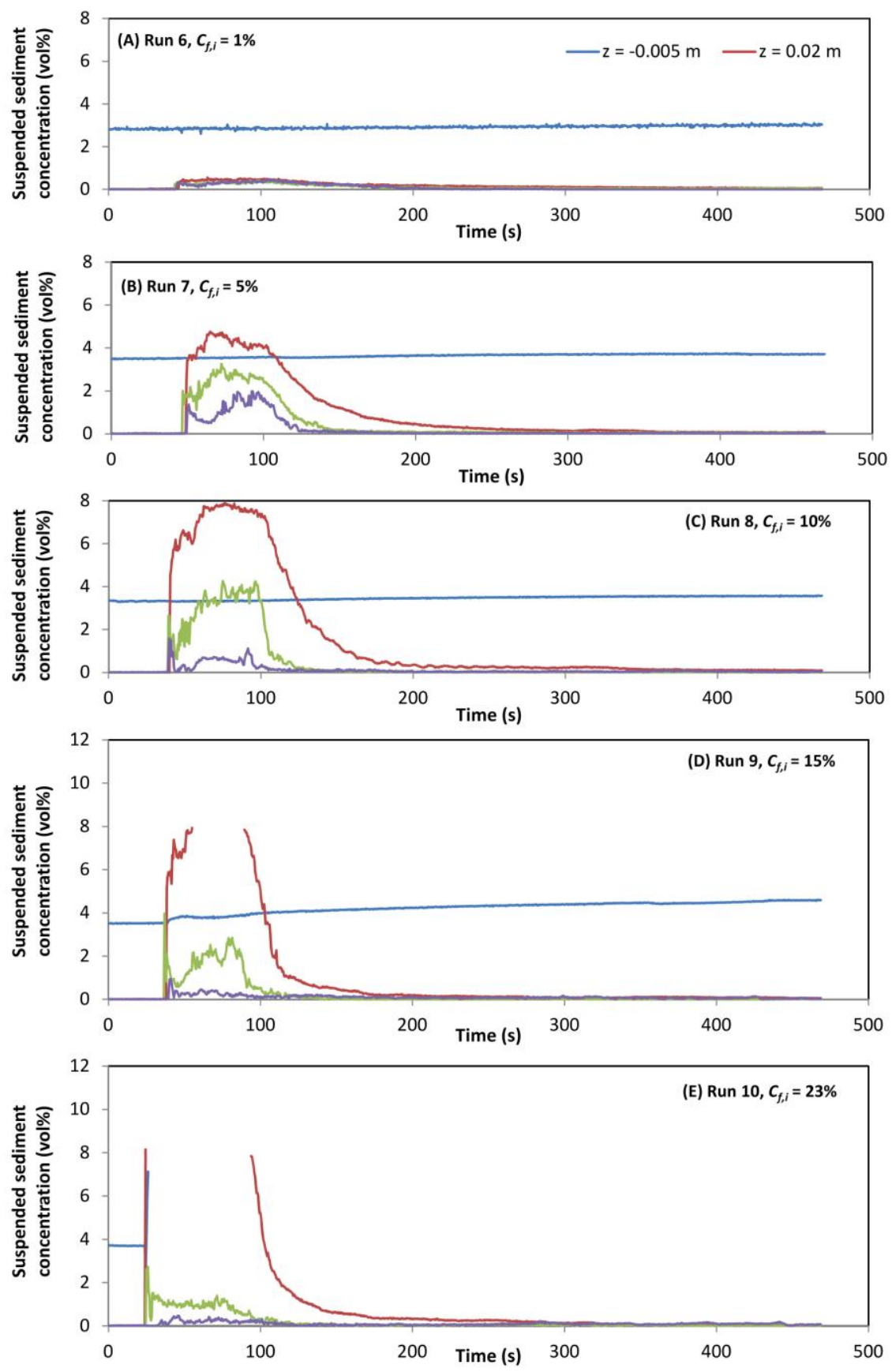

This article is protected by copyright. All rights reserved. 


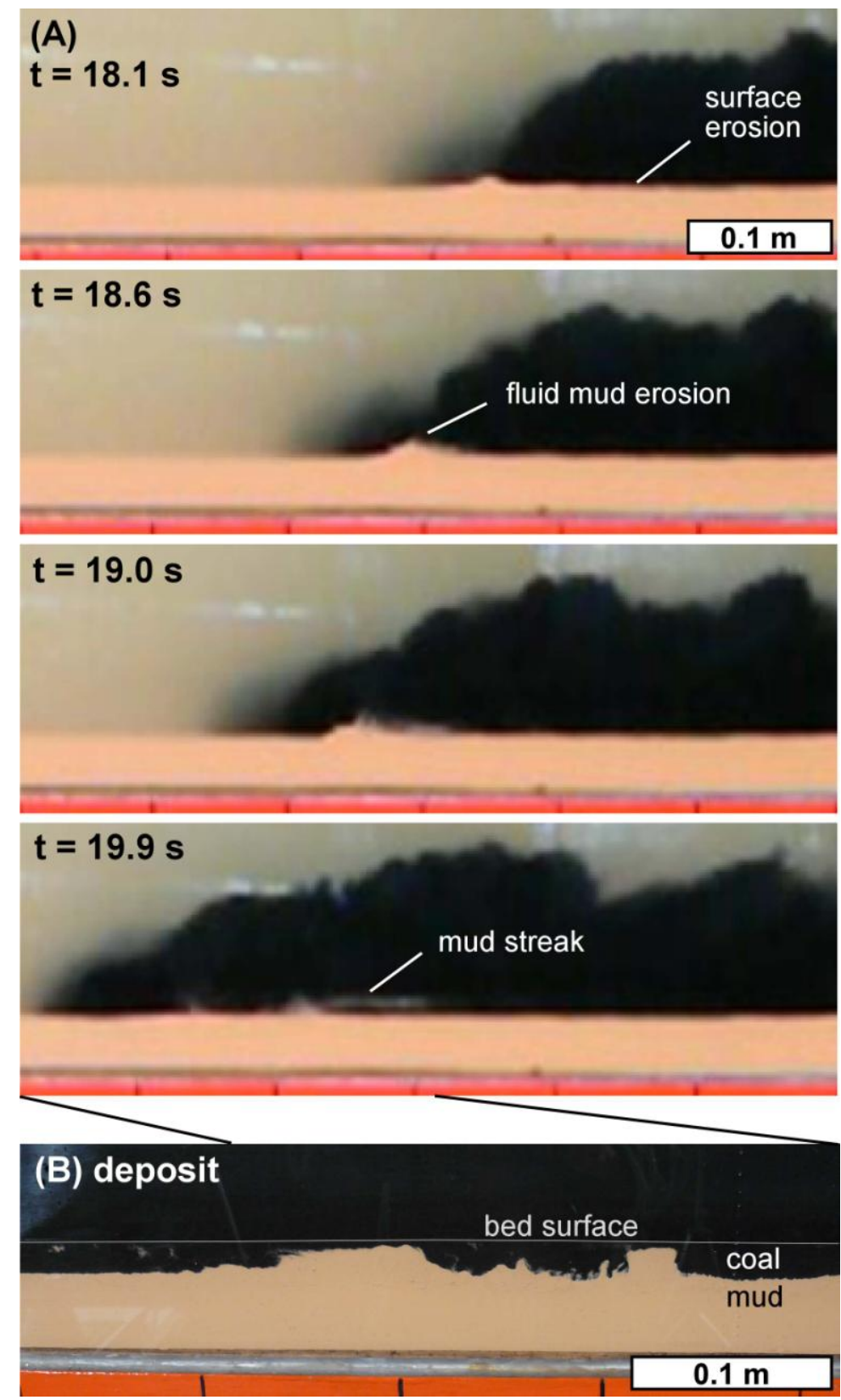

This article is protected by copyright. All rights reserved. 

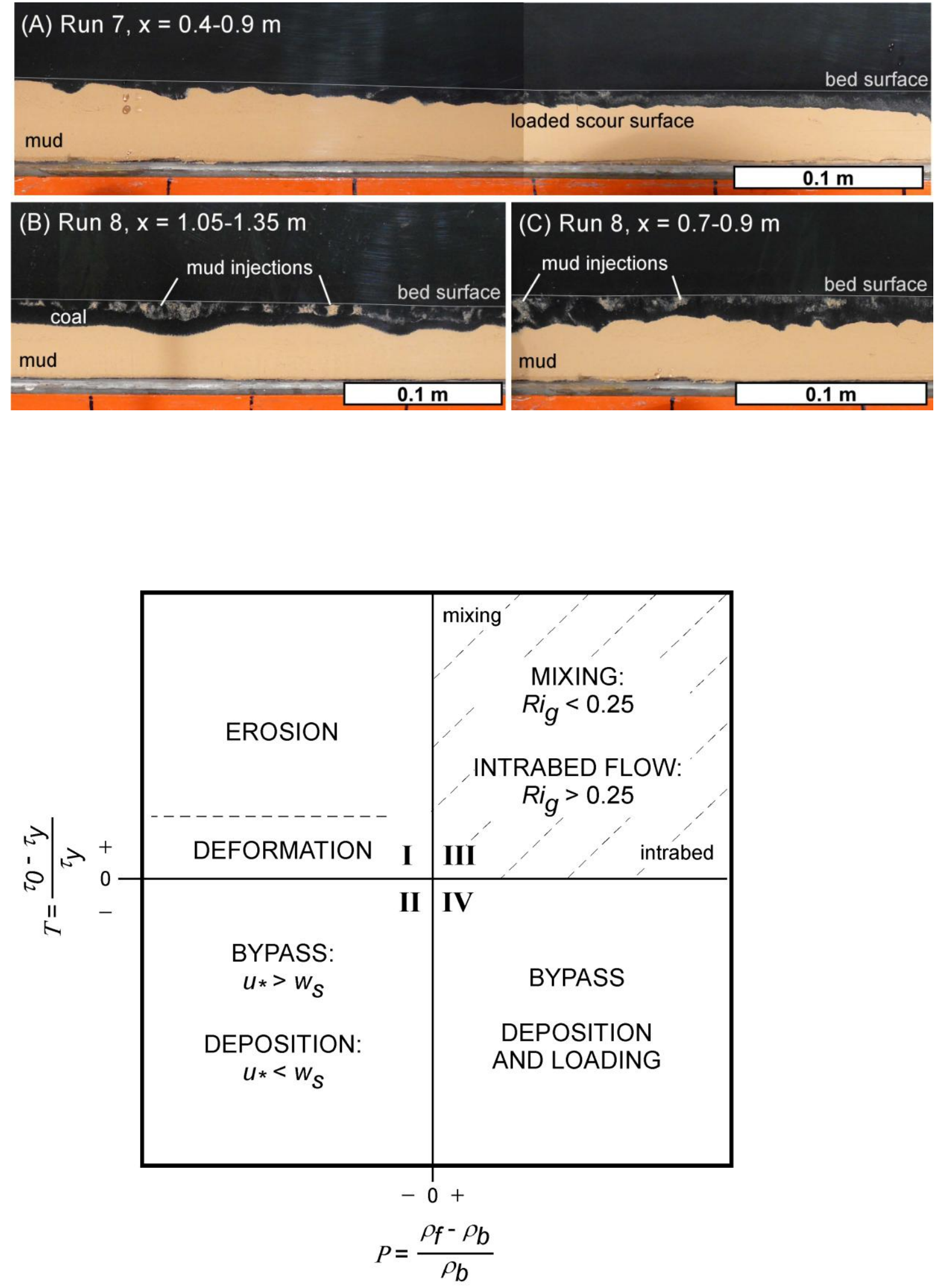

This article is protected by copyright. All rights reserved. 


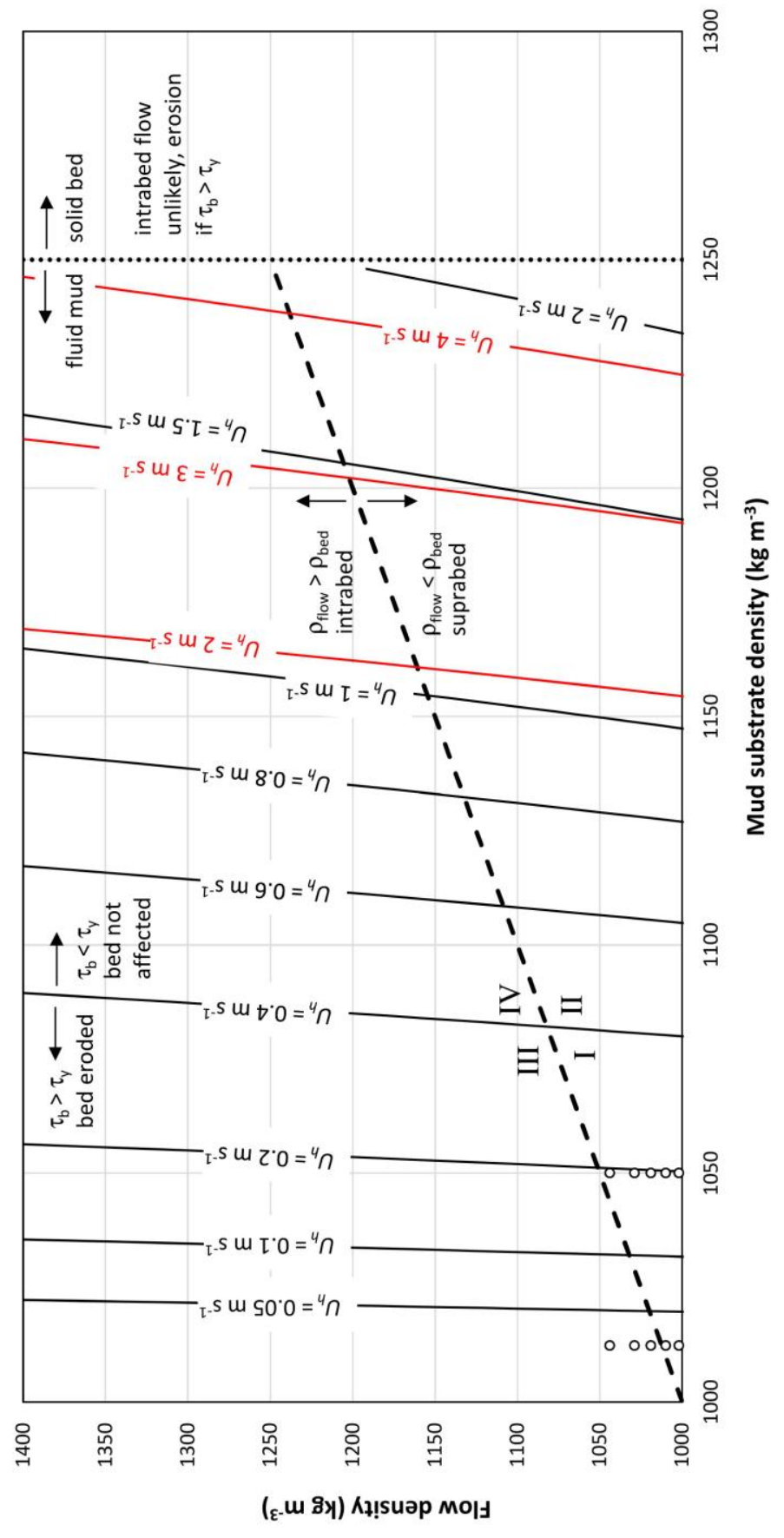

This article is protected by copyright. All rights reserved. 

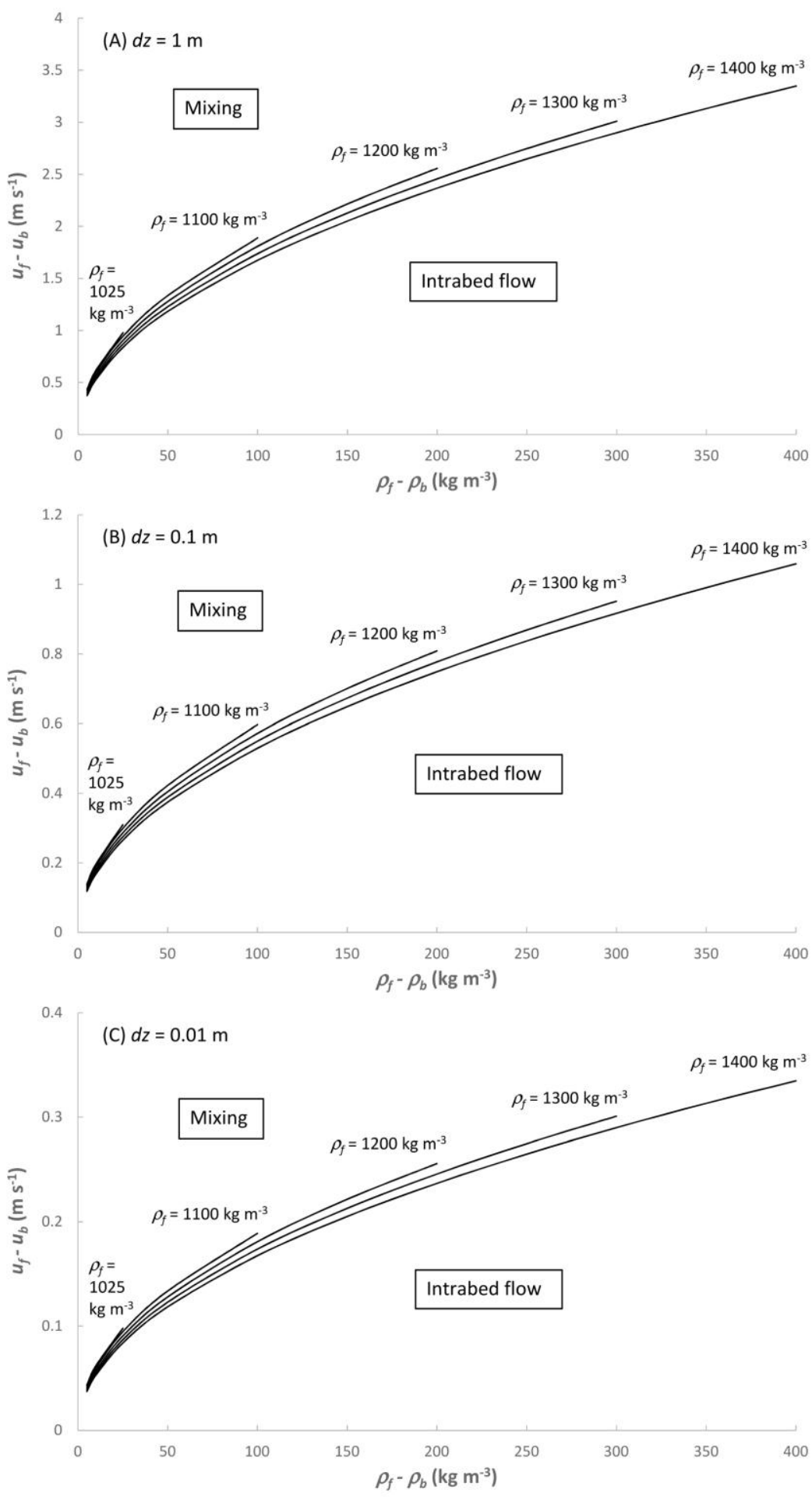

This article is protected by copyright. All rights reserved. 
(A) Intrabed turbidite

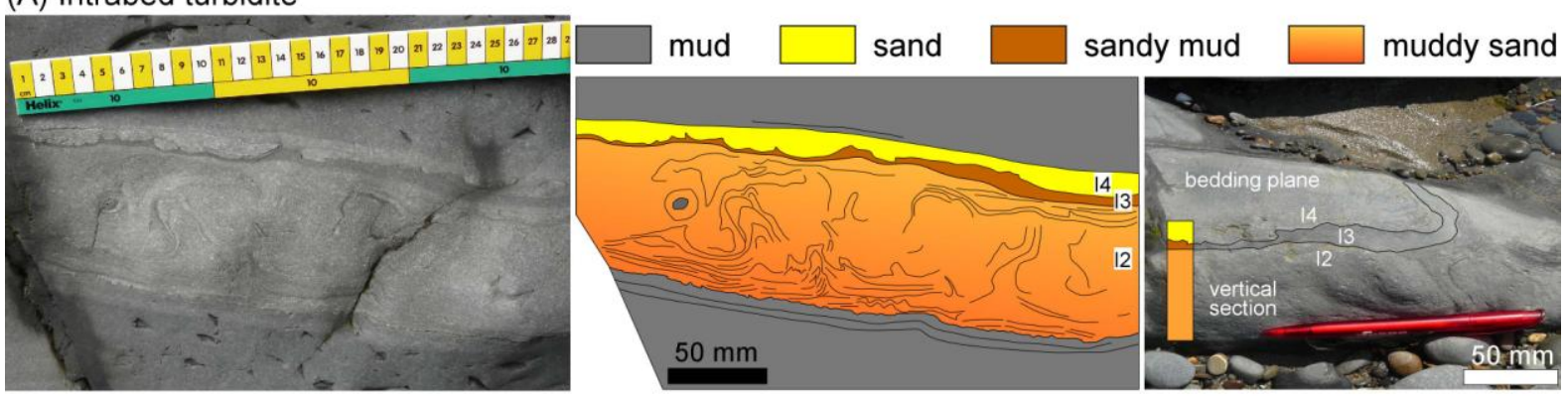

(B) Hybrid event beds
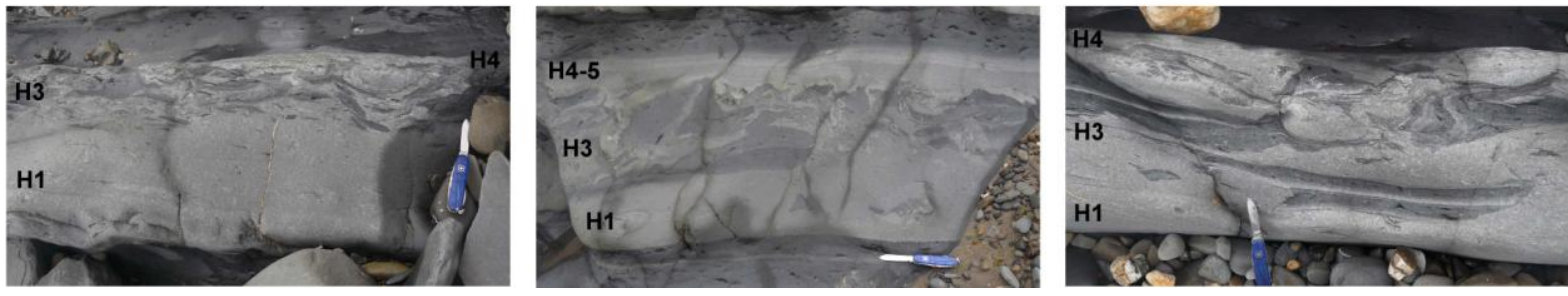

This article is protected by copyright. All rights reserved. 